\title{
EFEITOS DO MODELO NA APRENDIZAGEM DO NADO SINCRONIZADO
}

O nado sincronizado é um esporte olímpico regido pela Federação Internacional de Natação (FINA), que a limita ao sexo feminino. Outrora conhecido como balé aquático, há muito que sua imagem não está mais relacionada a moças flutuando ao som de uma música lenta e suave. Segundo ALENTEJANO, MARSHALL e BELL (2008) é o único esporte no qual manobras complexas são feitas na água, muitas vezes em apneia prolongada. Estreou em campeonatos mundiais no ano de 1953 e nos jogos Olímpicos, em 1984. Segundo a FINA (2009), na última década, o esporte se tornou popular no mundo inteiro - cerca de 100 nações têm programas regulares, e o desempenho mudou drasticamente, com a criação de novas figuras, movimentos e combinações que tornaram o espetáculo mais atraente.

Para interpretar um tema musical, nadando com estética e fluência, as participantes devem ter capacidade aeróbia e anaeróbia desenvolvidas em nível de excelência, além da potência, flexibilidade e domínio das habilidades motoras envolvidas (CHU, 1999; MOUNTJOY, 1999). Para ser considerada habilidosa, a execução deve ter harmonia e suavidade, isto é, aparente ausência de esforço para alcançar o objetivo.

As competições de nado sincronizado podem conter provas de figuras e de rotinas. Figuras são sequências de posições codificadas pela FINA, das quais 36 são pré-estabelecidas a cada quatro anos, segundo a categoria etária. Nas provas de figura, não há música, e as atletas se apresentam individualmente. As provas de rotina, por sua vez, são constituídas por coreografias denominadas solo (uma atleta), dueto e equipe (de quatro a 10 atletas), em que se interpreta um tema com música, num tempo estipulado.

As figuras são os fundamentos do nado sincronizado. $O$ ensino das habilidades do nado sincronizado começa com as posições e os movimentos básicos, e a sequência de uma posição básica para outra resulta nas figuras listadas 
pela FINA. Elas podem ser consideradas habilidades de alto nível de complexidade, pois apresentam grande interação entre os elementos (MAGILL, 2000).

O processo de aprendizagem de habilidades motoras é influenciado por fatores como a instrução, a prática e o conhecimento de resultados (SCHMIDT; WRISBERG, 2001). A instrução, ou seja, a informação anterior à prática é essencial à aquisição de habilidades motoras (HODGES; FRANKS, 2002; FREUDENHEIM; IWAMIZU; SANTOS, 2008). Entre outras coisas, ela esclarece as alunas sobre 0 objetivo do ensino e, assim, ao padrão de movimento desejado (TANI, 1989). Estudos vêm procurando verificar como favorecer a aprendizagem por meio de informações prévias.

A partir de 2004, maior importância tem sido dada ao ensino do nado sincronizado, com a elaboração de um manual de ensino (HERCOWITZ, LOBO, XAVIER, PÉRILLIER \& BUNN, 2004), mas ainda se baseia no senso comum. É frequente $O$ instrutor associar a demonstração a uma instrução verbal. $\mathrm{Na}$ demonstração, apresenta-se um modelo, principalmente pela projeção de um vídeo com um atleta experiente ou um colega executando os movimentos ou pela manipulação de uma boneca articulada (synchro doll). A escolha entre um ou de outro desses modelos ou de sua alternância respeita a critérios pessoais do instrutor e se condiciona aos recursos disponíveis. Assim, o ensino do nado sincronizado ainda está baseado na tradição acumulada pelos instrutores, e não orientado por conhecimentos teórico-científicos.

O foco deste estudo é na investigação dos efeitos do tipo de modelo boneca ou humano -, na aprendizagem das habilidades motoras do nado sincronizado, mais especificamente de suas figuras. 


\section{REVISÃO DE LITERATURA}

\subsection{As figuras do nado sincronizado}

Quando se fala em nado sincronizado, é comum virem à mente mulheres jovens flutuando na água. Essa imagem era verdadeira na década de 1940, mas, hoje, o nado sincronizado evoluiu para um esporte olímpico, que envolve a execução de figuras isoladas ou como parte de rotinas mais extensas. As figuras são constituídas de posições e movimentos de transição encadeados numa dada sequência. De modo geral, são componentes de uma figura: a posição inicial, as transições para a posição principal, a posição principal, as transições para a posição final e a posição final. As posições são posturas relativamente estáticas, e os movimentos de transição permitem mudar de uma posição para outra. A posição principal é aquela que caracteriza a figura. Na realização das figuras a executante deve mostrar alinhamento e ângulos precisos, além de máxima altura em relação à linha da água, bem como estabilidade e ritmo contínuo nas transições (FUGITA, 2009).

As habilidades motoras podem ser definidas como tarefas com finalidade específica que exigem movimentação voluntária (GALLAHUE, 2002). Na área de aprendizagem motora, para generalizar os conhecimentos produzidos, têm sido propostas classificações de habilidades motoras agrupando-as por similaridade.

Sendo uma sequência formada por habilidades motoras com começo e fim claramente definidos, segundo a classificação unidimensional apresentada por MAGILL (2000), uma figura de nado sincronizado pode ser considerada uma habilidade motora seriada. Segundo o mesmo sistema de classificação, no que diz respeito à estabilidade do ambiente, considera-se aberta uma habilidade que deve ser executadas num ambiente em constante mudança. Por sua vez, no extremo oposto de um espectro contínuo, é fechada uma habilidade que se desenvolve num ambiente estável. Assim, as figuras do nado sincronizado são predominantemente fechadas, embora possam ser mais ou menos fechadas, segundo o contexto de realização da figura. Nas provas de figuras, por exemplo, o ambiente é controlado, ou seja, não há manifestação do público, há pouca movimentação da água, colocam-se 
panos vermelhos abaixo da superfície, como referência, e as atletas se apresentam individualmente, para executar uma figura a cada entrada. Já em provas de rotinas, é permitida a manifestação do público, é obrigatória a sincronização entre as atletas e destas com a música, e há movimentação da água, decorrente da participação concomitante de várias atletas.

Pelos critérios propostos por MAGILL (2000), as figuras do nado sincronizado podem ser consideradas complexas, pois seus componentes têm alto grau de interação. Essa classificação é reforçada pelos critérios apresentados por WULF e SHEA (2002), segundo os quais, embora seja difícil quantificar a complexidade de uma tarefa, são complexas as habilidades que não podem ser dominadas numa única sessão de prática, têm muitos graus de liberdade e, ainda, validade ecológica. O domínio das figuras do nado sincronizado envolve necessariamente o processo de aprendizagem.

\subsection{Os estágios de aprendizagem de habilidades motoras}

A aprendizagem motora refere-se a mudanças internas relativamente permanentes na capacidade de realizar tarefas motoras, que são fruto de experiência e prática (SCHMIDT; LEE, 1999; MAGILL, 2000; SCHMIDT; WRISBERG, 2001; TANI, FREUDENHEIM, MEIRA-JUNIOR; CORRÊA, 2004). Por envolver processos internos, a aprendizagem de habilidades motoras não é diretamente observável e, portanto, deve ser inferida a partir da melhora e manutenção de níveis relativamente estáveis do desempenho do aprendiz. Nesse sentido, o desempenho é observável e pode ser influenciado por fatores como motivação, fadiga e condição física. Em contraste, a aprendizagem motora é um processo interno que reflete a capacidade de desempenho do executante (SCHMIDT; WRISBERG, 2001).

Segundo FITTS e POSNER (1967), o processo de aprendizagem motora tem três estágios. No primeiro, denominado cognitivo, há grande demanda de processamento de informação, pois o aprendiz deve entender qual é o objetivo da tarefa e como executá-la. Nesse estágio, o desempenho dos aprendizes varia muito, eles cometem muitos erros, no mais das vezes grosseiros, os raros acertos são casuais, e, embora tenham consciência deles, não sabem ainda como evitá-los ou 
corrigi-los. Assim, dependem de informação externa para passar ao estágio seguinte. No segundo estágio, o associativo, os executantes tentam associar algumas pistas ambientais e usam informações sobre desempenhos bem-sucedidos para detectar seus erros. Detendo melhor os fundamentos básicos da habilidade, têm desempenho menos variável, cometem menos erros e estes são menos grosseiros. Depois de muita prática, o aprendiz atinge o terceiro estágio, o autônomo, caracterizado por um comportamento automatizado, portanto, com menor demanda cognitiva, o que possibilita, por exemplo, executar duas tarefas concomitantes.

Procurando formular uma teoria suficientemente robusta para explicar a aprendizagem, ADAMS (1971) propôs que a aprendizagem motora ocorre em dois estágios. No primeiro, o verbal-motor, o aprendiz, devido a sua pouca experiência, tem uma representação pobre do movimento e, por isso, não consegue interpretar o feedback da resposta produzida. O estágio verbal-motor se caracteriza essencialmente pelo fato de o aprendiz precisar de informação externa e também reproduzir verbal e/ou mentalmente a habilidade a ser executada de modo a favorecer sua execução. Com a prática, essa reprodução verbal e/ou mental não é mais necessária, melhora a capacidade de o aprendiz interpretar o feedback da resposta e, consequentemente, seu desempenho passa a ser cada vez mais proficiente e consistente.

No contexto do ensino, GENTILE (1972) propõe dois estágios, identificados pelas metas do aprendiz. Segundo a interpretação de MAGILL (2000), primeiro, ele deve "captar a ideia do movimento" (p. 151), ou seja, identificar o que precisa fazer para atingir a meta da habilidade, estabelecendo o padrão básico do movimento. Também é nesse estágio que aprende a discriminar os aspectos ambientais que especificam como os movimentos devem ser produzidos e os que não os afetam (condições ambientais reguladoras e não reguladoras). Para GENTILE (1972), o indivíduo terá adquirido a ideia do movimento quando, em várias tentativas, conseguir alcançar a meta com movimentos executados conforme o planejado - em suma, quando aprender a relação meio/fim. Na segunda fase, dependendo da natureza da habilidade a ser aprendida, o comportamento genérico adquirido na primeira fase deve ser fixado ou modificado. Em habilidades fechadas, em que os estímulos relevantes não mudam, o aprendiz escolhe uma maneira de alcançar a 
meta e a pratica para torná-la mais consistente e eficiente. Entretanto, em habilidades abertas, em que mudam os estímulos ambientais relevantes durante a execução da ação, o aprendiz deve aprender a ajustar seus movimentos às demandas ambientais. Nesse caso, ele desenvolve um vasto repertório de respostas, diversificando a maneira de alcançar a meta. Portanto, para GENTILE (1972), dependendo da natureza da habilidade (aberta ou fechada), depois da primeira fase de aprendizagem, deve-se enfatizar a fixação ou a modificação do comportamento. Segundo esse referencial, tratando-se de habilidades predominantemente fechadas (MAGILL, 2002), como é o caso das figuras do nado sincronizado, fica clara a necessidade de, uma vez adquirida a ideia do movimento, o aprendiz selecionar uma maneira de alcançar a meta e praticá-la com o intuito de torná-la mais consistente e eficiente.

PELLEGRINI (2000), assim como FITTS e POSNER (1967), também prevê três estágios para o processo de aprendizagens. Segundo a autora, no primeiro estágio, o executante novato e inexperiente tenta identificar as características invariantes da tarefa e faz movimentos desnecessários e descoordenados, com muitos erros. Além disso, como os acertos são quase sempre casuais, não lhe indicam como deve agir. No segundo estágio, o aprendiz, agora em nível intermediário, devido à prática, vai diminuído o número de erros e com isso descobre que pode gastar menos energia e tempo na execução. Em habilidades realizadas em ambientes com maior estabilidade, o aprendiz procura ganhar consistência na forma e na ação e, nas realizadas em ambientes mais abertos, procura adaptar o padrão motor às mudanças. Nesse ponto, a autora reitera a proposta de GENTILE (1972), que distingue a ação do aprendiz de acordo com a característica da tarefa, ou seja, em função da estabilidade do ambiente. No terceiro estágio, o aprendiz está num nível avançado, caracterizado pela certeza de como atingir a meta com fluência e eficiência. Como precisa de um mínimo de atenção, pode dirigir parte dela a elementos até então menos relevantes para o êxito da ação.

Em síntese, segundo os modelos apresentados, o processo de aprendizagem motora começa com a compreensão da tarefa (fase cognitiva), estágio no qual o aprendiz tem movimentos descoordenados e comete erros grosseiros, e termina com a estabilização do comportamento (fase autônoma). Assim, na medida 
em que o aprendiz passa por esses estágios, espera-se tenha um desempenho melhor. Em relação às figuras do nado sincronizado, pode-se inferir que houve aprendizado a partir da melhora e da manutenção de níveis relativamente estáveis do desempenho do aprendiz (MAGILL, 2000). Mais especificamente, pela verificação da melhora e da manutenção da qualidade dos movimentos, constatada por erros cada vez menos grosseiros na execução da tarefa. No entanto, não constam na literatura consultada estudos sobre os estágios de aprendizagem de habilidades motoras do nado sincronizado.

Quanto à aprendizagem motora, por mais de um século pesquisadores têm estudado meios de manipular as condições do ambiente de modo a maximizar seu êxito (ADAMS, 1987). Em função de sua relevância, um dos fatores estudados é a informação prévia.

\subsection{A informação prévia na aprendizagem de habilidades motoras}

O processo de aprendizagem é afetado por fatores intrínsecos e extrínsecos ao aprendiz (LIMA, 1999). Associadas a outras peculiaridades, suas características pessoais - entre elas, genética, idade e gênero - influem no nível maturacional e na prontidão para a aprendizagem. Além disso, a aprendizagem sofre interferência de características externas, ligadas a fatores do ambiente e, portanto, manipuláveis. Estes podem ser classificados, segundo o momento da prática em que intervêm, em prévios (exemplo: instrução e demonstração), concomitantes (exemplo: estrutura de prática) ou posteriores à prática (exemplo: conhecimento de resultado $\mathrm{e}$ conhecimento de performance) (GODINHO, 2002). A informação prévia é fundamental para o processo de aquisição de uma habilidade motora, pois ela ajuda o aprendiz a compreender o objetivo da tarefa e o orienta quanto às melhores soluções (PÚBLIO, TANI \& MANOEL, 1995).

Os meios mais utilizados pelos profissionais do movimento para dar informações prévias são a instrução verbal, a demonstração e suas associações (GUEDES, 2001). A forma verbal envolve a descrição e o detalhamento do que e como fazer. Ela pode englobar informações sobre a meta da tarefa, a especificação da tarefa (o que fazer), o modo de executá-la (como fazer) e também sobre a 
semelhança entre tarefas (SCHMIDT \& WRISBERG, 2001). A demonstração, por sua vez, é uma instrução visual, que compreende a imagem da habilidade sendo executada. Ela pode ser dada por meio de um modelo vivo ou por meios visuais auxiliares, como modelo em vídeo, fotografias e desenhos que apresentem a ação em curso (SANCHEZ, 1986; MENDES, 2004). A demonstração pode dar uma ideia global do movimento e, ao mesmo tempo, a percepção de relações entre as partes (SCULLY; NEWELL, 1985). Assim, a observação de um modelo apropriado pode ajudar o aprendiz a ter uma ideia do objetivo a atingir (CORRÊA; BENDA; UGRINOWITSCH, 2006) e ainda facilitar-lhe a aquisição dos padrões de resposta corretos (HOO, TAKEMOTO \& McCULLAGH, 2004). Os benefícios da apresentação de modelos demonstrando a ação a ser executada são usualmente mais claros quando o padrão de movimento - e não o resultado da ação no ambiente - é determinante do desempenho (SIDAWAY; HAND, 1993), como, por exemplo, as habilidades da ginástica e do nado sincronizado.

Em consonância com a literatura de aprendizagem motora, no ensino do nado sincronizado, a demonstração frequentemente exibe um modelo humano executando a tarefa (ao vivo ou em vídeo) e um modelo boneca desenvolvido para esse fim. A synchro doll é bidimensional, articulada e mede aproximadamente de 40 x 5 centímetros, características que permitem sua manipulação dinâmica pelo instrutor, para demonstrar as posições e transições corretas do corpo.

Há anos o fornecimento da informação verbal e/ou visual (demonstração) vem sendo uma preocupação central dos pesquisadores em aprendizagem motora (AL-ABOOD, DAVIDS \& BENNET, 2001; AL-ABOOD, DAVIDS, BENNET, ASHFORD \& MARIN, 2001). Embora, como se verá no próximo tópico, com exceção de um estudo exploratório (FUGITA \& FREUDENHEIM, 2005), também não constam na literatura disponível estudos sobre a aprendizagem específica de habilidades do nado sincronizado. Considera-se aqui que uma revisão dos estudos sobre aprendizagem motora em geral deve servir como base para o desenvolvimento de toda pesquisa em que se pretenda compreender melhor os meios de manipular a instrução prévia para maximizar o êxito dos aprendizes. 


\subsubsection{Estudos sobre a informação prévia}

Os estudos sobre a informação prévia têm focalizado vários aspectos, principalmente o tipo de instrução (instrução verbal, demonstração e suas combinações), as características do modelo (status, nível de habilidade) e a distribuição temporal da demonstração (frequência relativa e absoluta, antes e/ou durante a prática).

A maior parte dos estudos sobre o tipo de instrução não se limita à mera comparação entre a instrução verbal e a demonstração, mas aborda preferencialmente a associação entre diferentes modalidades. Entre eles, WEISS (1983) investigou o efeito de três tipos de instrução no desempenho de uma tarefa motora seriada. Participaram do estudo 84 crianças, de ambos os gêneros, entre $4 \mathrm{e}$ 5 e 7 e 8 anos de idade. Elas tiveram que reproduzir uma sequência de seis habilidades, tendo uma demonstração a cada duas tentativas, num total de nove. As crianças de cada faixa etária foram divididas em grupos, de acordo com o tipo de instrução: demonstração (observaram um modelo vivo executando duas vezes a tarefa), demonstração mais instrução verbal (observaram um modelo vivo executando duas vezes a tarefa e tiveram instrução verbal) e sem demonstração. Os resultados indicam que as crianças mais velhas obtiveram melhor desempenho, independentemente da condição experimental, e ainda que houve relação entre idade e tipo de modelo; mais especificamente, as crianças entre 7 e 8 anos de idade tiveram bom desempenho tanto na condição de demonstração como na de demonstração associada à instrução verbal, enquanto as de 4 ou 5 anos só desempenharam bem nesta última condição. Possivelmente, as informações verbais tenham ajudado as crianças mais novas a prestar atenção nos aspectos relevantes da tarefa.

Em estudo exploratório, FUGITA e FREUDENHEIM (2005) investigaram o efeito de três tipos de instrução no desempenho de uma tarefa motora seriada. 27 atletas de nado sincronizado foram distribuídas em três grupos balanceados quanto à faixa etária, de 8 a 15 anos, e ao nível de habilidade - iniciante, intermediário e avançado. Elas deviam executar uma simplificação da figura de nado sincronizado denominada barracuda. Em todos os grupos, a instrução foi dada duas vezes antes 
da execução da tarefa. Para os integrantes do grupo com instrução verbal, a instrução foi lida; aos do grupo demonstração por vídeo, mostrou-se um filme de uma atleta executando a tarefa; e, para os do grupo verbal-demonstração, a instrução lida foi seguida da apresentação do filme. Três crianças do grupo verbal e uma do grupo demonstração não executaram a figura pedida. No grupo verbal-demonstração, todas as crianças cumpriram a tarefa corretamente. Verificou-se que as crianças que não executaram a tarefa eram iniciantes. No entanto, mesmo as iniciantes do grupo verbal-demonstração executaram a tarefa como indicado. Considerando as limitações inerentes a um estudo exploratório, as autoras concluíram que o tipo de instrução afeta o desempenho de indivíduos menos habilidosos.

Quanto ao desempenho, corroborando o estudo de WEISS (1983), para crianças iniciantes, a instrução verbal só parece ser útil se for acompanhada de demonstração. Talvez, para o iniciante, a instrução verbal isolada seja um detalhamento excessivo das ações a executar.

CARROLL e BANDURA (1990) compararam os efeitos da demonstração e da instrução verbal na aprendizagem de uma sequência de nove habilidades motoras. A amostra de 56 sujeitos foi dividida em quatro grupos, segundo as seguintes condições de prática: (1) duas demonstrações associadas à instrução verbal; (2) duas demonstrações; (3) oito demonstrações associadas à instrução verbal; e, (4) oito demonstrações. Os resultados mostraram que o grupo na condição 3 obteve melhores resultados do que o grupo na condição 4, e que os grupos das condições 1 e 2 não se diferenciaram. De acordo com isso, quando se dão mais instruções, a demonstração associada à instrução verbal favorece mais a aprendizagem do que só a demonstração. É provável que haja necessidade de repetir mais vezes as informações verbais, para que elas sejam assimiladas e ajudem os aprendizes a prestar atenção aos aspectos mais relevantes da tarefa.

DARIDO (1991) investigou os efeitos da demonstração e da instrução verbal na aprendizagem da habilidade motora de subir a escada de Bachman. Participaram 146 escolares de 9 e 14 anos de idade. Os alunos de cada faixa etária foram divididas em quatro grupos, de acordo com a condição experimental: (1) instrução verbal; (2) instrução verbal - controle; (3) demonstração; e (4) 
demonstração - controle. Aos grupos de instrução verbal e demonstração, foi dada a informação duas vezes antes da primeira tentativa e uma vez antes da 17ª , nos três dias do experimento. Já aos grupos controle, ela foi dada duas vezes antes da primeira tentativa, apenas no primeiro dia. Uma semana depois da fase de aquisição, foi feito o teste de retenção, com cinco tentativas sem informação prévia. Os resultados mostraram que todos os grupos aprenderam a tarefa, independentemente da forma de apresentação da informação prévia. Na faixa dos 14 anos, observou-se um desempenho significativamente superior do grupo demonstração sobre o verbal. Assim, crianças mais velhas se beneficiam mais da demonstração do que da instrução isolada. Possivelmente esse resultado se deva a sua capacidade de prestar atenção aos aspectos mais relevantes da tarefa demonstrada, ou seja, aos aspectos gerais do movimento e a sua dinâmica. Entre as crianças de 9 anos de idade, não foram encontradas diferenças entre os grupos nas diferentes condições.

PÚBLIO, TANI e MANOEL (1995) fizeram dois experimentos para investigar os efeitos da demonstração e da instrução verbal na aquisição de habilidades motoras da ginástica artística numa situação real de ensinoaprendizagem. As condições experimentais relativas à informação prévia foram: (1) demonstração; (2) instrução verbal; e (3) demonstração associada à instrução verbal. O primeiro experimento contou com 23 participantes de 7 a 12 anos, com prática na modalidade distribuídos em três grupos. A tarefa consistiu na execução de oito exercícios de solo, que também fizeram parte da avaliação de entrada, cuja finalidade foi a formação de grupos homogêneos. Os resultados mostraram que os grupos nas condições demonstração e demonstração mais instrução verbal foram superiores ao grupo na condição de instrução verbal e que, neste último, as 16 sessões de prática não foram suficientes para provocar uma mudança significativa no desempenho. Os autores concluíram que a aprendizagem motora é mais eficaz com demonstração e demonstração associada à instrução verbal. No segundo experimento, investigaram os efeitos da demonstração e demonstração mais instrução verbal em crianças com nível de habilidade mais avançado que o das do primeiro experimento, mas não detectaram diferença significativa entre os grupos.

KAMPIOTIS e THEODORAKU (2006) investigaram os efeitos de cinco tipos de instrução. 93 jovens com idade entre 17 e 21 anos participaram no estudo, 
divididos nos seguintes grupos: (1) instrução verbal do instrutor; (2) demonstração; (3) demonstração associada à instrução verbal do instrutor; (4) demonstração associada à instrução verbal do executante modelo; e (5) demonstração de modelo em vídeo associada à instrução verbal do instrutor.

Os resultados apontaram diferença significativa do pré ao pós-teste para a amostra inteira, indicando que houve aprendizagem em todos os grupos. Para a aprendizagem (teste de retenção), a melhor dentre as condições foi a (4), demonstração associada à instrução verbal do executante modelo, e a pior foi (2), demonstração. Quanto às condições intermediárias, a (5), demonstração de modelo em vídeo associada à instrução verbal do instrutor, foi melhor do que a (3), demonstração associada à instrução verbal do instrutor, seguida da (1), instrução verbal do instrutor. Os autores concluíram que, embora diferentes em relação a quem fornecesse a instrução verbal (modelo executante ou instrutor), as condições de demonstração associadas à instrução verbal foram as que mais favoreceram a aprendizagem.

Em suma, em nenhum dos estudos com apenas instrução verbal essa condição experimental se revelou superior às demais. Ainda, os estudos em que houve diferenças sugerem que a demonstração associada à instrução verbal é uma condição que favorece mais tanto o desempenho como a aprendizagem de habilidades motoras.

Em relação às características do modelo, com o objetivo de investigar o efeito do status e de seu nível de habilidade, LANDERS e LANDERS (1973) conduziram um experimento cuja tarefa era subir os degraus da escada de Bachman. Participaram 100 meninas com idade entre 10 e 12 anos, que viram duas demonstrações antes da prática. As crianças foram distribuídas em quatro grupos, segundo as seguintes condições experimentais relativas a, respectivamente, status e nível de habilidade do modelo: (1) professor conhecido e habilidoso, (2) professor conhecido e pouco habilidoso, (3) par desconhecido e habilidoso, e (4) par desconhecido e pouco habilidoso. Os resultados mostraram que a primeira condição - professor conhecido e habilidoso - resultou em melhor aprendizagem que as demais. Os autores argumentaram que, nessa condição, os aprendizes provavelmente se sentiram mais motivados a aprender a tarefa. 
LIRGG e FELTZ (1991) replicaram o estudo de LANDERS e LANDERS (1973), também com 100 alunas. Como no anterior, a tarefa foi subir a escada de Bachman, mas, neste estudo, nenhum dos quatro modelos era conhecido. As condições experimentais em que se distribuíram as crianças foram: (1) professor habilidoso, (2) professor não habilidoso, (3) par habilidoso, e (4) par não habilidoso. Verificou-se que observar um modelo habilidoso foi melhor do que observar um não habilidoso e que não houve interação entre status e nível de habilidade. Esses resultados com modelos desconhecidos permitiram concluir que o nível de habilidade do modelo é mais relevante que seu status.

O efeito da observação do modelo habilidoso e do não habilidoso foi depois investigado por POLLOCK e LEE (1992), na aprendizagem de um jogo de perseguição no computador. Nesse estudo, o modelo não habilidoso foi um modelo aprendendo a tarefa. Participaram 54 estudantes de graduação, distribuídos aleatoriamente em três grupos experimentais: (1) aprendizes observadores de modelo habilidoso, (2) aprendizes observadores de modelo não habilidoso aprendendo, (3) modelo iniciante aprendendo. Os sujeitos dos grupos (2) e (3) formaram 18 pares. Um único executante habilidoso serviu como modelo para os 18 aprendizes de modelo habilidoso. Segundo os resultados, não houve diferença entre observar um modelo habilidoso e não habilidoso aprendendo, mas a aprendizagem foi melhor nos dois grupos que observaram um modelo do que no grupo de modelos iniciantes aprendendo. Os autores concluíram que, independentemente do tipo, a observação de um modelo vivo é benéfica, pois cria uma situação dinâmica de observação.

Por sua vez, o objetivo do estudo desenvolvido por ZETOU, FRAGOULI e TZETZIS (1999) foi investigar a influência do modelo perito com status de estrela na modalidade e do automodelo na aprendizagem de habilidades do voleibol (passe e saque). Participaram 58 crianças de 11 anos de idade, distribuídas em dois grupos. $\mathrm{Na}$ fase de aquisição, às crianças do grupo estrela era apresentado vídeo com um perito demonstrando a tarefa a ser aprendida. Ao grupo automodelo, um vídeo com seu próprio movimento. Em ambos os grupos, a demonstração era associada à instrução verbal. Os resultados mostraram que, na fase de retenção, o grupo com modelo perito desempenhou melhor as tarefas do que o grupo automodelo, e a 
explicação remeteu à maior motivação do grupo que observou o perito, que queria se assemelhar ao modelo considerado uma estrela na modalidade.

BOSCHKER e BAKKER (2002) tiveram como propósito avaliar se a observação de um modelo perito faria escaladores inexperientes perceber e executar novas possibilidades de ação e se isso facilitaria seu desempenho na escalada. Eles partiram da suposição de que, mostrando aos inexperientes um modelo de escalada habilidoso, Ihes possibilitariam perceber características funcionais que de outra forma permaneceriam desconhecidas. Em consequência, iniciantes poderiam passar a adotar padrões de ação característicos de indivíduos habilidosos. Três grupos de 24 participantes inexperientes observaram, respectivamente, vídeos projetando um padrão habilidoso de escalada - modelo perito -, um padrão iniciante de escalada modelo inexperiente - ou a parede de escalada sem modelo. Após a apresentação da demonstração, os participantes escalavam a parede. Esse procedimento foi repetido cinco vezes. A análise do desempenho permitiu verificar que os participantes que observaram um padrão habilidoso de escalada adotaram-no e escalaram mais depressa e com mais desenvoltura do que os que observaram um padrão iniciante ou não tiveram modelo. Assim, os autores confirmaram suas suposições de que a apresentação de modelo perito favorece a adoção de padrões de ação característicos de indivíduos habilidosos por parte dos iniciantes.

Em suma, quanto às características do modelo, os estudos mostram que, de modo geral, a observação de modelos habilidosos conduz a uma aprendizagem superior do que a observação de modelos iniciantes ou sem status.

SIDAWAY e HAND (1993) quiseram investigar os efeitos da frequência relativa de apresentação de um modelo perito na aquisição de uma habilidade motora. A tarefa consistiu em rebater uma bola de golfe para acertar um alvo a 9,7 metros de distância. Participaram 40 universitárias sem experiência prévia na tarefa. Elas fizeram 150 tentativas de prática, na fase de aquisição, distribuídas em quatro grupos experimentais: com 100\%, 20\% e 10\% de frequência relativa de apresentação do modelo e um grupo controle, que recebeu apenas as instruções iniciais. Nas fases de retenção e transferência, não houve apresentação do modelo.

BRUZZI (2006) estudou o efeito do número de demonstrações na aprendizagem do arremesso de dardo com movimento póstero-anterior. Para 
aprendizagem desta tarefa, a amostra foi constituída de 40 adultos (18 a 40 anos) de ambos os sexos que foram alocados aleatoriamente para dois grupos, sendo D2 com 2 demonstrações e D10 com 10 demonstrações. Como resultados, D2 e D10 não foram diferentes quanto ao número de tentativas usadas para alcance do desempenho critério, entretanto, os resultados de D10 foram superiores ao de D2 para o número de sujeitos que executaram o padrão correto e para o número de sujeitos que atingiram o desempenho critério. Concluiu-se que houve efeito do número de demonstração na qualidade do padrão espacial de movimento, sendo D10 superior a D2.

Os resultados mostraram que, quanto maior foi a frequência de apresentação do modelo, tanto melhor foi o desempenho alcançado na prática, fosse pela capacidade de manter o nível de desempenho na retenção, fosse pela de transferi-la para uma nova versão da tarefa original.

Em síntese, os estudos sobre a informação prévia mostraram que (a) a demonstração associada à instrução verbal é a condição que mais favorece tanto o desempenho como a aprendizagem de habilidades motoras, (b) a observação de modelos habilidosos conduz a uma aprendizagem melhor do que a observação de modelos iniciantes ou sem status, e (c) quanto maior for a frequência relativa de apresentação, tanto mais se favorece a aprendizagem.

Esses conhecimentos serviram de referência para o desenvolvimento do presente estudo, sobretudo no que tange à metodologia empregada.

\section{PROBLEMA}

No ensino das habilidades motoras do nado sincronizado, um dos recursos usados para favorecer a aprendizagem é a apresentação de um modelo humano (colega ou instrutor), do modelo boneca ou de sua alternância associada à instrução verbal. No dia a dia, a escolha responde a critérios pessoais do instrutor e está condicionada aos recursos disponíveis, ou seja, como já foi dito, não se baseia em conhecimentos teórico-científicos. 
Resultados de estudos em aprendizagem motora levam a crer que a demonstração associada à instrução verbal é a condição que favorece mais tanto o desempenho como a aprendizagem de habilidades motoras. Nesses termos, a apresentação da demonstração é considerada uma medida efetiva para o aprendiz, que precisa ter uma ideia clara do objetivo a atingir e/ou estabelecer um referencial para a correção da ação. Esse benefício é usualmente mais claro em tarefas em que o padrão de movimento - e não o resultado da ação no ambiente - é determinante do desempenho. Algumas habilidades esportivas são avaliadas em termos do padrão de movimento, como é o caso do nado sincronizado. Nesse sentido, a instrução verbal associada à demonstração no ensino de figuras e rotinas da modalidade está em consonância com as indicações da literatura.

No entanto, resultados de estudos sobre aprendizagem motora mostram que ela também é afetada pelas características do modelo apresentado. Mais especificamente, que a aprendizagem é mais eficaz quando o modelo é habilidoso do que quando é iniciante. Mostrar uma maneira habilidosa de solucionar o problema permite aos inexperientes perceber características funcionais que, com a apresentação de modelos iniciantes, permanecem desconhecidas. A vantagem é em que essa percepção favorece a adoção de padrões de ação mais fluentes e eficazes, típicos de indivíduos habilidosos.

No ensino do nado sincronizado, embora tenham características distintas, os modelos humano e boneca são empregados indiscriminadamente. Com este, o instrutor pode simular a execução correta dos movimentos, mas há limites para as características funcionais que podem ser apresentadas. Por exemplo, não se vêem as ações de rotação e circundução das articulações do pescoço, das mãos e dos pés e a "execução" da boneca não ocorre em contexto real, ou seja, não é feita na água. Por isso, não se informa o nível da água durante a execução. Nesse sentido, a apresentação do modelo humano dá mais informações ao aprendiz do que o modelo boneca.

As figuras do nado sincronizado podem ser consideradas seus fundamentos, pois sua execução se dá tanto isoladamente quanto como parte de rotinas. Neste estudo, verifica-se se as características dos modelos boneca e humano afetam a aprendizagem das figuras do nado sincronizado. 
O objetivo deste estudo foi investigar os efeitos dos modelos boneca e humano na aprendizagem da tina do nado sincronizado (experimento 1) e ainda os efeitos da ordem de apresentação desses modelos na aprendizagem da mesma figura (experimento 2).

O estudo foi aprovado pelo Comitê de Ética em Pesquisa da Escola Superior de Educação Física de Jundiaí (ESEF-Jundiaí), processo no 008/07 - CAEE - 0006.0.335.000-07.

5

\section{EXPERIMENTO 1}

\section{$5.1 \quad$ OBJETIVO}

Investigar os efeitos do tipo de modelo boneca e humano na aprendizagem da tina do nado sincronizado.

\section{$5.2 \quad$ MÉTODO}

\subsubsection{Amostra}

A amostra foi constituída por 20 adultos jovens, voluntários, do gênero feminino, com idade média de 23,1 anos ( $D P=4,1$ ). Na época da coleta, todas a participantes estavam adaptadas ao meio aquático, apresentando deslocamento independente na parte rasa da piscina e flutuação com auxílio das mãos. Nenhuma tivera experiência anterior com qualquer das habilidades do nado sincronizado.

\subsubsection{Tarefa}

O experimento foi realizado em piscina coberta e aquecida de 25 metros de comprimento por 12,5 metros de largura, com profundidade de $1,30 \mathrm{~m}$ em toda a área. 
A tarefa consistiu na execução da tina, figura muito utilizada na iniciação do nado sincronizado e que compreende uma sequência composta por três posições e dois movimentos de transição: (1) posição inicial, (2) transição para a tina, (3) posição de tina; (4) transição para a posição final, e (5) posição final (FIGURA 1).

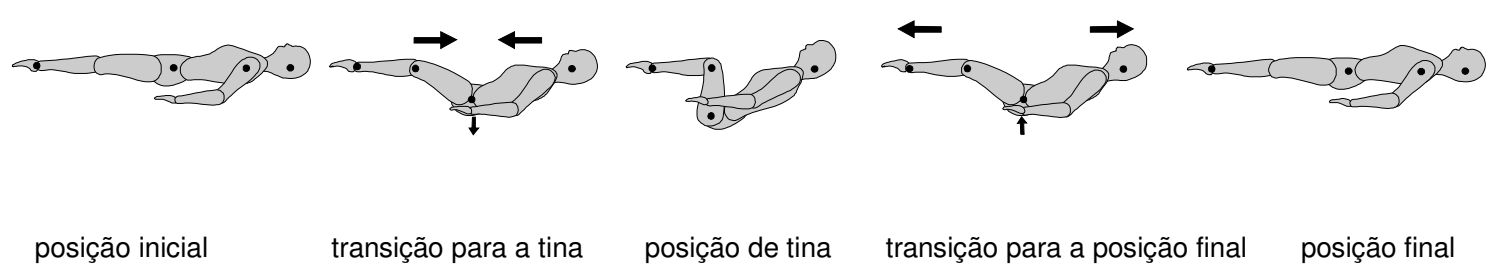

FIGURA 1 - Sequência de componentes da tina

De acordo com a descrição da Federação Internacional de Natação (CBDA, s/d), a posição de tina compreende: "Pernas flexionadas e juntas, pés e joelhos na superfície e paralelos a ela, e coxa perpendicular. Cabeça alinhada com o tronco e face na superfície."

Essa figura foi escolhida como tarefa, pois, (1) dentre as figuras do nado sincronizado, é uma habilidade relativamente simples, passível de ser aprendida por sujeitos iniciantes, e (2) tem componentes de posição e transição claramente definidos, com requisitos explícitos de desenho e controle que permitem a avaliação do desempenho.

\subsubsection{Delineamento}

As participantes $(n=20)$ foram distribuídas em dois grupos de 10: o grupo modelo boneca (GB) e o grupo modelo humano $(\mathrm{GH})$. O delineamento experimental teve duas fases. A fase de aquisição envolveu a prática na tarefa e a fase de retenção, a testagem relativa à manutenção do desempenho alcançado na fase de aquisição. 
Precedendo à fase de aquisição, aplicou-se um pré-teste para garantir a homogeneidade da amostra e, assim, evitar resultados que se pudessem atribuir a eventuais diferenças em sua composição. Independentemente do grupo, todas a participante fizeram 6 tentativas consecutivas, tendo sido a informação prévia sobre a execução correta da tarefa (tina do nado sincronizado) fornecida por instrução verbal.

$\mathrm{Na}$ fase de aquisição, todos fizeram 60 tentativas. A demonstração foi feita por meio de um vídeo, projetando, para o GB, um modelo boneca executando a tina e, para ० $\mathrm{GH}$, um modelo humano. Em ambos os casos, a demonstração esteve associada a instrução verbal.

Para verificar possíveis mudanças no desempenho depois da fase de aquisição, aplicou-se o pós-teste após 10 minutos de intervalo para descanso. Como o pré-teste, o pós-teste compreendeu 6 tentativas antecedidas apenas de instrução verbal. Essa inclusão permitiu a comparação dos desempenhos anterior (pré-teste) e posterior (pós-teste) à fase de aquisição.

No dia seguinte à fase de aquisição e à aplicação do pós-teste, todas as participantes, independentemente do grupo, foram submetidas ao teste de retenção. Essa fase consistiu na realização de dois blocos de seis tentativas, aqui designados por RE1 e RE2, e as participantes não receberam instrução.

Em suma, conforme apresentado no QUADRO 2, o delineamento experimental consistiu de pré-teste (PRÉ), fase de aquisição (AQ1-AQ10), pós-teste (PÓS) e teste de retenção em dois blocos (RE1 e RE2). Na fase de aquisição, bem como nos pré e pós testes, a informação prévia foi dada antes de cada tentativa, ou seja, a frequência de fornecimento (100\%) foi a que consta na literatura como sendo a que mais favorece a aprendizagem de habilidades motoras. 
QUADRO 1 - Delineamento do experimento 1

\begin{tabular}{|l|c|c|c|c|}
\hline testes e fases & pré-teste & aquisição & $\begin{array}{c}\text { pós-teste } \\
(10 \text { min após })\end{array}$ & $\begin{array}{c}\text { retenção } \\
\text { (dia seguinte) }\end{array}$ \\
\hline blocos & $\mathrm{PRÉ}$ & $\mathrm{AQ} \mathrm{1} \mathrm{a} \mathrm{AQ} \mathrm{10}$ & $\mathrm{PÓS}$ & $\mathrm{RE1} \mathrm{e} \mathrm{RE2}$ \\
\hline número de tentativas & 6 & 60 & 6 & $6+6$ \\
\hline instrução GB & verbal & boneca e verbal & verbal & sem \\
\hline instrução GH & verbal & humano e verbal & verbal & sem \\
\hline
\end{tabular}

\subsubsection{Instrumentos}

\subsubsection{Registro e análise dos dados}

\section{Filmadora}

O registro dos dados foi feito por uma filmadora digital de definição 1080i, marca Sony, modelo HDR-SR11, com resolução de 10.2-MP e memória de 60GB.

\section{Gravador e reprodutor de DVD}

As imagens foram gravadas em mídia DVD e projetadas, para fins de análise, num aparelho da marca Samsung, modelo DVD-R150, com os recursos do aparelho, sem uso de software.

\section{Lista de checagem da tina (LCT)}

Em competições internacionais de nado sincronizado, julga-se 0 desempenho das atletas pelo regulamento da FINA (2005), que contém as descrições e as regras que são estipuladas por um comitê. A escala de avaliação oficial é dividida em 12 categorias, de "fraca" a "perfeita". A interpretação dos critérios é feita pelos árbitros reconhecidos por essa federação internacional e treinados para atribuir notas de 0 a 10 com precisão de décimos.

No Brasil, para tornar mais objetivo o julgamento em torneios e campeonatos, usa-se um instrumento guia da banca de arbitragem denominado 
escala de notas explicada (ANEXO II). Trata-se de uma tradução da escala oficial feita pela atual supervisora de arbitragem da Confederação Brasileira de Desportos Aquáticos (CBDA), a Prof ${ }^{a}$ Ana Maria da Silveira Lobo. Esse instrumento ajuda os árbitros a esclarecer ambiguidades de interpretação de critérios como, por exemplo, "controle pobre", "altura média", "pequenas inconsistências".

No entanto, mesmo com esse instrumento, constatam-se diferenças entre o julgamento dos árbitros, o que permite inferir suas limitações para uma análise mais aprofundada do desempenho das habilidades do nado sincronizado e, mais especificamente, da tina, examinada no presente estudo. Entre elas, poderíamos citar a atribuição de valores sem a correspondente análise qualitativa do padrão de movimento adotado (MEIRA JUNIOR, 2003). Assim, não se explicitam a diferença entre $o$ esperado e o executado e nem o erro cometido, dificultando a análise criteriosa do desempenho.

Para tanto, FUGITA e FREUDENHEIM (2006) propuseram uma lista de checagem cujos itens foram sugeridos por especialistas em nado sincronizado da Federação Aquática Paulista (FAP): 1) rosto em relação à superfície da água, 2) orelhas em relação à superfície, 3) joelhos em relação à superfície, 4) afastamento dos joelhos, 5) ângulo entre perna e coxa, 6) afastamento das pernas, 7) pernas em relação à superfície, 8) afastamento dos pés, 9) pés em relação à superfície, 10) extensão dos tornozelos, 11) afastamento dos calcanhares, 12) estabilidade do corpo na água, e 13) deslocamento do corpo na água.

Para a validação dessa lista, seis alunas iniciantes de nado sincronizado, com idade entre 8 a 16 anos e níveis variados de habilidade, foram filmadas de perfil, individualmente, na execução da sequência para a tina. As imagens foram analisadas por três árbitros de São Paulo. Embora considerada clara, objetiva e viável pelas técnicas de nado sincronizado, a concordância entre observadores (CEO) (THOMAS \& NELSON, 2002) foi de $70 \%$, um percentual considerado baixo.

Assim, para o presente estudo, elaborou-se uma nova lista de checagem da tina (LCT), agora baseada nos cinco componentes a ser executados: $(\mathrm{PI})$ posição inicial; (TT) transição para a tina; (PT) posição de tina; (TF) transição para a posição final e (PF) posição final (ANEXO III). Para cada componente, estabeleceram-se 
critérios de avaliação (ANEXO IV) segundo aspectos considerados essenciais à execução correta por especialistas da modalidade.

A amostra para validação desse instrumento foi composta por 10 adultos do sexo feminino cuja média de idade foi 21,2 anos ( $D P=2,7$ ). A tarefa foi a execução da tina do nado sincronizado. O conteúdo foi analisado por cinco especialistas em nado sincronizado, com formação acadêmica (ANEXO V), e três especialistas, também com formação acadêmica (ANEXO VI), participaram da determinação das correlações inter e intra-avaliadores.

Depois da análise da LCT e dos critérios, os especialistas para a avaliação de conteúdo responderam a um questionário e, feito isso, consideraram os critérios "muito claros" (100\%) e sua aplicabilidade, "muito viável" (100\%). Quanto ao conteúdo técnico, ela foi considerada "muito adequada" (80\%) e "adequada" (20\%).

Ainda como procedimento de validação, os três especialistas para a consistência e da reprodutibilidade da LCT estudaram seus critérios, da LCT e foram avaliados quanto à concordância que mantiveram entre duas observações feitas em dias diferentes. Avaliaram-se 15 critérios, e os percentuais de concordância foram considerados satisfatórios: $91 \%$ para o avaliador 1, de $86 \%$ para o avaliador 2 e de $87 \%$ para 0 avaliador 3 . O percentual de concordância entre avaliadores para 0 primeiro e o segundo dia foi de $83 \%$. Portanto, pode-se inferir que a LCT é adequada quanto à consistência e reprodutibilidade. Os dados sobre a concordância inter e intra-avaliadores nos critérios 1 a 15 estão disponíveis nos ANEXOS VII a XXI.

A partir dos resultados, concluiu-se que a LCT proposta é um instrumento válido para a avaliação qualitativa da tina do nado sincronizado, e, assim, foi adotado neste estudo.

\subsubsection{Projeção da informação prévia}

\section{Vídeos}

A informação prévia foi fornecida por meio da projeção de três vídeos especialmente produzidos. Um deles mostrava uma boneca sendo manipulada pelo experimentador e continha a instrução verbal. $\mathrm{O}$ vídeo com modelo humano 
mostrava um indivíduo habilidoso (o experimentador) executando a tina e também continha a instrução verbal. O último mostrava apenas uma tela branca (papel branco como fundo) enquanto transmitia a instrução verbal. A escolha do modelo humano se deveu ao fato de a revisão da literatura ter indicado que um modelo habilidoso favorece a aprendizagem de habilidades motoras.

A boneca utilizada como modelo é bidimensional, foi confeccionada em papelão revestido de plástico impermeável e mede $40 \mathrm{~cm}$ de comprimento por $5 \mathrm{~cm}$ de largura (ANEXO XXII). Conforme especificação da SYNCHRO CANADA RESOURCE CENTER (2008), ela é toda articulada.

A captação de imagens e do áudio associado foi feita numa filmadora da marca Sony, modelo Cybershot DSC-H5.

\section{Notebook}

Perto da borda da piscina, foi posto um notebook marca HP, modelo Livestrong, com processador AMD Turion 64, sistema Microsoft Windows XP-2002, que dava a demonstração e a instrução, de modo que, mesmo dentro da água, a participante tivesse uma boa visão da figura.

\subsubsection{Procedimentos}

A filmadora também foi posicionada na beira da piscina, sobre tripé, num ângulo de $45^{\circ}$ no eixo vertical e $90^{\circ}$ no eixo horizontal, em relação ao eixo longitudinal do corpo da participante. 


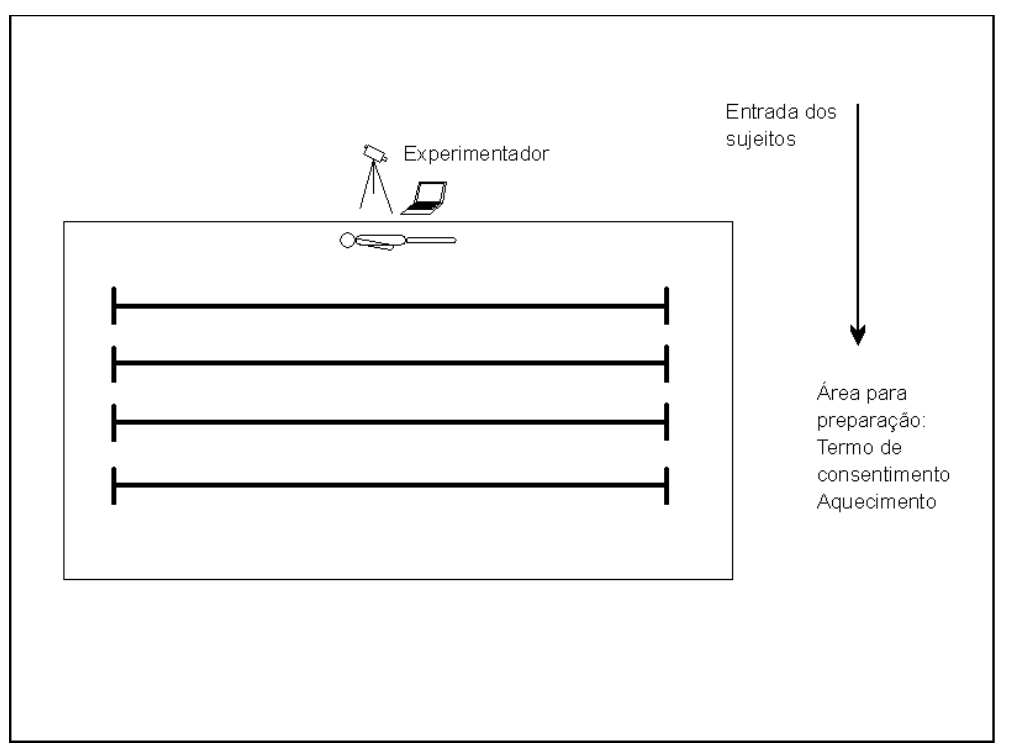

FIGURA 2 - Visão panorâmica do ambiente da coleta de dados

As participantes chegaram ao ambiente de coleta de dados (FIGURA 2) uma de cada vez, onde receberam explicações sobre a pesquisa e a carta de informação ao sujeito da pesquisa e o termo de consentimento livre e esclarecido, que leram e assinaram.

Para evitar contato entre as participantes, todo o procedimento de coleta foi individual. Fora da água e sob a orientação do experimentador, começava a sessão de exercícios preparatórios para as articulações do pescoço e dos membros superiores e membros inferiores, que durava no máximo 10 minutos. Depois, na piscina, a atleta molhava o rosto e se deslocava livremente para adaptar-se à temperatura da água.

Após essa preparação, ela ficava em pé, perto da borda da piscina, de frente para a tela do notebook, numa posição confortável de onde pudesse ver bem a projeção das informações prévias. Ela foi instruída a prestar muita atenção às informações. No pré-teste, a instrução verbal foi dada uma vez e, logo depois, a participante fez 6 tentativas consecutivas da tina do nado sincronizado. A instrução verbal era: "Corpo bem reto em cima da água. Afundar o quadril trazendo os joelhos em direção ao queixo. Coxa e perna em ângulo de 90 graus. Subir o quadril, levando as pernas para frente. Corpo bem reto em cima da água." 
Para sincronizar a câmera e marcar o início de cada tentativa, a execução foi precedida dos comandos "prepare, vá". A cada tentativa, a participante foi orientada a ficar em pé e, se necessário, se deslocar para ficar no centro da filmagem.

Finalizadas as tentativas de pré-teste, após intervalo de 10 minutos, para descanso, começaram os procedimentos correspondentes à fase de aquisição. Antes de cada uma das 60 tentativas, apresentou-se à participante a informação prévia segundo sua condição experimental. Para as do GB, projetou-se o vídeo com o modelo boneca e para as do $\mathrm{GH}$, o vídeo com o modelo humano, ambos sempre associados à mesma instrução verbal fornecida no pré-teste. Após o término das tentativas de aquisição, a participante descansava 10 minutos.

Depois, começou o pós-teste, com procedimentos idênticos aos do préteste: deu-se apenas a instrução verbal.

No dia seguinte, em horário marcado, cada participante chegou individualmente ao recinto da piscina para o teste de retenção. Novamente, ela fez o alongamento e o aquecimento, ouviu a explicação de que não teria nenhum tipo de instrução e executaria a tarefa em dois blocos de 6 tentativas.

\subsubsection{Variáveis dependentes}

As medidas utilizadas foram obtidas pela análise da filmagem da execução da figura. Respeitam-se à qualidade de execução e têm como referência os 15 itens da lista de checagem. Depois da observação do registro de cada tentativa, cada itens recebeu nota de 0 a 3 , sendo: (0) toque no chão ao invés de executar o movimento, (1) execução incorreta, (2) execução intermediária/instável, e (3) execução correta. Portanto, as medidas são qualitativas e consideram o desempenho na figura como um todo e também o especifico de cada componente. Para fim de análise, contaramse blocos de 6 tentativas. Assim, as medidas utilizadas correspondem, respectivamente, ao desempenho global (DG) e ao desempenho por componente (DC), como segue: 
Desempenho global (DG): expressa o desempenho na figura como um todo. Os escores obtidos pela participante em cada um dos 15 critérios foram somados, resultando no seu DG por tentativa. A medida representativa do bloco foi obtida pelo cálculo da mediana e transformada em escore relativo, sendo 270 o correspondente a $100 \%$ para o bloco de 6 tentativas. O DG representativo do grupo foi obtido pelo cálculo da mediana desse escore relativo.

Desempenho por componente (DC): expressa o desempenho em cada componente da figura. Essa medida foi analisada em escore relativo por componente. Os escores obtidos em cada componente da figura foram somados, resultando no DC da tentativa. Ao final do bloco, obteve-se o DC do bloco pelo cálculo da mediana, e este foi tomado como escore relativo do componente. Como cada bloco foi composto por 6 tentativas e sendo a pontuação máxima por tentativa em cada componente igual a 9 , a pontuação máxima do componente por sujeito (por bloco) foi 54 , equivalente a $100 \%$. O DC do grupo foi obtido pelo cálculo da mediana desses escores relativos dos componentes.

\subsubsection{Análise dos dados}

Para o tratamento matemático e a análise estatística dos dados, utilizaramse os programas: Excel 2003 e SPSS Statistics 17.0. Toda a análise foi baseada em THOMAS e NELSON (2002), CALLEGARI-JACQUES (2004) e SIEGEL e CASTELLAN (2006).

Foram conduzidas análises intra e intergrupos para as mesmas variáveis relativas ao $D G$ e ao $D C$. A análise intragrupo pretendeu comparar as medidas $D G$ (\%EG) e DC (\%EC) entre o pré-teste (PRÉ), pós-teste (PÓs) e dois blocos do teste de retenção (RE1 e RE2). Pela natureza dos dados e tendo sido violados os pressupostos para esta análise, adotaram-se técnicas não paramétricas. $O$ teste de Friedman foi usado para comparar os escores de PRÉ, PÓS, RE1 e RE2, e foi considerada diferença significativa para $p \leq 0,05$. Ao se detectarem diferenças significativas, foi realizado o teste de Wilcoxon. Para a análise intergrupos, aplicou-se o teste U Mann-Whitney nas medidas DG (\%EG) e DC (\%EC), no PRÉ, para testar a 
homogeneidade e em RE1/RE2, para verificar a aprendizagem. Foi considerada diferença significativa para $p \leq 0,05$.

\subsection{RESULTADOS}

\subsubsection{Pré-teste}

A FIGURA 3 mostra o DG e o DC referentes ao pré-teste. Foi realizada a comparação intergrupos para testar a homogeneidade da amostra constituída por 20 participantes, divididas em GB (N=10) e $\mathrm{GH}(\mathrm{N}=10)$.

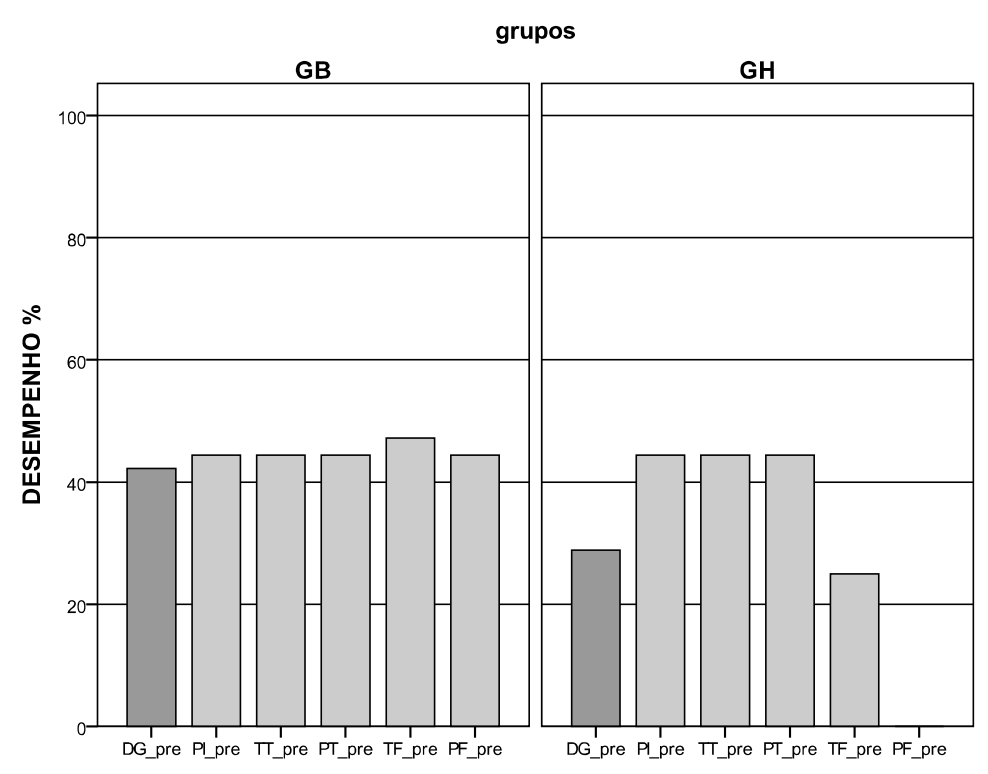

FIGURA 3 - Mediana do desempenho global e do desempenho por componente, dos componentes posição inicial (PI), transição para a tina (TT), posição de tina (PT), transição para a posição final (TF) e posição final (PT) no pré-teste, em bloco de 6 tentativas, de GB e GH. 


\subsubsection{Desempenho global}

Na FIGURA 3, considerando a coluna correspondente ao PRÉ, verifica-se que o desempenho na tina como um todo no pré-teste parece superior para o GB em relação ao $\mathrm{GH}$. No entanto, o teste $U$ de Mann-Whitney, não detectou foi diferença significativa entre GB e $G H(z=-1,104 ; p=, 269)$. Sendo assim, quanto ao DG as amostras podem ser consideradas homogêneas.

\subsubsection{Desempenho por componente}

Posição inicial: na FIGURA 3, na coluna correspondente (PI), verifica-se que o desempenho neste componente parece ter sido superior para o $\mathrm{GB}$ em relação ao $\mathrm{GH}$. No entanto, não foram encontradas diferenças significativas entre $\mathrm{GB}$ e $\mathrm{GH}$, em relação ao mesmo ( $z=-, 734 ; p=, 463)$.

Transição para a tina: na coluna correspondente (TT), verifica-se que o desempenho neste componente foi semelhante para o GB e $\circ$ GH (FIGURA 3). Comprovando esta tendência, não foi detectada diferença significativa entre GB e $\mathrm{GH}$, no mesmo ( $z=-, 083 ; p=, 934)$.

Posição de tina: na coluna correspondente (PT), verifica-se na FIGURA 3 que o desempenho neste componente foi semelhante para $\circ \mathrm{GB}$ e $\circ \mathrm{GH}$. Comprovando esta tendência, não foi detectada diferença significativa entre GB e $\mathrm{GH}$, no mesmo $(z=-, 758 ; p=, 448)$.

Transição para a posição final: neste componente na coluna correspondente (TF), verifica-se (FIGURA 3) que o desempenho do GB parece superior ao do $\mathrm{GH}$. Como para os demais, o teste $U$ de Mann-Whitney não revelou diferenças significativas entre $\mathrm{GB}$ e $\mathrm{GH}$, em relação a este componente ( $\mathrm{z}=-1,771$; $\mathrm{p}=, 077)$. 
Posição final: na FIGURA 3, na coluna correspondente (PF), verifica-se que o desempenho neste componente parece ter sido superior para o $\mathrm{GB}$ em relação ao $\mathrm{GH}$. Na análise estatística detectou-se que 6 valores de GB são maiores que a mediana e 4 são menores; para GH ocorre o oposto. $O$ teste $U$ de Mann-Whitney não revelou diferenças significativas entre $\mathrm{GB}$ e $\mathrm{GH}$, em relação a este componente ( $\mathrm{z}=-$ ,730; $p=, 465)$.

Em suma, em conjunto, os resultados referentes ao pré-teste mostram que as amostras GB e GH podem ser consideradas homogêneas.

\subsubsection{Aquisição}

Esta fase foi composta pelos blocos pré-teste, pós-teste e blocos 1 e 2 do teste de retenção.

\subsubsection{Desempenho global}

A FIGURA 4 apresenta o DG obtido pelo grupo GB, no pré-teste (PRE) no pós-teste (PÓS) e nos blocos de retenção (RE1 e RE2).

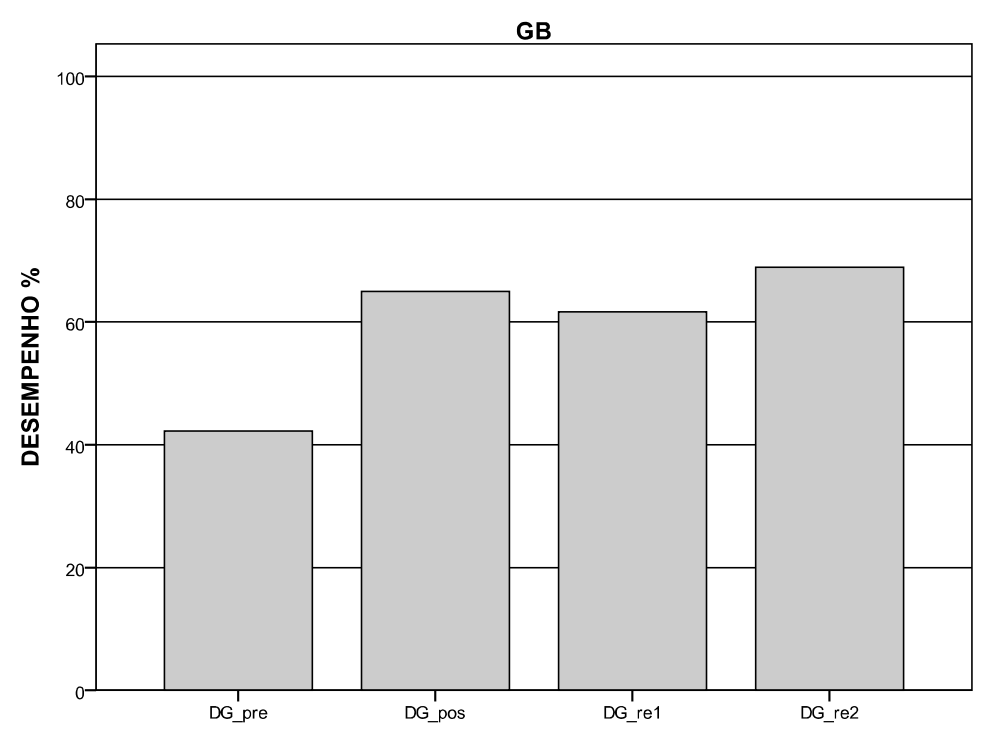

FIGURA 4 - Mediana do desempenho global do GB nos testes (PRE, PÓS) e na fase de retenção (RE1 e RE2), em blocos de 6 tentativas 
Em relação ao GB, pode-se verificar (FIGURA 4) que o DG no bloco PRÉ, é menor que o do bloco PÓS, apontando para uma tendência de melhora do desempenho em função das tentativas de aquisição. Observa-se ainda, o que parece ser um desempenho semelhante em PÓS e RE1, e um aumento de RE1 para RE2.

O teste de Friedman detectou diferença significativa na comparação dos quatro blocos $\left(x^{2}=20,212 ; p=, 000\right)$. O teste de Wilcoxon localizou diferenças significativas somente entre PRÉ e PÓS $(z=-2,803 ; p=, 005)$. Não houve diferença significativa entre PÓS e RE1 ( $z=-1,228 ; p=, 219)$, entre PÓS-RE2 $(z=-1,125 ; p=, 261)$, e entre RE1e RE2 ( $z=-1,424 ; p=, 154)$.

Estes resultados permitem inferir que o GB, melhorou seu desempenho em função das tentativas de aquisição e que foi capaz de manter este desempenho.

A FIGURA 5 apresenta o DG obtido pelo grupo GH, no pré-teste (PRÉ) no pós-teste (PÓS) e nos blocos de retenção (RE1 e RE2).

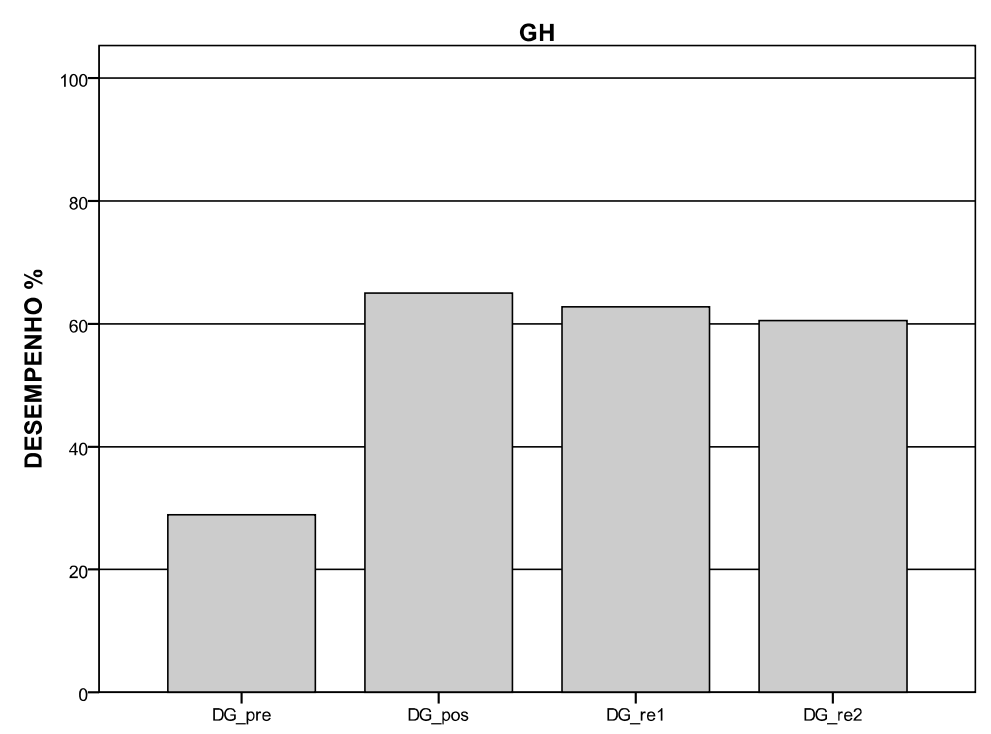

FIGURA 5 - Mediana do desempenho global do GH nos testes (PRÉ, PÓS) e na fase de retenção (RE1 e RE2), em blocos de 6 tentativas. 
Em relação ao $\mathrm{GH}$, pode-se observar na FIGURA 5 que o DG no bloco PRÉ, é bem menor que o do bloco PÓs, apontando, portanto também para este grupo uma tendência de melhora do desempenho em função das tentativas de aquisição. Observa-se ainda, o que parece ser um desempenho semelhante de PÓs, RE1 e RE2.

Para GH o teste de Friedman detectou diferença significativa na comparação entre os quatro blocos $\left(x^{2}=14,781 ; p=, 002\right)$ e o teste de Wilcoxon localizou diferenças significativas somente entre PRÉ e PÓS $(z=-2,805 ; p=, 005)$. Portanto não houve diferença significativa entre PÓS e RE1 $(z=-, 831 ; p=, 406)$, entre PÓS e RE2 ( $z=-, 957 ; p=, 339)$, e entre RE1e RE2 ( $z=-, 211 ; p=, 833)$.

Estes resultados permitem inferir que o $\mathrm{GH}$, também foi capaz de melhorar seu desempenho em função das tentativas de aquisição e de mantê-lo após um dia de intervalo.

\subsubsection{Desempenho por componente}

\section{Posição inicial}

A FIGURA 6 apresenta o desempenho obtido pelo grupo GB, no pré-teste (PRÉ), no pós-teste (PÓS), e na retenção (RE1 e RE2), referentes ao componente posição inicial $(\mathrm{PI})$. 


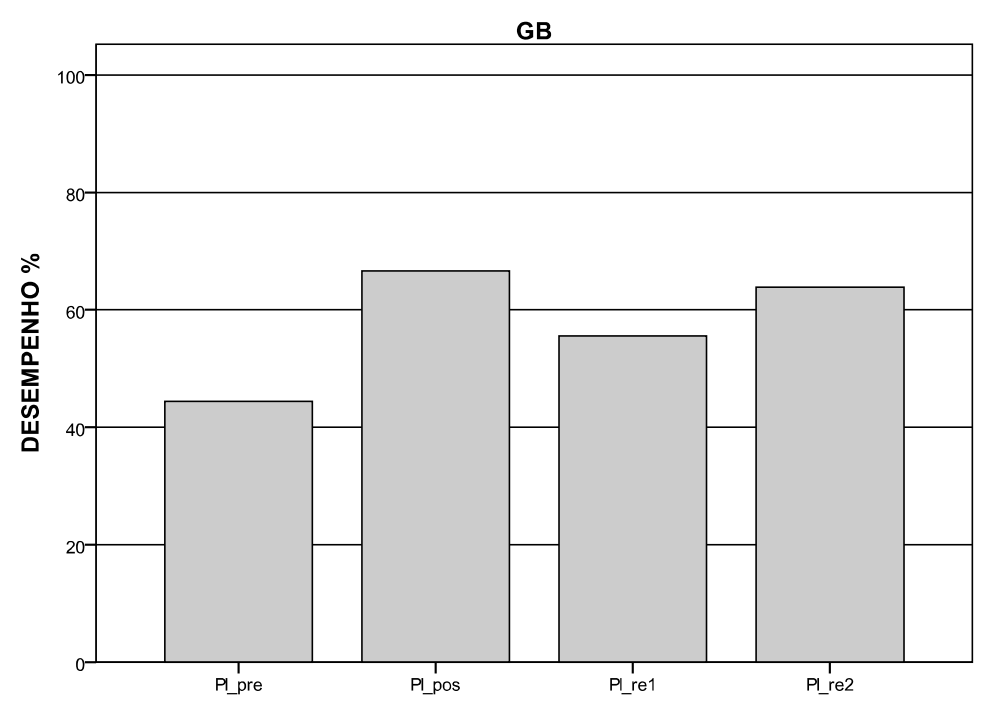

FIGURA 6 - Mediana do desempenho no componente posição inicial (PI) do GB nos blocos de 6 tentativas correspondentes ao pré-teste (PRÉ) ao pós-teste (PÓS) e à retenção (RE1 e RE2).

Em relação ao GB, pode-se observar (FIGURA 6) que o desempenho no bloco PRÉ, é menor que o do bloco PÓS, indicando tendência de melhora neste componente em função das tentativas de aquisição. Verifica-se também uma tendência de declínio deste valor atingido no bloco RE1, seguido de um aumento no bloco RE2.

A análise estatística indicou diferença significativa na comparação dos quatro blocos $\left(x^{2}=15,867 ; p=, 001\right)$. O teste de Wilcoxon, localizou as diferenças entre PRÉ-PÓS ( $z=-2,451 ; p=, 014)$. Não houve diferença significativa entre PÓS-RE1 $(Z=-, 478 ; p=, 633)$ e PÓS-RE2 ( $z=-, 085 ; p=, 932)$, portanto a diminuição do DC entre PÓS-RE1 e PÓS-RE2 não pode ser considerada significativa. Também não foi encontrada diferença significativa para o aumento da mediana entre RE1-RE2 ( $z=-$ , $813 ; p=, 416$ ). 
A FIGURA 7 apresenta o desempenho obtido pelo grupo $\mathrm{GH}$, no pré-teste (PRE), no pós-teste (POS), e na retenção (RE1 e RE2), referentes ao componente posição inicial $(\mathrm{PI})$.

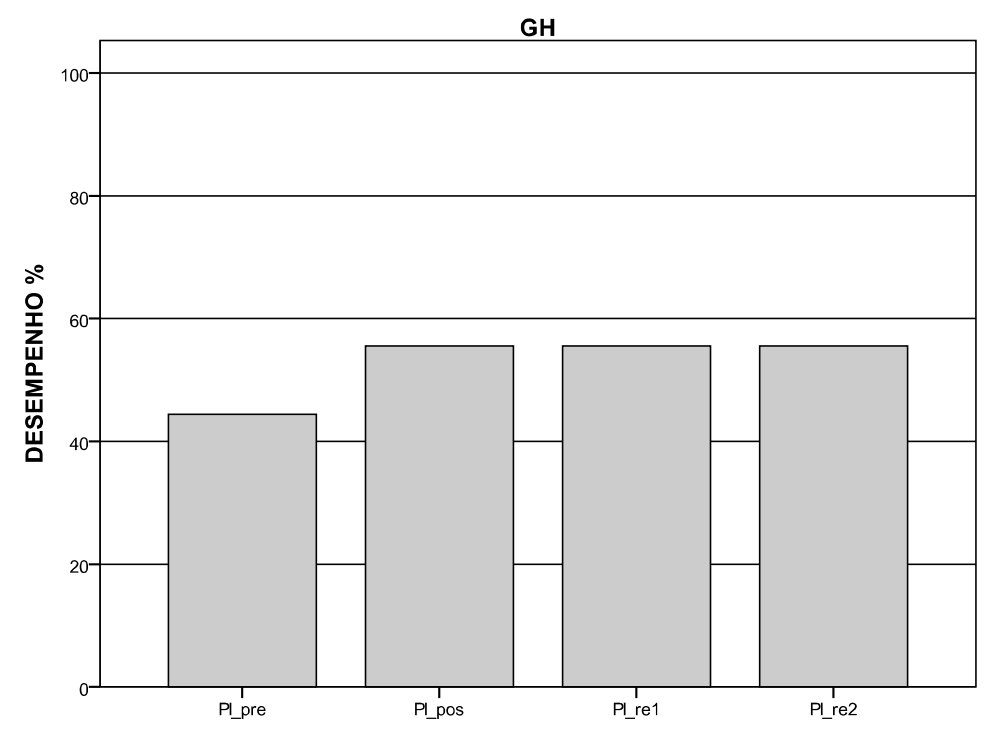

FIGURA 7 - Mediana do desempenho no componente posição inicial (PI) do GH nos blocos de 6 tentativas correspondentes ao pré-teste (PRE) ao pós-teste (POS) e à retenção (RE1 e RE2).

Em relação ao desempenho no componente $\mathrm{Pl}$ do $\mathrm{GH}$, observando a FIGURA 7 parece ter havido melhora do bloco PRE para o POS e manutenção em RE1 e em RE2. Portanto, em relação ao PRE os desempenhos nos blocos POS, RE1 e RE2 parecem superiores.

A análise inferencial detectou diferença significativa entre os blocos para este componente $\left(x^{2}=11,320 ; p=, 010\right)$. A aplicação do teste de Wilcoxon localizou as diferenças entre PRE-POS $(z=-2,263 ; p=, 024)$. Portanto, a aparente manutenção do desempenho entre POS-RE1 foi confirmada $(z=, 000 ; p=1,000)$, assim como em POSRE2 ( $z=-, 850 ; p=, 395)$.

A partir destes resultados pode-se inferir que ambos os modelos, boneca e humano, associados à instrução verbal possibilitaram a ocorrência da aprendizagem da posição inicial da tina. 


\section{Transição para tina}

A FIGURA 8 apresenta o desempenho obtido pelo grupo GB, no pré-teste (PRÉ) no pós-teste (PÓS) e na retenção (RE1 e RE2), referentes ao componente transição para a tina (TT).

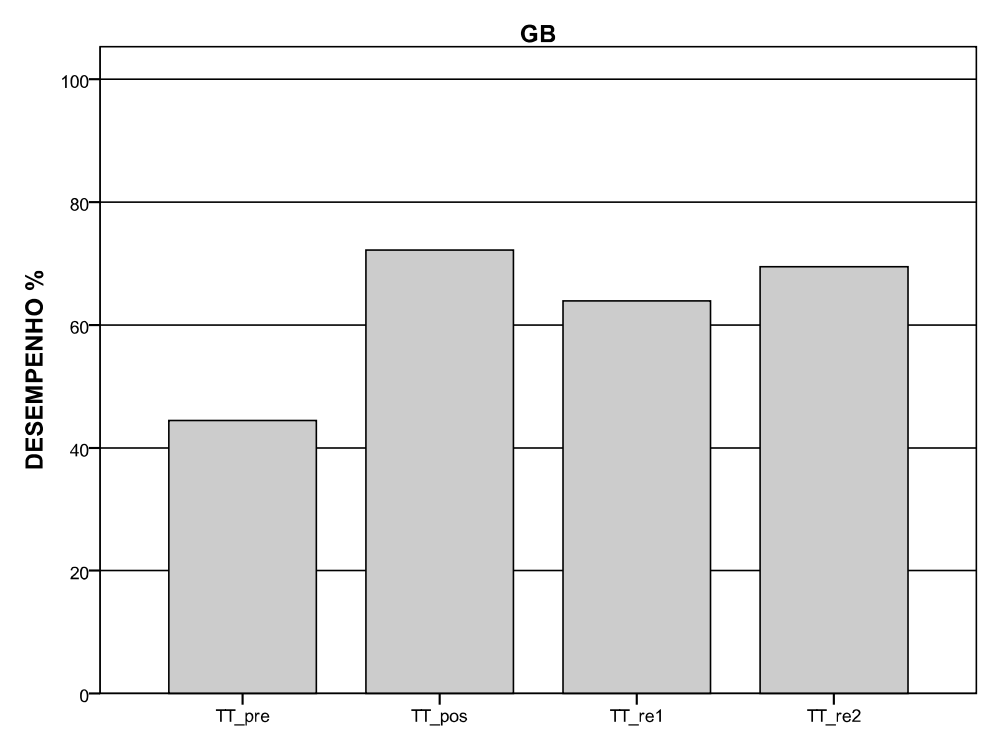

FIGURA 8 - Mediana do desempenho no componente transição para a tina (TT) do GB nos blocos de 6 tentativas correspondentes ao pré-teste (PRE) ao pós-teste (PÓS) e à retenção (RE1 e RE2).

No componente transição para a tina, o GB parece ter melhorado o desempenho do bloco PRÉ para o PÓS, e diminuído o desempenho do PÓS para o RE1 e aumentando deste para o RE2 (FIGURA 8).

$O$ teste de Friedman detectou diferença significativa na comparação dos quatro blocos $\left(x^{2}=18,833 ; p=, 000\right)$. Foram localizadas diferenças entre PRE-POS $(z=-$ 2,675; $p=, 007)$. Portanto a melhora entre PRE e POS foi confirmada e a aparente piora entre POS-RE1 não pode ser considerada significativa $(z=-, 762 ; p=, 446)$, nem entre POS-RE2 $(z=-, 853 ; p=, 394)$. 
Na FIGURA 9 o desempenho obtido pelo grupo GH, no pré-teste (PRÉ) no pós-teste (PÓS) e na retenção (RE1 e RE2), referentes ao componente transição para a tina $(\mathrm{TT})$.

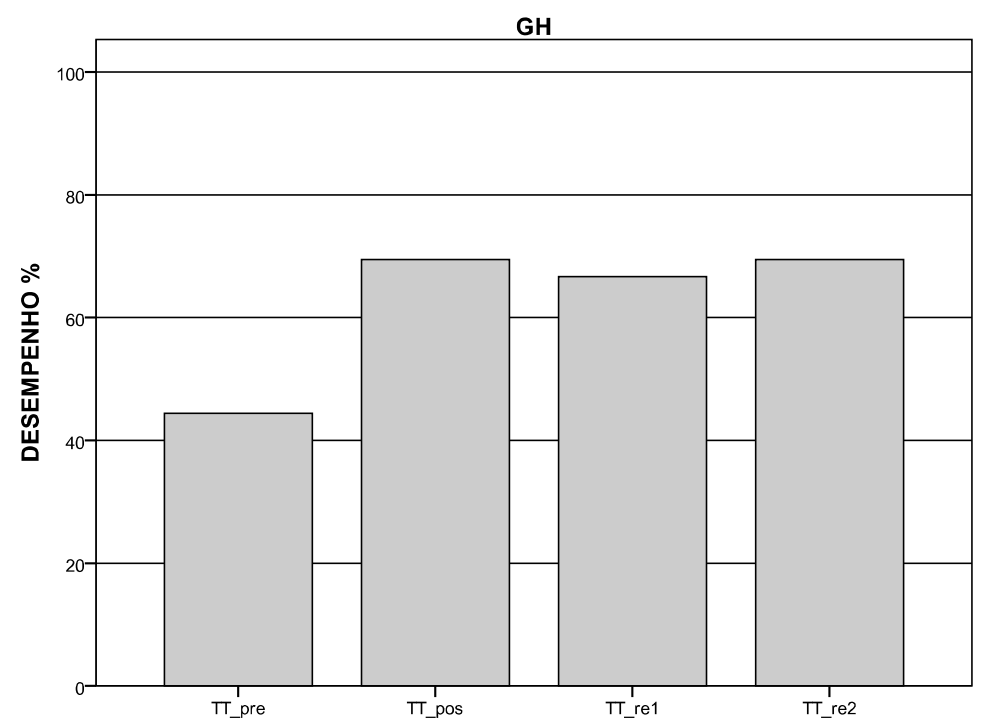

FIGURA 9 - Mediana do desempenho no componente transição para a tina (TT) do GH nos blocos de 6 tentativas correspondentes ao pré-teste (PRE) ao pós-teste (PÓS) e à retenção (RE1 e RE2).

Da mesma forma, o $\mathrm{GH}$, no componente transição para a tina, parece ter melhorado o desempenho do bloco PRE para o PÓS, e mantido o desempenho do PÓS para o RE1 e deste para o RE2 (FIGURA 9).

A análise inferencial detectou diferença significativa na comparação dos quatro blocos $\left(x^{2}=12,120 ; p=, 007\right)$ e o teste de Wilcoxon, localizou diferenças entre PRE-PÓS $(z=-2,384 ; p=, 017)$. Foi confirmada manutenção entre PÓS-RE1 ( $z=-$ $, 516 ; p=, 606)$ e PÓS-RE2 $(z=-, 276 ; p=, 783)$.

A partir destes resultados pode-se inferir que ambos os modelos, boneca e humano, associados à instrução verbal possibilitaram a ocorrência da aprendizagem da transição para a tina. 


\section{Posição de tina}

A FIGURA 10 apresenta o desempenho obtido pelo grupo GB, no pré-teste (PRE) no pós-teste (POS) e na retenção (RE1 e RE2), referentes ao componente posição de tina (PT).

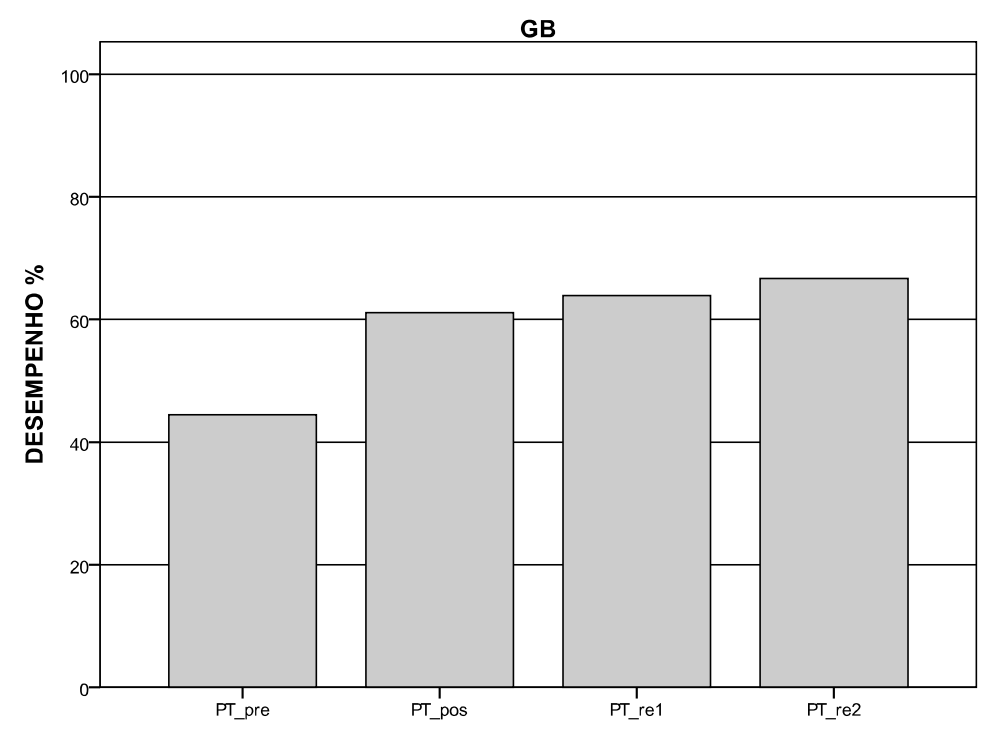

FIGURA 10 - Mediana do desempenho no componente PT do GB ao longo das fases (PRÉ, PÓS, RE1 e RE2).

Em relação ao GB observa-se que o desempenho parece ter melhorado do PRÉ para o PÓS (FIGURA 10), piorado em relação a este último bloco no RE1 e apresentou melhora novamente do RE1 para o RE2.

A análise inferencial detectou diferença significativa na comparação dos quatro blocos $\left(x^{2}=17,323 ; p=, 001\right)$. O teste de Wilcoxon localizou diferenças entre PRE-POS ( $z=-2,527 ; p=, 012)$ e POS-RE2 portanto a tendência de melhora entre POS-RE2 pode ser considerada significativa $(z=-2,155 ; p=, 031)$,. 
A FIGURA 11 apresenta o desempenho obtido pelo grupo $\mathrm{GH}$, no pré-teste (PRÉ) no pós-teste (PÓS) e na retenção (RE1 e RE2), referentes ao componente posição de tina (PT).

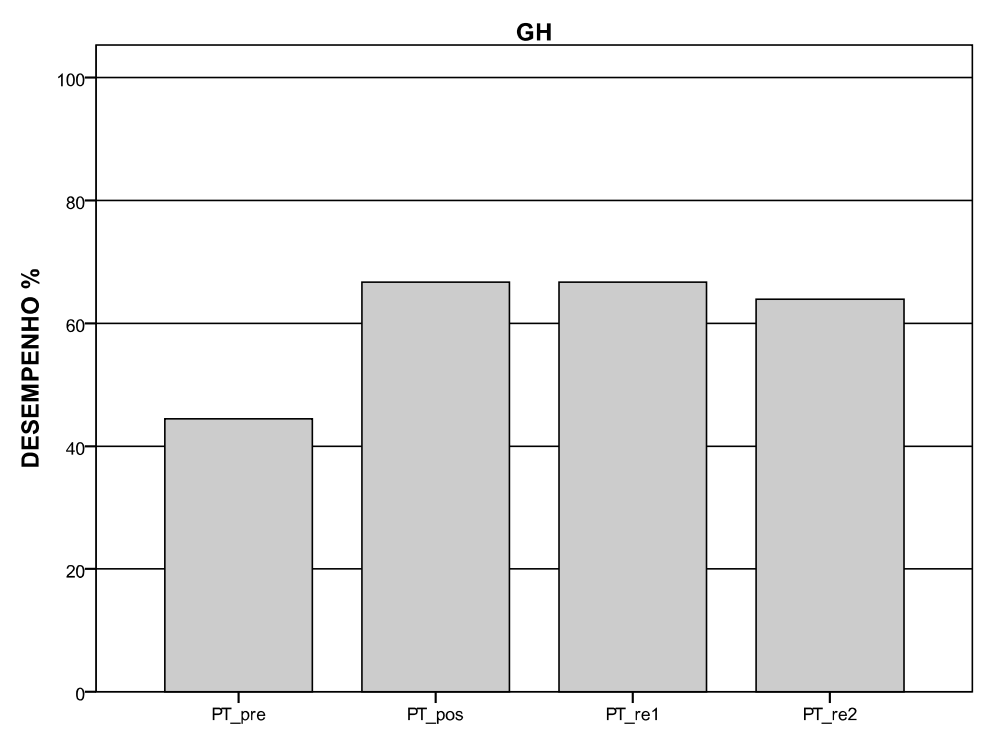

FIGURA 11 - Mediana do desempenho no componente PT do GH ao longo das fases (PRE, POS, RE1 e RE2).

No componente posição de tina, o $\mathrm{GH}$ parece ter melhorado 0 desempenho do bloco PRÉ para o PÓS, mantido o desempenho do PÓS para o RE1 e diminuído deste para o RE2 (FIGURA 11).

A análise inferencial detectou diferença significativa na comparação dos quatro blocos $\left(x^{2}=15,841 ; p=, 001\right)$ sendo que foi localizada diferença somente entre PRE-POS $(z=-2,677 ; p=, 007)$. Estes resultados confirmam a tendência de manutenção do desempenho observada entre POS-RE1 $(z=-1,063 ; p=, 288)$ e POSRE2 $(z=-1,134 ; p=, 257)$.

Os resultados permitem inferir que ambos os modelos associados à instrução verbal foram eficazes em promover a aprendizagem do componente posição de tina. 


\section{Transição para a posição final}

A FIGURA 12 apresenta o desempenho obtido pelo grupo GB, no pré-teste (PRÉ) no pós-teste (PÓS) e na retenção (RE1 e RE2), referentes ao componente transição para a posição final (TF).

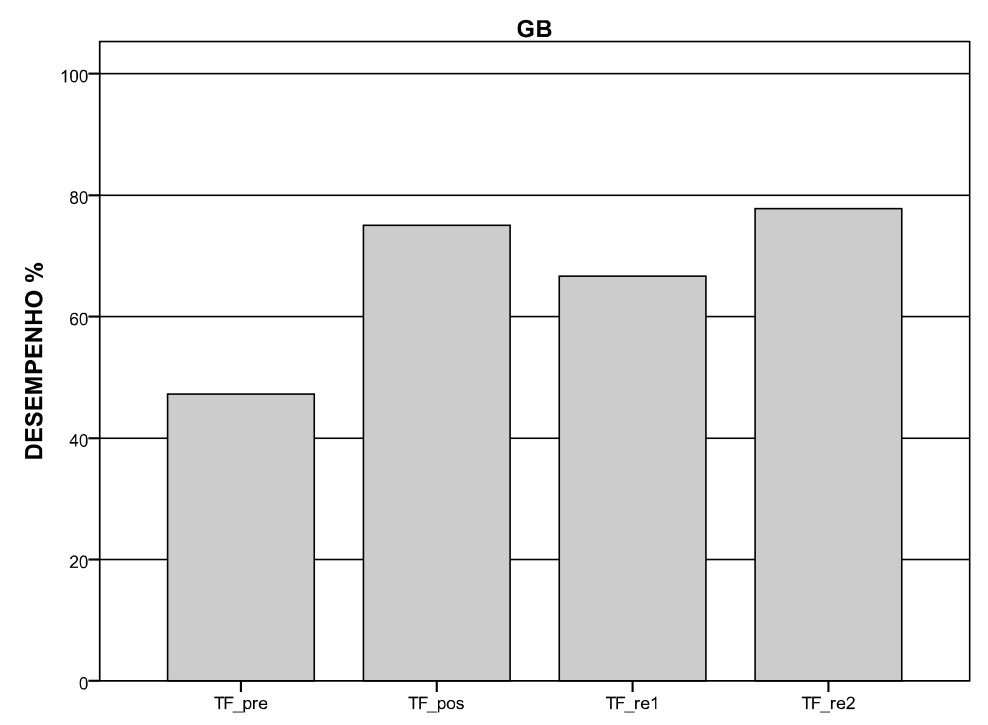

FIGURA 12 - Mediana do desempenho no componente TF do GB ao longo das fases (PRÉ, PÓS, RE1 e RE2).

Em relação ao GB observa-se que o desempenho parece ter melhorado do PRÉ para o PÓS, piorado do PÓS para o RE1 e se recuperado do RE1 para o RE2 (FIGURA 12).

A análise inferencial detectou diferença significativa na comparação dos quatro grupos $\left(x^{2}=19,964 ; p=, 000\right)$. Foi localizada diferença entre PRÉ-PÓS ( $z=-$ $2,677 ; p=, 007)$. Portanto, as tendências de piora entre POS-RE1 $(z=-, 946 ; p=, 344)$, e de melhora no desempenho entre POS-RE2 $(z=.-1,127 ; p=, 200)$ e RE1-RE2 ( $z=-$ 1,$420 ; p=, 156$ ) não foram confirmadas. 
A FIGURA 13 apresenta o desempenho obtido pelo grupo $\mathrm{GH}$, no pré-teste (PRÉ) no pós-teste (PÓS) e na retenção (RE1 e RE2), referentes ao componente transição para a posição final (TF).

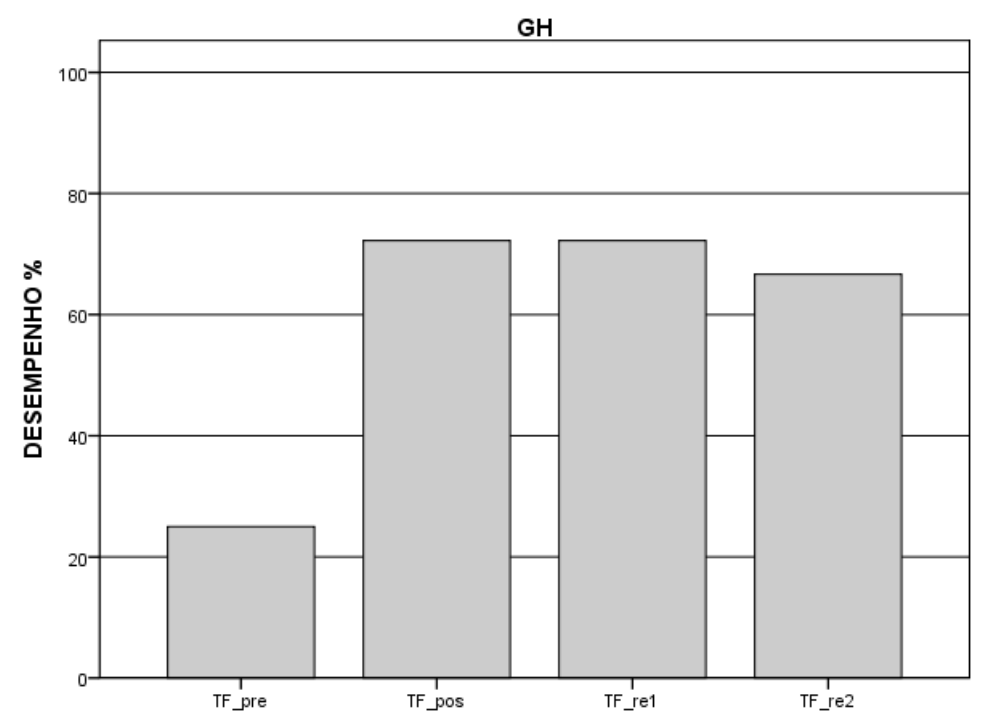

FIGURA 13 - Mediana do desempenho no componente TF do GH ao longo das fases (PRÉ, PÓS, RE1 e RE2).

O GH, no componente transição para a posição final, parece ter melhorado o desempenho do bloco PRÉ para o PÓS, e mantido o desempenho do PÓS para o RE1 e piorado deste para o RE2 (FIGURA 13).

A análise estatística inferencial detectou diferença significativa na comparação dos quatro blocos $\left(x^{2}=16,871 ; p=, 001\right)$. $O$ teste de Wilcoxon localizou as diferenças entre PRE-PÓS ( $z=-2,807 ; p=, 005)$ e entre PÓS-RE2 $(z=-1,975 ; p=, 048)$.

Portanto a tendência de melhora do desempenho em função das tentativas de aquisição foi confirmada. Além disso, foi detectada uma piora do PÓS para RE2, mas manutenção entre PÓS-RE1 ( $z=-, 362 ; p=, 717$ ).

Os resultados permitem inferir que o GH aprendeu o componente transição para a posição final. No entanto, não manteve o desempenho em RE2. 


\section{Posição final}

A FIGURA 14 apresenta o desempenho obtido pelo grupo GB, no pré-teste (PRÉ) no pós-teste (PÓS) e na retenção (RE1 e RE2), referentes ao componente posição final (PF).

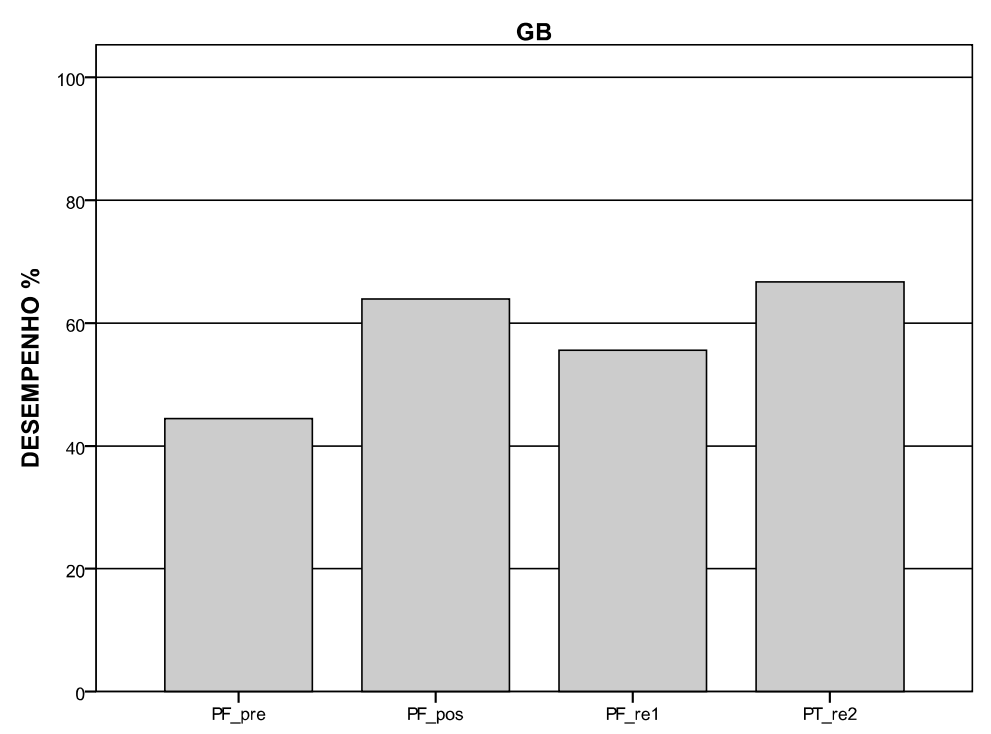

FIGURA 14 - Mediana do desempenho no componente PF do GB ao longo das fases (PRÉ, PÓS, RE1 e RE2).

Em relação ao GB observa-se que o desempenho parece ter melhorado do PRÉ para o PÓS (FIGURA 14), diminuído entre PÓS e RE1 e apresenta tendência de melhora novamente do RE1 para o RE2.

A análise inferencial detectou diferença significativa na comparação dos quatro blocos $\left(x^{2}=18,290 ; p=, 000\right)$. Foi localizada diferença somente entre PRE-PÓS $(z=-2,807 ; p=, 005)$, não confirmando a piora entre PÓS-RE1 $(z=-1,077 ; p=, 282)$ e nem a de melhora entre RE1-RE2 $(z=-1,405 ; p=, 160)$. 
A FIGURA 15 apresenta o desempenho obtido pelos grupos $\mathrm{GH}$, no préteste (PRÉ) no pós-teste (PÓS) e na retenção (RE1 e RE2), referentes ao componente posição final (PF).

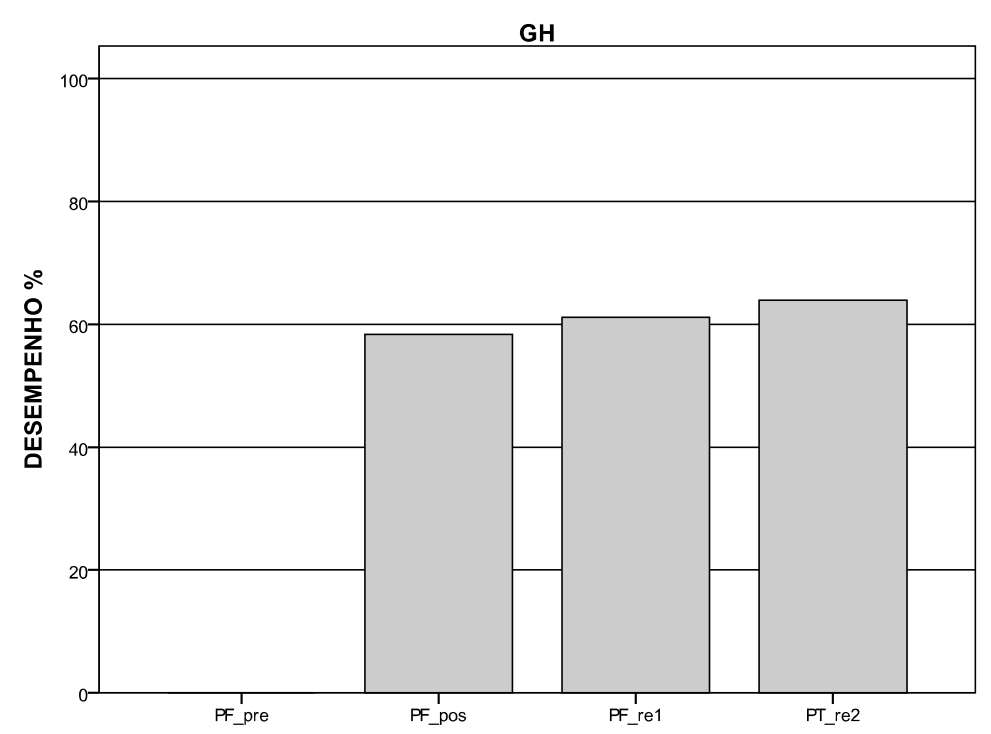

FIGURA 15 - Mediana do desempenho no componente PF do GH ao longo das fases (PRE, PÓS, RE1 e RE2).

No componente posição final, o GH parece ter melhorado o desempenho do bloco PRÉ para o PÓS, e mantido o desempenho do PÓS para o RE1 e melhorado deste para o RE2 (FIGURA 15).

A análise inferencial detectou diferença significativa entre os blocos $\left(x^{2}=17,598 ; p=, 001\right)$. Foi localizada diferença somente entre PRÉ-PÓS $(z=-2,677$; $p=, 007)$. Portanto houve manutenção entre PÓS-RE1 ( $z=-, 957 ; p=, 339)$ e entre PÓSRE2 $(z=, 000 ; p=1,000)$.

Os resultados permitem inferir que o $\mathrm{GB}$ e $\circ \mathrm{GH}$ aprenderam a posição final da tina. 


\subsubsection{RETENÇÃO}

\subsubsection{Desempenho global}

A FIGURA 16 apresenta o desempenho obtido pelos grupos $\mathrm{GB}$ e $\mathrm{GH}$, no bloco 1 do teste de retenção (RE1) referentes ao desempenho global (DG) e desempenho nos componentes (DC).

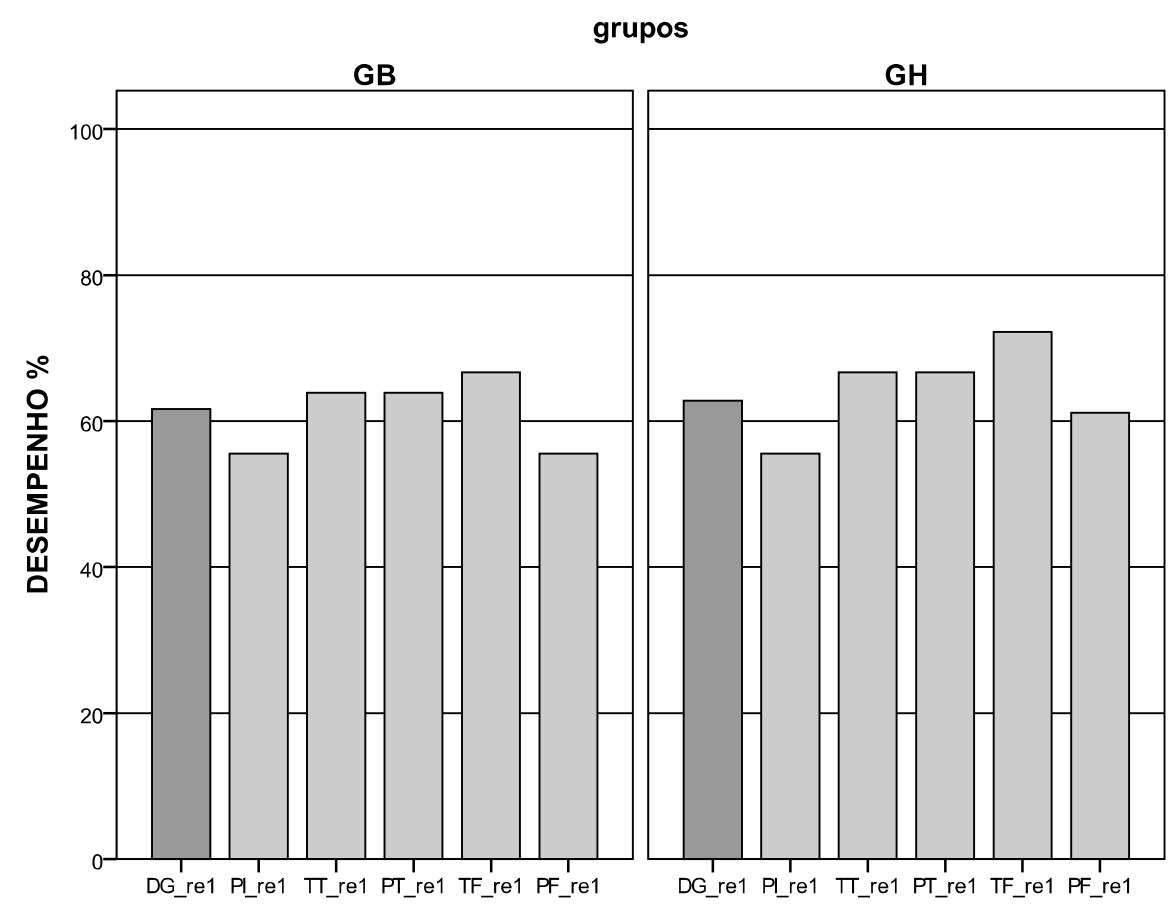

FIGURA 16 - Mediana do desempenho global e do desempenho por componente, de GB e GH, no bloco 1 do teste de retenção.

A FIGURA 17 apresenta o desempenho obtido pelos grupos GB e GH, no bloco 2 do teste de retenção (RE1) referentes ao desempenho global (DG) e desempenho nos componentes (DC). 


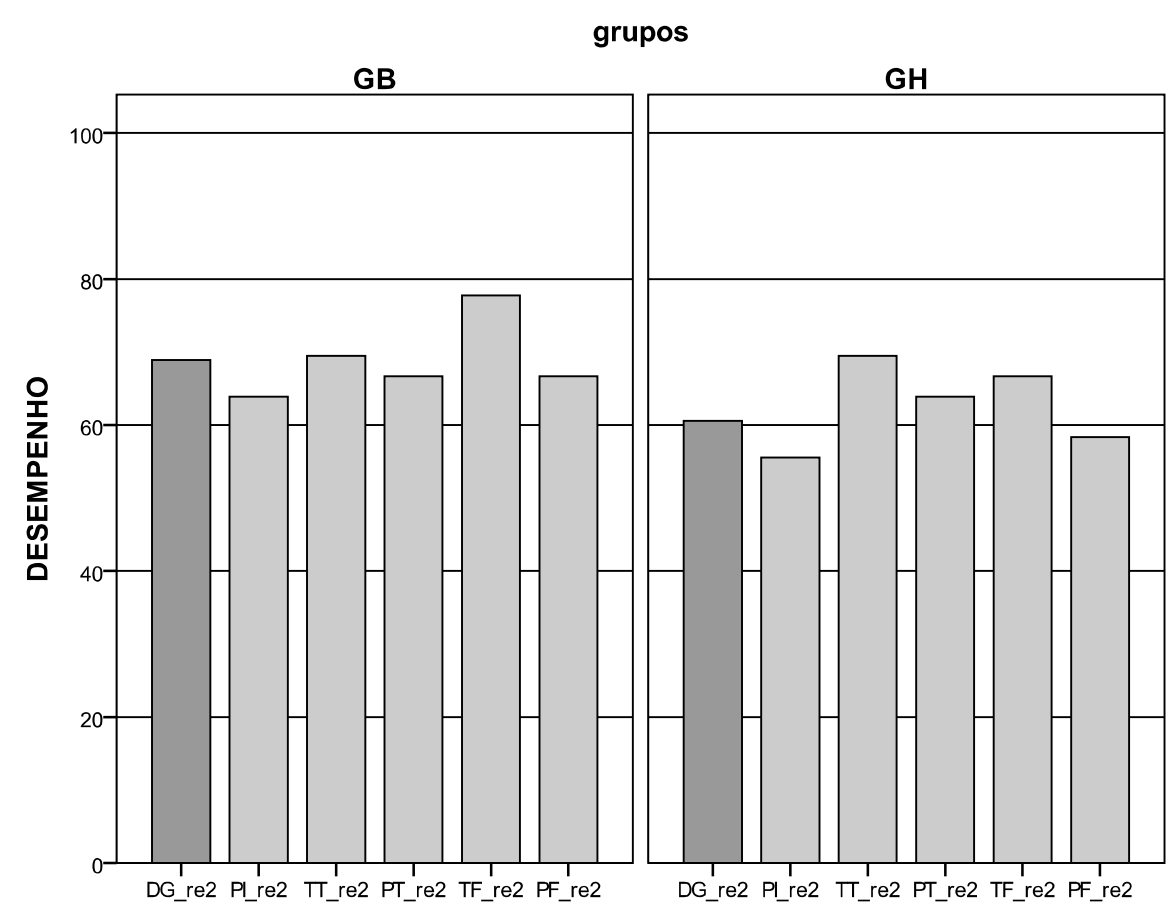

FIGURA 17 - Mediana do desempenho global e do desempenho por componente, de GB e GH, no bloco 2 do teste de retenção.

Na FIGURA 16, considerando a coluna correspondente ao DG, verifica-se que o desempenho na tina como um todo no RE1 parece semelhante para o GB em relação ao $\mathrm{GH}$. O teste $U$ de Mann-Whitney, não detectou diferença significativa entre GB e GH em RE1 ( $z=-, 076 ; p=, 940)$. Sendo assim, quanto ao DG não houve diferenças significativas entre GB e GH no bloco 1 do teste de retenção.

Considerando a coluna correspondente ao DG, na FIGURA 17 verifica-se que o desempenho na tina como um todo no RE2 parece superior para o GB em relação ao $\mathrm{GH}$. O teste $\mathrm{U}$ de Mann-Whitney, não detectou diferença significativa entre GB e GH em RE2 ( $z=-, 871 ; p=, 384)$. Sendo assim, quanto ao $D G$ não houve diferenças significativas entre GB e GH no bloco 2 do teste de retenção. 


\subsubsection{Desempenho por componente}

\section{Posição inicial}

$\mathrm{Na}$ FIGURA 16, na coluna correspondente à $\mathrm{PI}$ verifica-se que $\mathrm{O}$ desempenho da PI em RE1 é semelhante para GB e GH. Não foram encontradas diferenças significativas entre $G B$ e $G H$, em relação ao mesmo $(z=-, 430 ; p=, 667)$.

Verifica-se (FIGURA 17) na coluna PI que o desempenho parece superior para $\mathrm{GB}$ em relação ao $\mathrm{GH}$, no RE2. Não foram encontradas diferenças significativas entre GB e $\mathrm{GH}$, em relação ao mesmo $(z=-, 692 ; p=, 489)$.

\section{Transição para a tina}

Na coluna correspondente à TT, verifica-se que o desempenho em RE1 neste componente parece ser superior para GH em relação ao GB (FIGURA 16). No entanto, não foi detectada diferença significativa entre $\mathrm{GB}$ e $\mathrm{GH}$, no mesmo $(z=-, 346$; $\mathrm{p}=, 729$ ).

Na FIGURA 17, coluna correspondente à TT, verifica-se que 0 desempenho em RE2 neste componente parece semelhante para GB e GH (FIGURA 17). Confirmando, não foi detectada diferença significativa entre $G B$ e $G H$, no mesmo $(z=-, 307 ; p=, 759)$.

\section{Posição de tina}

$\mathrm{Na}$ coluna correspondente à PT, verifica-se na FIGURA 16 que o desempenho neste componente parece superior para $\mathrm{GH}$ em relação ao GB. Não foi detectada diferença significativa entre GB e GH, em RE1 ( $z=-, 116 ; p=, 908)$.

$\mathrm{Na}$ FIGURA 17, na coluna PT, verifica-se que o desempenho neste componente parece superior para GB em relação ao $\mathrm{GH}$. Não foi detectada diferença significativa entre GB e GH, em RE2 ( $z=-1,645 ; p=, 100)$. 


\section{Transição para a posição final}

Neste componente na coluna correspondente à TF, verifica-se (FIGURA 16) que o desempenho do GB parece inferior ao do $\mathrm{GH}$. Como para os demais, o teste $U$ de Mann-Whitney não revelou diferenças significativas entre GB e GH em $R E 1$, em relação a este componente ( $z=-, 267 ; p=, 789$ ).

Na coluna TF, verifica-se (FIGURA 17) que o desempenho do GB parece superior ao do $\mathrm{GH}$. No entanto, o teste $\mathrm{U}$ de Mann-Whitney não revelou diferenças significativas entre GB e GH, em relação a este componente em RE2 ( $z=-1,532$; $\mathrm{p}=, 125)$.

\section{Posição final}

$\mathrm{Na}$ FIGURA 16, na coluna correspondente à PF, verifica-se que 0 desempenho neste componente parece ter sido superior para o $\mathrm{GH}$ em relação ao GB. $O$ teste $U$ de Mann-Whitney não revelou diferenças significativas entre $G B$ e GH, em relação a este componente em RE1 ( $z=-1,008 ; p=, 313)$.

$\mathrm{Na}$ coluna correspondente à PF, na FIGURA 17, verifica-se que o desempenho neste componente parece ter sido superior para o GB em relação ao GH. O teste $U$ de Mann-Whitney não revelou diferenças significativas entre $G B$ e GH, em relação a este componente em RE2 ( $z=-, 619 ; p=, 536)$.

Em suma, os resultados mostraram que não houve diferenças significativas entre GB e GH, no bloco 1 e 2 do teste de retenção, nem para desempenho global, nem para desempenho por componente. 


\subsection{Discussão}

O objetivo do experimento 1 foi Investigar os efeitos do tipo de modelo boneca e humano na aprendizagem da tina do nado sincronizado. A tarefa consistiu na execução da tina, figura muito utilizada na iniciação do nado sincronizado e que compreende uma sequência composta por três posições e dois movimentos de transição: (1) posição inicial, (2) transição para a tina, (3) posição de tina; (4) transição para a posição final, e (5) posição final.

Considerando o objetivo deste experimento, a discussão dos dados seguirá a mesma ordem de apresentação dos resultados a fim de responder 0 objetivo específico do experimento 1. Para fins de análise foram considerados os blocos referentes ao pré-teste, ao pós-teste, primeiro bloco da retenção e segundo bloco da retenção. O desempenho global (DG) foi considerado como a medida que expressa o desempenho na figura como um todo é, portanto, a medida principal. Por sua vez o desempenho por componente (DC), foi considerado a medida que expressa o desempenho em cada componente da figura é portanto, uma medida complementar.

Quanto à caracterização da amostra, de acordo com os resultados do préteste, os grupos não se apresentaram diferentes, tanto em DG como em DC. Assim, as diferenças obtidas no desempenho e na aprendizagem da tina do nado sincronizado não podem ser atribuídas à heterogeneidade da amostra.

Em relação ao DG, a análise intragrupos possibilitou verificar que o grupo para o qual foi apresentado modelo boneca (GB) associado à instrução verbal, aprendeu a tarefa tina do nado sincronizado, pois melhorou o desempenho global do pré-teste para o pós-teste e manteve esta melhora nos dois blocos do teste de retenção. $O$ mesmo foi verificado em relação aos resultados obtidos para o grupo com modelo humano $(\mathrm{GH})$ associado à instrução verbal. Este grupo apresentou melhora no desempenho global do pré-teste para o pós-teste e manutenção do desempenho alcançado no bloco pós-teste nos blocos 1 e 2 do teste de retenção. $A$ partir destes resultados pode-se inferir que GB e GH aprenderam a tina do nado sincronizado. 
Em relação à medida de desempenho por componente (DC), seguindo a mesma lógica anterior em relação à interpretação dos resultados relativos ao DG, pode-se inferir que o grupo com modelo boneca (GB) aprendeu todos os cinco componentes da tina do nado sincronizado. Especificamente, este grupo apresentou melhora do desempenho em todos os componentes, entre pré e pós-teste, e, do pósteste para o teste de retenção, manteve o desempenho em todos os componentes. Sendo assim, em relação ao GB, os resultados permitem afirmar que todos os componentes da tina do nado sincronizado foram adquiridos, ou seja, posição inicial $(\mathrm{PI})$, transição para a tina (TT), posição de tina (PT), transição para a posição final (TF), e posição final (PF). Nesse sentido, a aprendizagem da tina inferida a partir do $D G$, foi resultante da melhora nos seus cinco componentes.

Os resultados mostraram que na medida de DC, o grupo com modelo humano (GH) também apresentou melhora do desempenho em todos os componentes entre o pré e o pós-teste. Entretanto, embora tenha mantido o desempenho de PI, TT, PT, TF e PT no bloco 1 do teste de retenção (RE1), no bloco 2 do teste de retenção (RE2), no componente transição para a posição final (TF), houve piora no desempenho. Nesse sentido, os resultados permitem inferir que, em se tratando do $\mathrm{GH}$, a aprendizagem da tina (DG) ocorreu como resultante da melhora e manutenção desta em longo prazo em função de quatro de seus cinco componentes.

Em suma, referentes os resultados ao DC permitem inferir que o modelo boneca, associado à instrução verbal, foi eficaz em promover a aprendizagem de todos os componentes da tina. Por sua vez, que a apresentação do modelo humano, associado à instrução verbal, no entanto, não foi eficaz no que diz respeito à manutenção em longo prazo (1 dia) do desempenho do componente TF. Sendo assim, no caso do componente TF, mediante o modelo humano, a manutenção do desempenho parece ser temporária. Uma possível explicação para este resultado seria a relação entre a característica do componente e a quantidade de informação disponibilizada pelo modelo humano.

O movimento de transição é aquele que permite a mudança de uma posição relativamente estabilizada para outra, com características diferentes da anterior. No caso da TF, parte-se da posição de tina, que é bastante estável por 
estarem todos os segmentos corporais próximos ao centro de gravidade, para a posição final, que é estendida, e assim, menos estável. São necessários novos ajustes para manter toda a parte anterior do corpo na superfície e isto demanda uma grande quantidade de informação a ser retida.

Ainda, ao contrário do modelo boneca, a apresentação do modelo humano disponibiliza mais informações ao aprendiz do que o modelo boneca. A partir de sua apresentação o aprendiz pode observar as ações de rotação e circundução das articulações do pescoço, das mãos e dos pés sendo executadas no contexto real, ou seja, na água. Por isso, a informação do nível da água durante a execução também é disponibilizada com a utilização do modelo humano. Sendo a TF o penúltimo componente da figura, e sendo que para execução dos componentes anteriores também foi necessária a retenção de informações, o modelo humano pode ter disponibilizado uma quantidade de informação excessiva para este momento da tarefa e que pareceu ser impossível de ser retida em longo prazo.

Por sua vez, em relação à análise considerada central para o problema deste estudo, ou seja, a comparação intergrupos na fase de retenção, blocos RE1 e RE2, nas medidas DG e DC, não foram detectadas diferenças entre GB e GH na aprendizagem da tina do nado sincronizado. Estes resultados permitem inferir que, na aquisição compreendendo 60 tentativas, usando modelo habilidoso associado à instrução verbal e fornecendo a demonstração com frequência relativa de 100\%, não houve efeito do tipo de modelo, boneca ou humano, na aprendizagem da tina do nado sincronizado.

A tarefa deste estudo se caracteriza por ser uma habilidade complexa, composta por 5 componentes claramente definidos, em interação, sendo executados numa sequência definida e no meio liquido. Levando em conta esta característica da tarefa, para a seleção do método de pesquisa empregado neste experimento, consideraram-se os resultados de pesquisa dos estudos sobre informação prévia. Mais especificamente, foram consideradas as seguintes indicações da literatura consultada: (a) a demonstração associada à instrução verbal é a condição que mais favorece tanto o desempenho como a aprendizagem de habilidades motoras (WEISS,1983; CARROLL e BANDURA, 1990; DARIDO, 1991; PÚBLIO, TANI \& MANOEL, 1995; KAMPIOTIS e THEODORAKU, 2006), (b) a observação de modelos 
habilidosos conduz a uma aprendizagem melhor do que a observação de modelos iniciantes ou sem status (LANDERS \& LANDERS,1973; LIRGG \& FELTZ), e (c) quanto maior for a frequência relativa de apresentação, tanto mais se favorece a aprendizagem (SIDAWAY \& HAND, 1993).

Com isso, tanto o modelo boneca como o humano, associados a todos os cuidados metodológicos mencionados acima, talvez tenham se constituído de uma informação prévia igualmente eficiente. Essa é uma possível explicação para o fato de o tipo de modelo não ter representado um fator interferente para a aprendizagem da tina.

Um outro aspecto que pode ser considerado, é o fato de que o aprendiz, diante de uma modelo humano, embora este disponibilize mais informações, exatamente pelas suas características de iniciante, pode não ser capaz de assimilar todas as informações apresentadas (GUADAGNOLI \&LEE, 2004). Este fato igualaria ambos os modelos, já que o modelo boneca apresenta as informações consideradas essenciais à execução da tarefa, ou seja, da tina do nado sincronizado.

\section{EXPERIMENTO 2}

\subsection{Objetivo}

Investigar os efeitos da ordem de apresentação dos modelos, boneca e humano, na aprendizagem da tina do Nado Sincronizado.

\section{$6.2 \quad$ Método}

\subsubsection{Amostra}

Esta foi constituída por 20 voluntárias do gênero feminino, com média de idade igual 21,6 anos ( $\mathrm{DP}=2,8)$. Todas estavam adaptadas ao meio aquático, apresentando deslocamento independente na parte rasa da piscina e flutuação com auxílio das mãos. Nenhuma das participantes havia, até o período da coleta, tido experiência com qualquer das habilidades do nado sincronizado. 


\subsubsection{Tarefa}

Como no experimento 1 a coleta foi realizada em piscina coberta e aquecida de 25 metros de comprimento por 12,5 de largura, com profundidade de 1 metro e $30 \mathrm{~cm}$ em toda a área. A tarefa foi a mesma, ou seja, executar a tina do nado sincronizado (FIGURA 1).

\subsubsection{Delineamento}

As voluntárias $(n=20)$ foram distribuídas em dois grupos de 10 participantes cada, o grupo modelo boneca seguido de modelo humano (GBH) e o grupo modelo humano seguido de modelo boneca (GHB). Conforme apresentado no QUADRO 4, da mesma forma que no experimento 1 , o delineamento experimental consistiu de duas fases e dois testes (pré e pós-testes). A fase de aquisição envolveu a prática na tarefa e a fase de retenção, na qual houve testagem relativa à manutenção do desempenho alcançado na fase de aquisição.

$\mathrm{Na}$ fase de aquisição todos executaram 60 tentativas divididas em blocos de 6 tentativas cada. Das tentativas 1 a 30 (blocos AQ1 até AQ5), às participantes foi apresentado um dos modelos, boneca ou humano, e das tentativas 31 a 60 (blocos AQ6 até AQ10) o outro modelo de acordo com seu grupo. Ao GBH o primeiro modelo apresentado foi o boneca, seguido do modelo humano, para o GHB, esta ordem foi invertida, ou seja, na primeira metade da aquisição foi apresentado o modelo humano e na segunda, o modelo boneca. Nesta fase foi fornecida uma demonstração associada à instrução verbal a cada tentativa.

Da mesma forma que no experimento 1 , para garantir a homogeneidade da amostra e assim evitar viés na análise dos resultados, precedendo a fase de aquisição foi aplicado um pré-teste. Ao término da fase de aquisição, para verificar possíveis mudanças no desempenho em função da fase de aquisição, foi aplicado o pós-teste. Os testes foram constituídos de 6 tentativas cada, sendo que a informação prévia sobre a execução correta da tarefa (tina do nado sincronizado) foi fornecida através de instrução verbal, uma única vez antes das 6 tentativas. 
Intervalos e teste de retenção foram os mesmo descritos no experimento 1.

QUADRO 2 - Delineamento do experimento 2.

\begin{tabular}{|l|c|c|c|c|c|}
\hline testes e fases & Pré-teste & \multicolumn{2}{|c|}{ Aquisição } & $\begin{array}{c}\text { Pós-teste } \\
\text { (10 min após) }\end{array}$ & $\begin{array}{c}\text { Retenção } \\
\text { (dia seguinte) }\end{array}$ \\
\hline blocos & PRE & AQ 1 a AQ 5 & AQ 6 a AQ 10 & POS & RE1 e RE2 \\
\hline$n^{\circ}$ de tentativas & 6 & 30 & 30 & 6 & $6+6$ \\
\hline Instrução- GBH & Verbal & Boneca & Humano & Verbal & Sem \\
\hline Instrução- GHB & Verbal & Humano & Boneca & Verbal & Sem \\
\hline
\end{tabular}

\subsubsection{Instrumentos e procedimentos}

Para efetuar registro e análise dos dados bem como para a projeção da informação prévia, foram utilizados, respectivamente, filmadora, gravador, reprodutor de DVD, Lista de checagem da tina e três Vídeos e notebook, já especificados no experimento 1 .

\subsubsection{Procedimentos}

Os procedimentos foram os mesmos descritos no experimento1.

\subsubsection{Variáveis dependentes}

Assim como no experimento 1, as medidas analisadas foram obtidas via análise da filmagem da execução da figura. Referem-se à qualidade de execução tendo como referência 15 itens da lista de checagem e, portanto, são de natureza qualitativa, tendo sido compostas considerando o desempenho na figura como um todo e especifico para cada componente da figura. Sendo assim, foram utilizadas as 
medidas de desempenho global (DG) e de desempenho por componente (DC), descritas no item 5.2.6.

\subsubsection{Análise dos dados}

Para o tratamento matemático e análise estatística dos dados, utilizaramse os programas: Excel 2003 e SPSS Statistics 17.0. Toda a análise foi baseada nas seguintes fontes: THOMAS e NELSON, (2002), CALLEGARI-JACQUES, (2004) e SIEGEL e CASTELLAN JR (2006).

Foram conduzidas análises intra e inter grupos para as variáveis relativas ao DG e DC. Assim, a análise intragrupo foi realizada a fim de comparar as medidas $D G$ (\% EG); e DC (\% EC) entre o PRE, POS, RE1 e RE2. Devido à natureza dos dados e sendo que os pressupostos para esta análise foram violados, utilizaram-se técnicas não-paramétricas, sendo o teste de Friedman usado na análise intragrupo para comparar os escores entre o PRE, POS, RE1 e RE2. Foi considerada diferença significativa para $p \leq 0,05$. Ao serem detectadas diferenças significativas, foi realizado o Teste de Wilcoxon. Para a análise intergrupos foi aplicado o teste $U$ Mann-Whitney, para comparar os dados de GBH e GHB nas medidas DG (\%EG) e DC (\%EC), no PRE para testar a homogeneidade e em RE1 e RE2 para inferir a aprendizagem. Foi considerada diferença significativa para $p \leq 0,05$.

\subsection{RESULTADOS}

\subsubsection{Pré-teste}

A FIGURA 18 mostra o DG e o DC referentes ao pré-teste. Foi realizada a comparação intergrupos para testar a homogeneidade da amostra constituída por 20 participantes, divididas em GBH $(\mathrm{N}=10)$ e $\mathrm{GHB}(\mathrm{N}=10)$. 


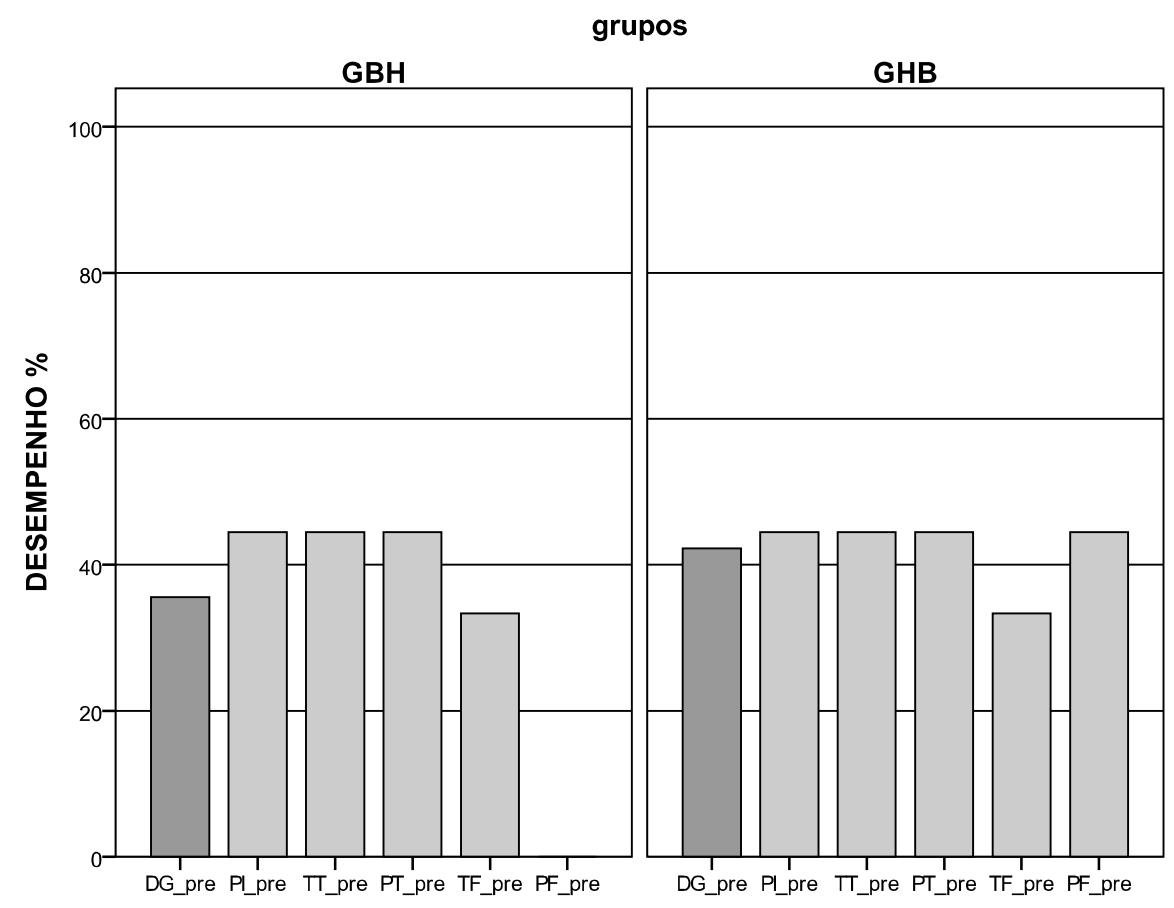

FIGURA 18 - Mediana do desempenho global e do desempenho por componente, dos componentes posição inicial ( $\mathrm{Pl}$ ), transição para a tina (TT), posição de tina (PT), transição para a posição final (TF) e posição final (PT) no pré-teste, em bloco de 6 tentativas, referente ao GBH e GHB.

\subsubsection{Desempenho global}

Na FIGURA 18, considerando a coluna correspondente ao PRÉ, verifica-se que o desempenho na tina como um todo no pré-teste parece inferior para o GB em relação ao $\mathrm{GH}$. No entanto, o teste $U$ de Mann-Whitney, não detectou foi diferença significativa entre GBH e GHB ( $z=-, 909 ; \mathrm{p}=, 363)$. Sendo assim, quanto ao DG as amostras foram consideradas homogêneas. 


\subsubsection{Desempenho por componente}

Posição inicial: na FIGURA 18, na coluna correspondente (PI), verifica-se que 0 desempenho neste componente parece ter sido semelhante para $\circ \mathrm{GBH}$ e GHB. Não foram encontradas diferenças significativas entre GBH e GHB, em relação ao mesmo $(z=-, 086 ; p=, 932)$.

Transição para a tina: na coluna correspondente (TT), verifica-se que o desempenho neste componente foi semelhante para o GB e $\circ \mathrm{GH}$ (FIGURA 18). Comprovando esta tendência, não foi detectada diferença significativa entre $\mathrm{GBH}$ e GHB, no mesmo $(z=-, 279 ; p=, 780)$.

Posição de tina: na coluna correspondente (PT), verifica-se na FIGURA 18 que o desempenho neste componente foi semelhante para $\circ \mathrm{GB}$ e $\circ \mathrm{GH}$. Comprovando esta tendência, não foi detectada diferença significativa entre GBH e GHB, no mesmo $(z=-, 039 ; p=, 969)$.

Transição para a posição final: neste componente na coluna correspondente (TF), verifica-se (FIGURA 18) que o desempenho do GBH parece semelhante ao do GHB. Como para os demais, o teste $U$ de Mann-Whitney não revelou diferenças significativas entre GBH e GHB, em relação a este componente ( $z=-, 079 ; p=, 937)$.

Posição final: na FIGURA 18, na coluna correspondente (PF), verifica-se somente o desempenho de GHB. $O$ teste $U$ de Mann-Whitney não revelou diferenças significativas entre GBH e GHB, em relação a este componente $(z=-1,799 ; p=, 072)$.

Em suma, em conjunto, os resultados referentes ao pré-teste mostram que as amostras GBH e GHB são homogêneas. 


\subsubsection{Aquisição}

Fase composta do pré-teste, pós-teste e retenção.

\subsubsection{Desempenho global}

A FIGURA 19 apresenta o DG obtido pelo grupo GBH e GHB, no pré-teste (PRE) no pós-teste (POS) e nos blocos de retenção (RE1 e RE2).

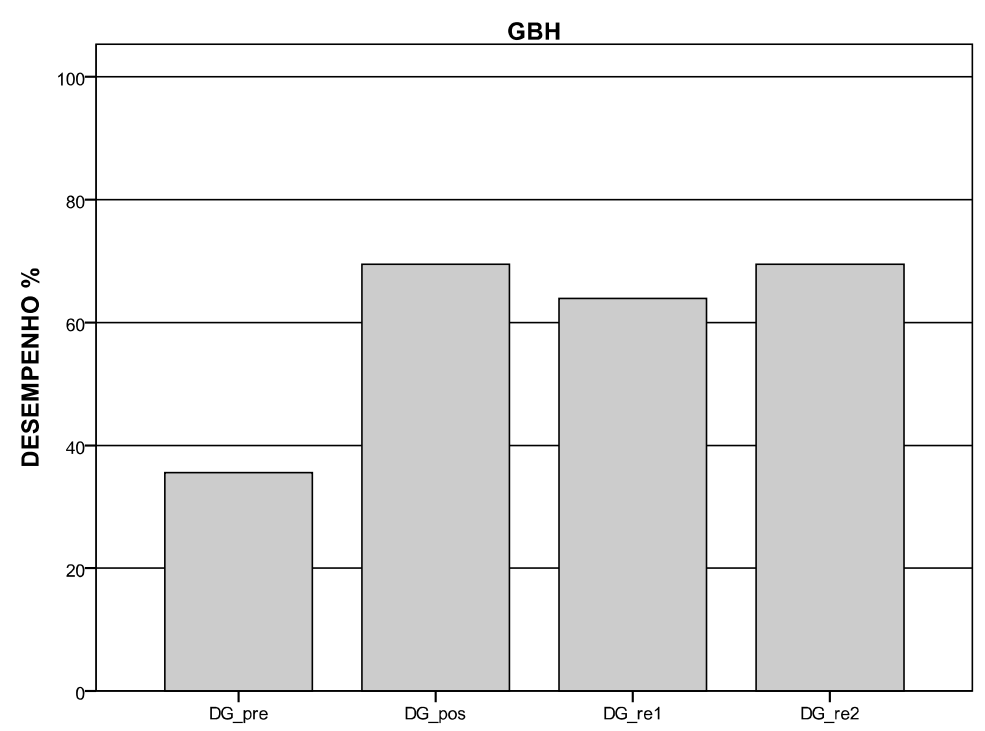

FIGURA 19 - Mediana do desempenho global do GBH nos testes (PRE, POS) e na fase de retenção (RE1 e RE2), em blocos de 6 tentativas.

Em relação ao $\mathrm{GBH}$, pode-se verificar (FIGURA 19) que o DG no bloco PRE, é menor que o do bloco POS, apontando para uma tendência de melhora do desempenho em função das tentativas de aquisição. Observa-se ainda, que o desempenho observado em POS diminui em RE1, havendo um aumento de RE1 para RE2.

O teste de Friedman detectou diferença significativa na comparação dos quatro blocos $\left(x^{2}=24,367 ; p=, 000\right)$. O teste de Wilcoxon localizou diferenças 
significativas entre PRÉ-POS ( $z=-2,803 ; p=, 005)$, POS-RE1 $(z=-2,449 ; p=, 014)$ e entre RE1-RE2 $(z=-2,552 ; p=, 011)$.

A FIGURA 20 apresenta o DG obtido pelo grupo GHB, no pré-teste (PRE) no pós-teste (POS) e nos blocos de retenção (RE1 e RE2).

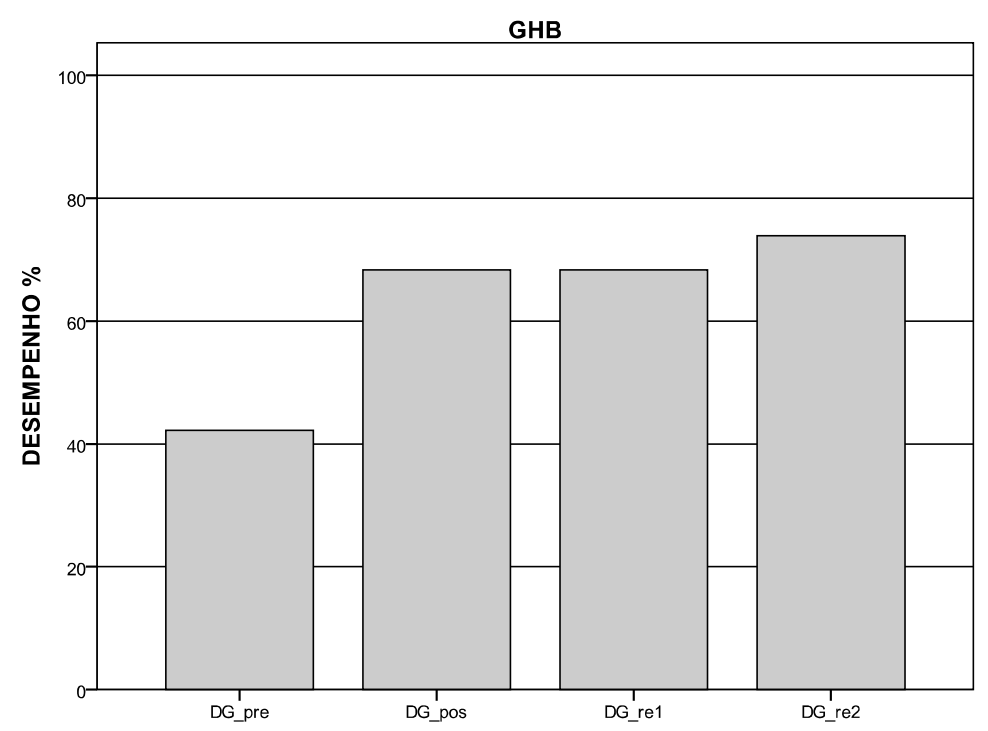

FIGURA 20 - Mediana do desempenho global do GHB nos testes (PRE, POS) e na fase de retenção (RE1 e RE2), em blocos de 6 tentativas.

Em relação ao GHB, pode-se observar na FIGURA 20 que o DG no bloco PRÉ, é menor que o do bloco POS, apontando, portanto também para este grupo uma tendência de melhora do desempenho em função das tentativas de aquisição. Observa-se ainda, o que parece ser um desempenho semelhante de POS e RE1, aumentou em RE2.

Para GHB o teste de Friedman detectou diferença significativa na comparação entre os quatro blocos $\left(x^{2}=21,031 ; p=, 000\right)$ e o teste de Wilcoxon localizou diferenças significativas somente entre PRE e POS $(z=-2,805 ; p=, 005)$. 
Portanto não houve diferença significativa entre POS-RE1 ( $z=-1,249 ; p=, 212)$, entre POS-RE2 ( $z=-, 538 ; p=, 591)$, e entre RE1 e RE2 $(z=-1,268 ; p=, 205)$.

Estes resultados permitem inferir que o $\mathrm{GBH}$ e GHB, melhoraram seu desempenho global após as tentativas de aquisição e foram capazes de mantê-lo após um dia de intervalo. Embora GBH tenha piorado o desempenho em RE1, foi capaz de manter este desempenho em RE2.

\subsubsection{Desempenho por componente}

\section{Posição inicial}

A FIGURA 21 apresenta o desempenho obtido pelo grupo $\mathrm{GBH}$, no préteste (PRÉ), no pós-teste (POS), e na retenção (RE1 e RE2), referentes ao componente posição inicial (PI).

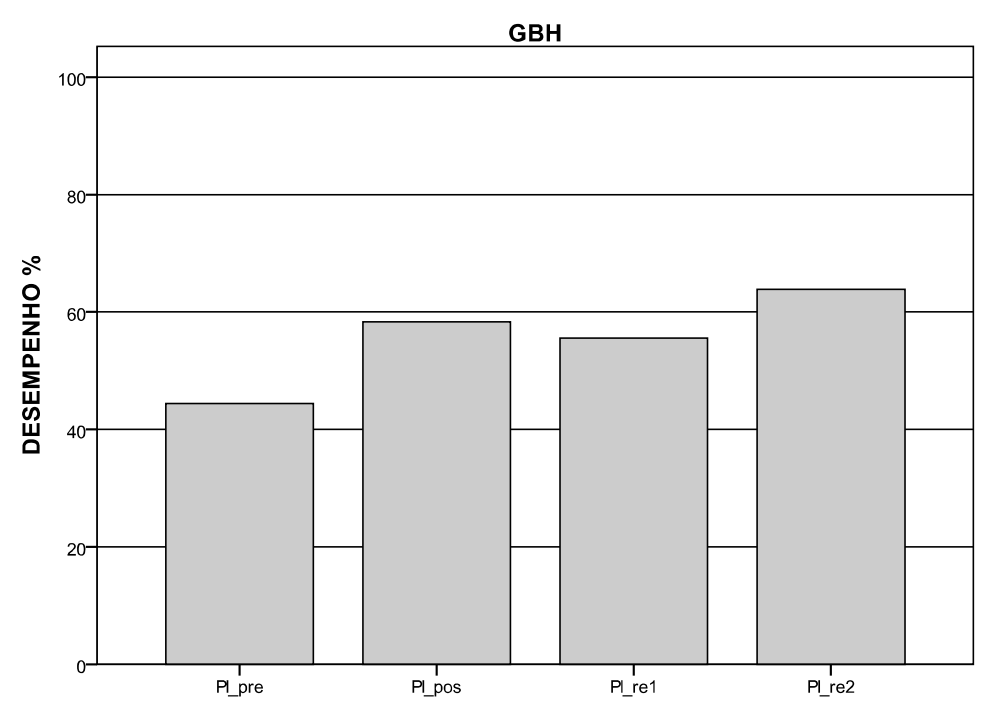

FIGURA 21 - Mediana do desempenho no componente posição inicial (PI) do GBH nos blocos de 6 tentativas correspondentes ao pré-teste (PRE) ao pós-teste (POS) e à retenção (RE1 e RE2). 
Em relação ao GBH, pode-se observar (FIGURA 21) que o desempenho no bloco PRE, é menor que o do bloco POS, indicando tendência de melhora neste componente em função das tentativas de aquisição. Verifica-se também uma tendência de declínio deste valor atingido no bloco RE1, seguido de um aumento no bloco RE2.

A análise estatística indicou diferença significativa na comparação dos quatro blocos $\left(x^{2}=15,731 ; p=, 001\right)$. O teste de Wilcoxon, localizou as diferenças entre PRE-POS $(z=-2,714 ; p=, 007)$. Não houve diferença significativa entre POS-RE1 $(Z=-1,579 ; p=, 114)$ e POS-RE2 ( $z=-, 216 ; p=, 829)$, portanto a diminuição do DC entre POS-RE1 e POS-RE2 não pode ser considerada significativa. Também não foi encontrada diferença significativa para $o$ aumento da mediana entre RE1-RE2 ( $z=-$ $1,890 ; p=, 059)$.

A FIGURA 22 apresenta o desempenho obtido pelo grupo GHB, no préteste (PRE), no pós-teste (POS), e na retenção (RE1 e RE2), referentes ao componente posição inicial (PI).

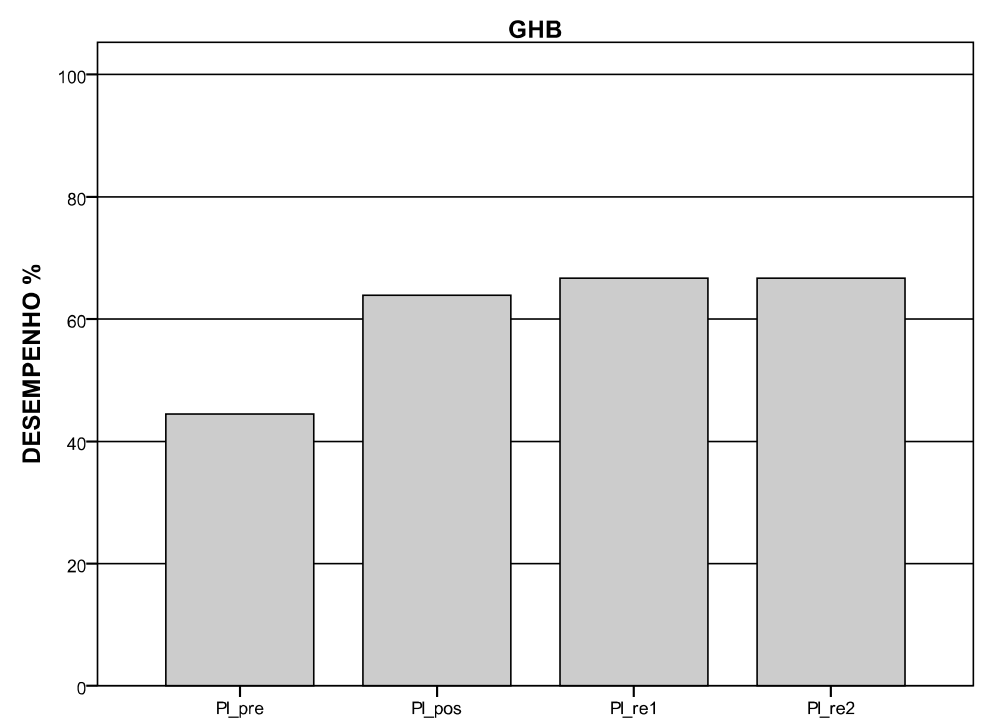

FIGURA 22 - Mediana do desempenho no componente posição inicial (PI) do GHB nos blocos de 6 tentativas correspondentes ao pré-teste (PRE) ao pós-teste (POS) e à retenção (RE1 e RE2). 
Em relação ao desempenho no componente $\mathrm{PI}$ do GHB, observando a FIGURA 22 parece ter havido melhora do bloco PRE para o POS e manutenção em RE1 e em RE2. Portanto, em relação ao PRE os desempenhos nos blocos POS, RE1 e RE2 parecem superiores.

A análise inferencial detectou diferença significativa entre os blocos para este componente $\left(x^{2}=11,609 ; p=, 009\right)$. A aplicação do teste de Wilcoxon localizou as diferenças entre PRE-POS $(z=-2,558 ; p=, 011)$ somente. Portanto, a aparente manutenção do desempenho entre POS-RE1 foi confirmada $(z=-, 552 ; p=, 581)$, assim como em POS-RE2 ( $z=-, 322 ; p=, 748)$.

A partir destes resultados pode-se inferir que o GBH e o GHB aprenderam a posição inicial da tina.

\section{Transição para tina}

A FIGURA 23 apresenta o desempenho obtido pelo grupo $\mathrm{GBH}$, no préteste (PRE) no pós-teste (POS) e na retenção (RE1 e RE2), referentes ao componente transição para a tina (TT). 


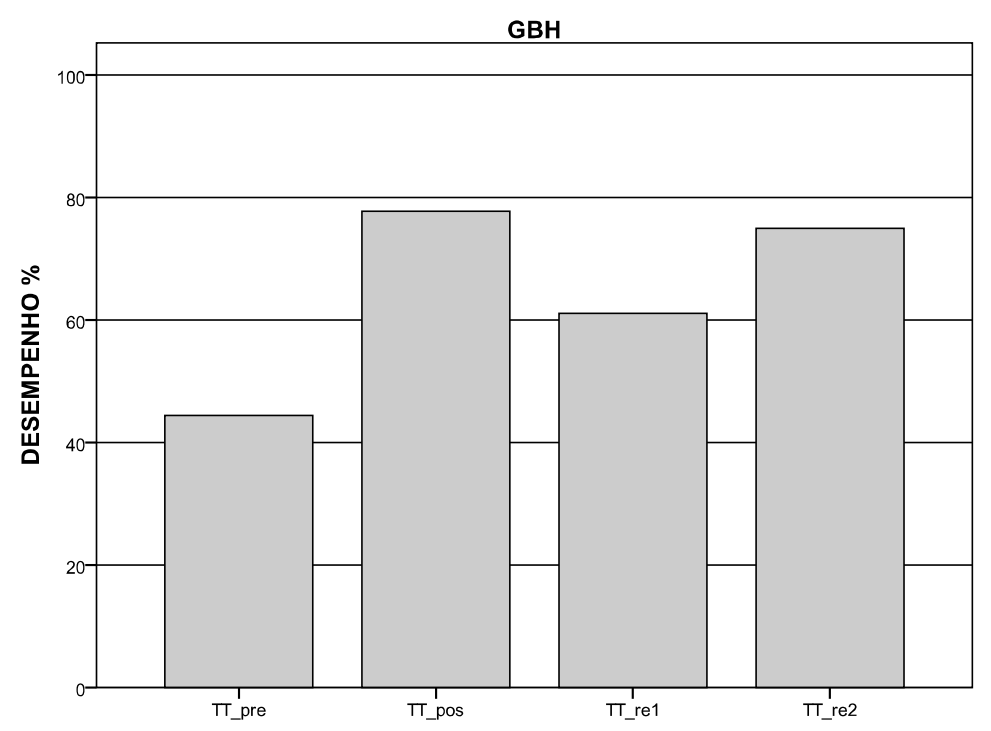

FIGURA 23 - Mediana do desempenho no componente transição para a tina (TT) do GBH nos blocos de 6 tentativas correspondentes ao pré-teste (PRE) ao pós-teste (POS) e à retenção (RE1 e RE2).

No componente transição para a tina, o $\mathrm{GBH}$ parece ter melhorado 0 desempenho do bloco PRE para o POS, e diminuído o desempenho do POS para o RE1 e aumentando deste para o RE2 (FIGURA 23).

O teste de Friedman detectou diferença significativa na comparação dos quatro blocos $\left(x^{2}=17,315 ; p=, 001\right)$. Foram localizadas diferenças entre PRE-POS ( $z=-$ $2,536 ; \quad p=, 011)$, entre POS-RE1 $(z=-2,307 ; p=, 021)$ e entre RE1-RE2 ( $z=-$ $2,388 ; p=, 017)$. Portanto a melhora entre PRE e POS foi confirmada, assim como a piora entre POS-RE1 e a melhora entre RE1-RE2.

Para o GBH há uma piora no desempenho do componente TT em RE1, que é recuperado em RE2.

A FIGURA 24 apresenta o desempenho obtido pelo grupo GHB, no préteste (PRE) no pós-teste (POS) e na retenção (RE1 e RE2), referentes ao componente transição para a tina (TT). 


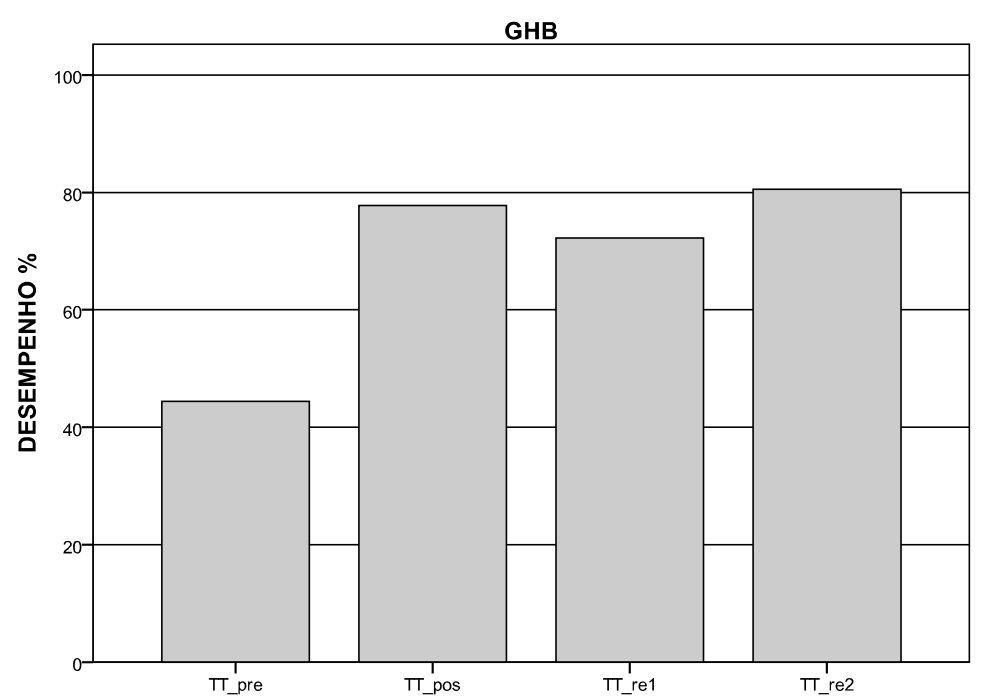

FIGURA 24 - Mediana do desempenho no componente transição para a tina (TT) do GHB nos blocos de 6 tentativas correspondentes ao pré-teste (PRE) ao pós-teste (POS) e à retenção (RE1 e RE2).

O GHB, no componente transição para a tina, parece ter melhorado o desempenho do bloco PRE para o POS, e diminuído o desempenho do POS para o RE1 e aumentando deste para o RE2 (FIGURA 24).

A análise inferencial detectou diferença significativa na comparação dos quatro blocos $\left(x^{2}=13,534 ; p=, 004\right)$ e o teste de Wilcoxon, localizou diferenças entre PRE-POS ( $z=-2,703 ; p=, 007)$ somente. Foi confirmada manutenção entre POS-RE1 $(z=-1,098 ; p=, 272)$ e entre POS-RE2 $(z=-, 122 ; p=, 903)$.

A partir destes resultados pode-se inferir que o $\mathrm{GBH}$ e $\circ \mathrm{GHB}$, aprenderam o componente transição para a tina (TT). 
A FIGURA 25 apresenta o desempenho obtido pelo grupo $\mathrm{GBH}$, no préteste (PRE) no pós-teste (POS) e na retenção (RE1 e RE2), referentes ao componente posição de tina (PT).

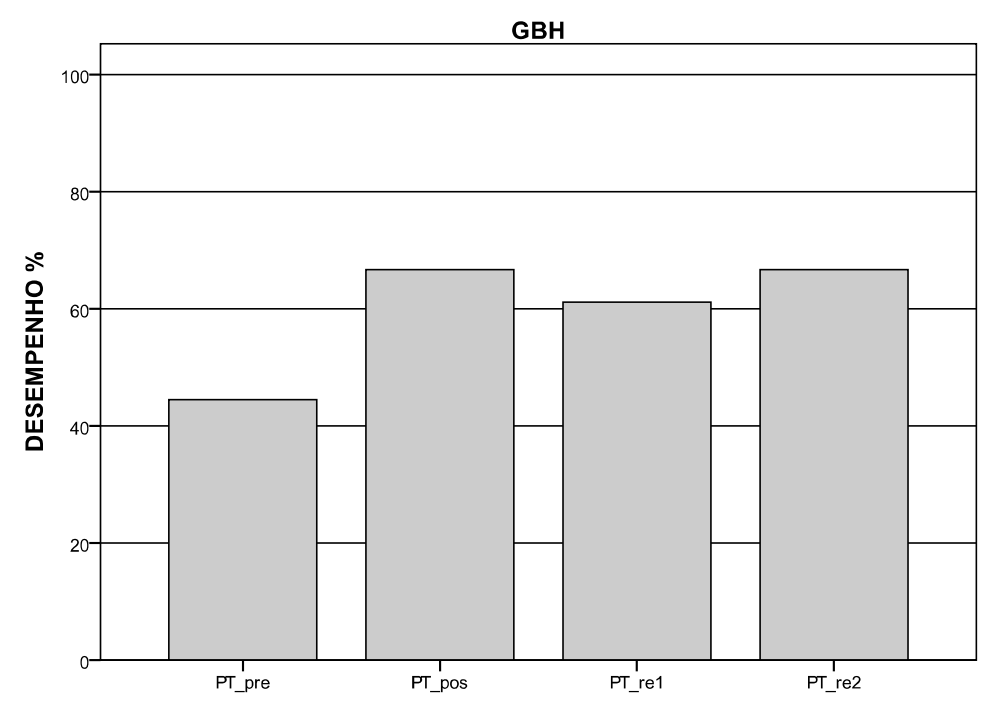

FIGURA 25 - Mediana do desempenho do componente PT do GBH ao longo das fases (PRE, POS, RE1 e RE2).

Em relação ao $\mathrm{GBH}$ observa-se que o desempenho parece ter melhorado do PRE para o POS (FIGURA 25), piorado entre este último bloco no RE1 e apresentando tendência de melhora novamente do RE1 para o RE2.

A análise inferencial detectou diferença significativa na comparação dos quatro blocos $\left(x^{2}=16,551 ; p=, 001\right)$. O teste de Wilcoxon localizou diferenças entre PRE-POS $(z=-2,667 ; p=, 007)$ somente, não localizando entre POS-RE1 $(z=-$ $1,510 ; p=, 131)$ e RE1-RE2 $(z=1,890 ; p=, 059)$ portanto a tendência de piora entre POSRE1 não foi confirmada.

A FIGURA 26 apresenta o desempenho, referente ao componente posição de tina (PT), obtido pelo grupo GHB, no pré-teste (PRE) no pós-teste (POS) e na retenção (RE1 e RE2). 


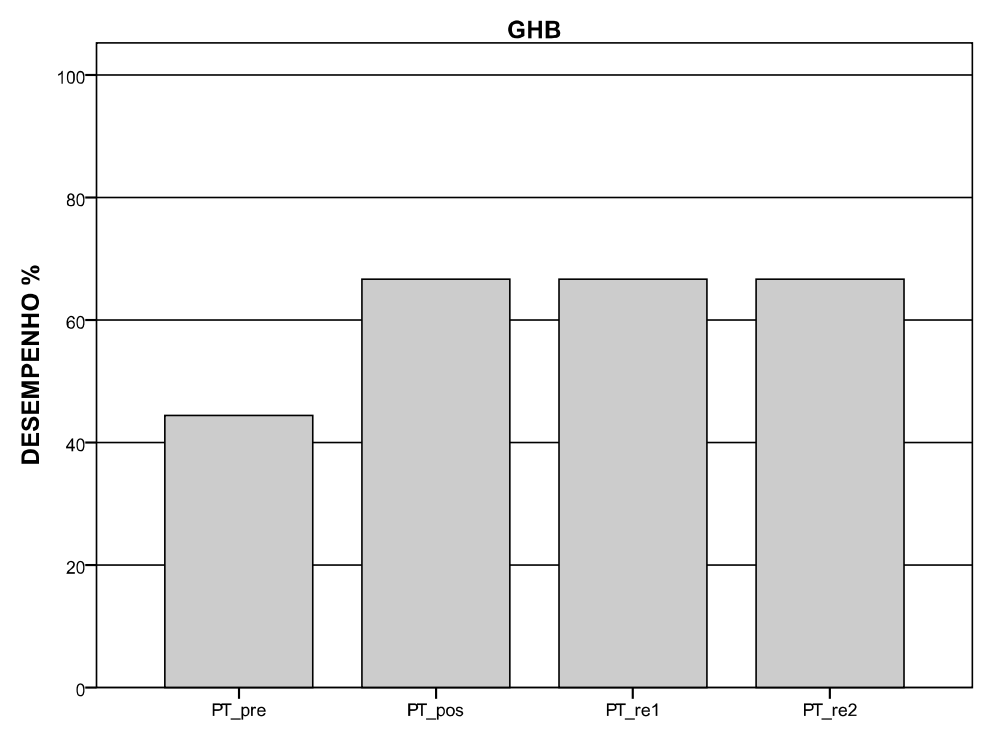

FIGURA 26 - Mediana do desempenho co componente PT do GHB ao longo das fases (PRE, POS, RE1 e RE2).

No componente posição de tina, o GHB parece ter melhorado o desempenho do bloco PRE para o POS, mantido o desempenho do POS para o RE1 e deste para o RE2 (FIGURA 26).

A análise inferencial detectou diferença significativa na comparação dos quatro blocos $\left(x^{2}=21,318 ; p=, 000\right)$ sendo que foi localizada, foi aplicado o teste de Wilcoxon que localizou as diferenças entre PRE-POS $(z=-2,814 ; p=, 005)$ e POS-RE1 $(z=-2,047 ; p=, 041)$. Portanto, houve uma perda em RE1 que foi recuperada em RE2.

Os resultados permitem inferir que o $\mathrm{GBH}$ e $\mathrm{O} \mathrm{GHB}$, aprenderam 0 componente posição de tina.

\section{Transição para a posição final}

A FIGURA 27 apresenta o desempenho obtido pelo grupo $\mathrm{GBH}$, no préteste (PRE) no pós-teste (POS) e na retenção (RE1 e RE2), referentes ao componente transição para a posição final (TF). 


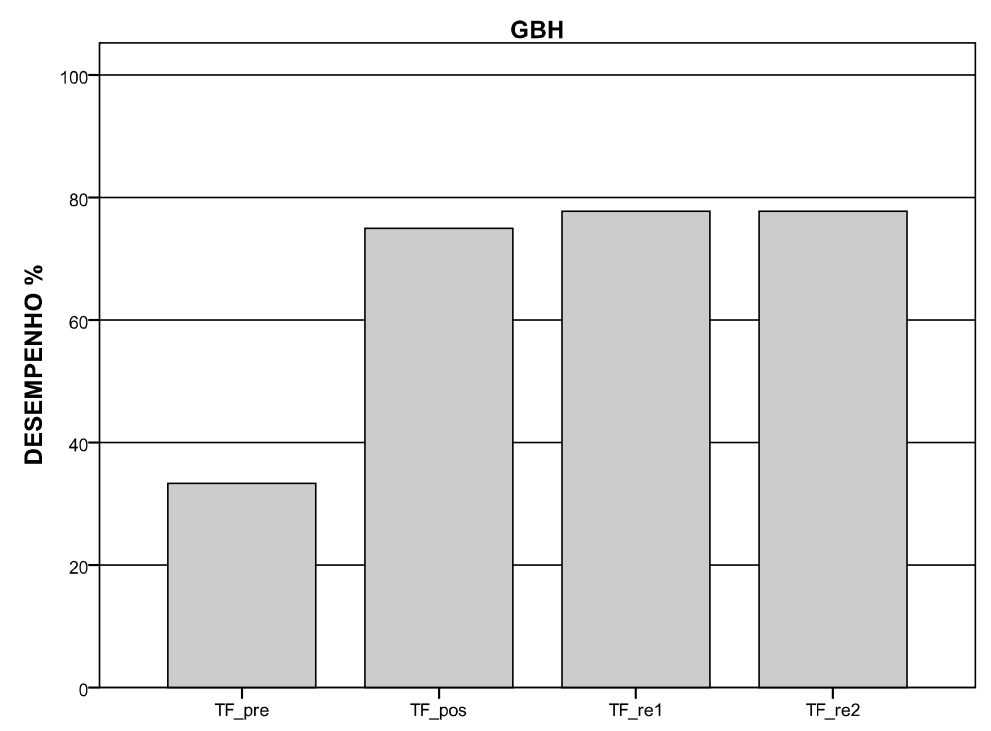

FIGURA 27 - Mediana do desempenho no componente TF do GBH ao longo das fases (PRE, POS, RE1 e RE2).

Em relação ao GBH observa-se que o desempenho pareceu melhorar do PRE para o POS e também do POS para o RE1, mantendo-se para o RE2 (FIGURA 27).

A análise inferencial detectou diferença significativa na comparação dos quatro grupos $\left(x^{2}=12,033 ; p=, 007\right)$. Foi localizada diferença entre PRE-POS ( $z=-$ 2,609; $p=, 009)$ somente. Portanto, as tendências de melhora entre PRÉ-PÓS e manutenção do desempenho em RE1 $(z=-, 071 ; p=, 944)$ e RE2 ( $z=-, 142 ; p=, 887)$ foram confirmadas.

A FIGURA 28 apresenta o desempenho obtido pelos grupos GHB, no préteste (PRE) no pós-teste (POS) e na retenção (RE1 e RE2), referentes ao componente transição para a posição final (TF). 


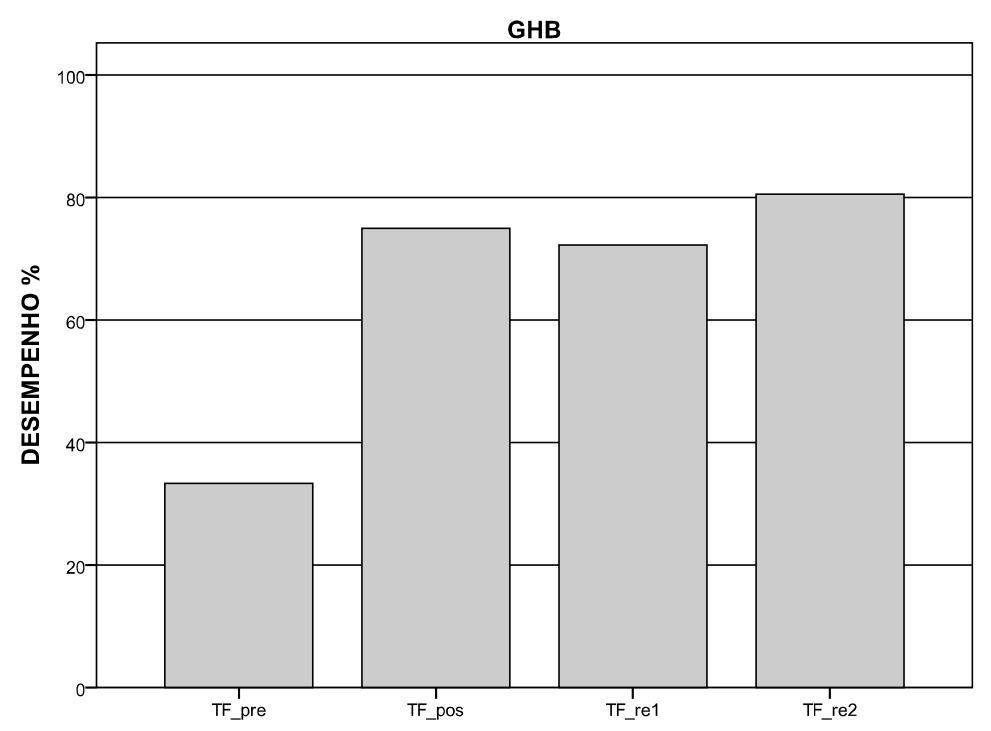

FIGURA 28 - Mediana do desempenho no componente TF do GHB ao longo das fases (PRE, POS, RE1 e RE2).

No componente transição para a posição final, o desempenho de GHB parece ter melhorado do bloco PRE para o POS, porém, diminuído do POS para o RE1 e melhorado deste para o RE2 (FIGURA 28).

A análise estatística inferencial detectou diferença significativa na comparação dos quatro blocos $\left(x^{2}=19,069 ; p=, 000\right)$. O teste de Wilcoxon localizou as diferenças entre PRE-POS $(z=-2,807 ; p=, 005)$ somente, portanto, a tendência de melhora do desempenho em função das tentativas de aquisição foi confirmada. Além disso, não foi confirmada piora, mas a manutenção entre POS-RE1 ( $z=-$ $1,403 ; p=, 161)$ e o mesmo entre RE1-RE2 $(z=-1,382 ; p=, 167)$.

Os resultados permitem inferir que para $\circ \mathrm{GBH}$ e para o GHB houve aprendizagem do componente transição para a posição final.

\section{Posição final}


A FIGURA 29 apresenta o desempenho obtido pelo grupo $\mathrm{GBH}$, no préteste (PRE) no pós-teste (POS) e na retenção (RE1 e RE2), referentes ao componente posição final (PF).

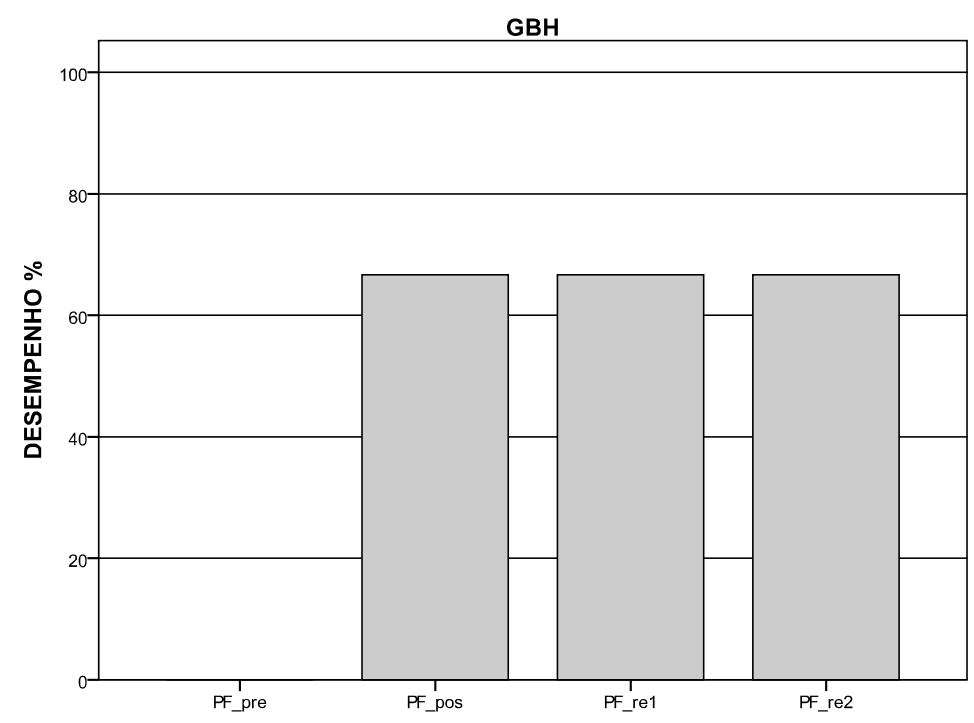

FIGURA 29 - Mediana do desempenho no componente da PF do GBH ao longo das fases (PRE, POS, RE1 e RE2).

Em relação ao $\mathrm{GBH}$ observa-se que o desempenho parece ter melhorado do PRE para o POS (FIGURA 29), sendo mantido entre POS-RE1 e PÓS-RE2. A análise inferencial detectou diferença significativa na comparação dos quatro blocos $\left(x^{2}=21,345 ; p=, 000\right)$. Foi localizada diferença somente entre PRE-POS $(z=-2,821$; $p=, 005$ ). Portanto, a tendência de manutenção entre POS-RE1 foi confirmada ( $z=-$ $, 782 ; p=, 434)$ e entre POS-RE2 ( $z=-, 597 ; p=, 551)$.

A FIGURA 30 apresenta o desempenho obtido pelos grupos GHB, no préteste (PRE) no pós-teste (POS) e na retenção (RE1 e RE2), referentes ao componente posição final (PF). 


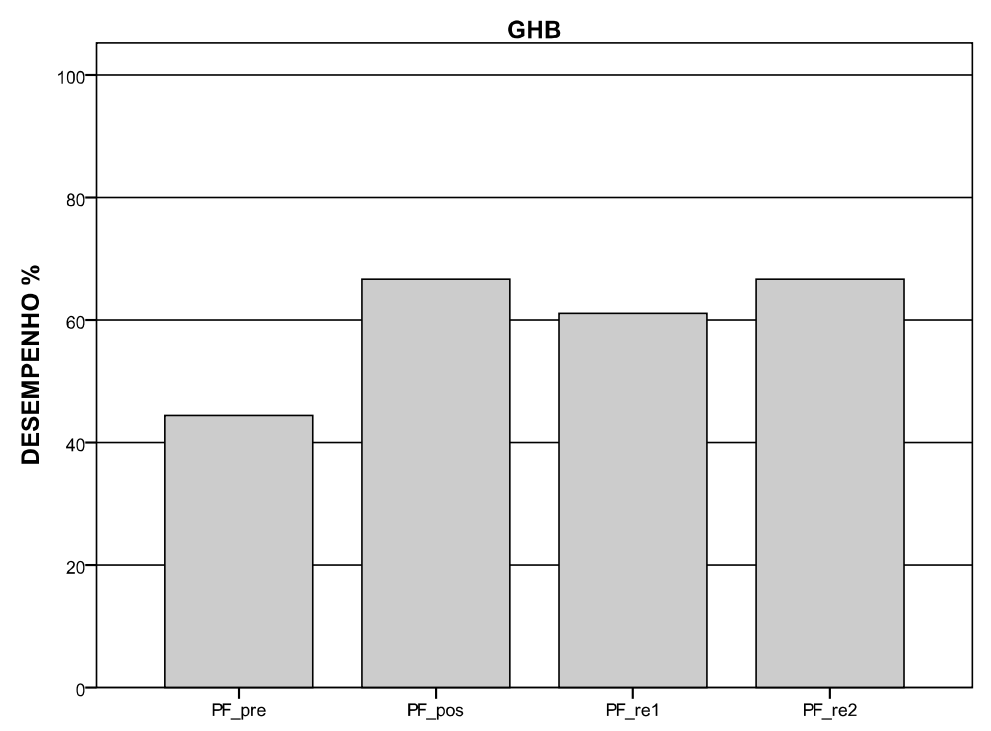

FIGURA 30 - Mediana do desempenho no componente da PF do GHB ao longo das fases (PRE, POS, RE1 e RE2).

No componente posição final, o GHB parece ter melhorado o desempenho do bloco PRE para o POS, e diminuído do POS para o RE1, melhorando deste para o RE2 (FIGURA 30).

A análise inferencial detectou diferença significativa entre os blocos $\left(x^{2}=18,380 ; p=, 000\right)$. Foi localizada diferença somente entre PRE-POS ( $z=-2,699$; $p=, 007)$. Portanto houve manutenção entre POS-RE1 $(z=-, 707 ; p=, 480)$ e entre POSRE2 ( $\mathrm{z}=-, 638 ; \mathrm{p}=, 524)$.

Os resultados permitem inferir que $0 \mathrm{GBH}$ e $\circ \mathrm{GHB}$, aprenderam 0 componente posição final. 


\subsubsection{Retenção}

\subsubsection{Desempenho global}

A FIGURA 31 apresenta o desempenho obtido pelos grupos GBH e GHB, no bloco 1 do teste de retenção (RE1) referentes ao desempenho global (DG) e desempenho nos componentes (DC).

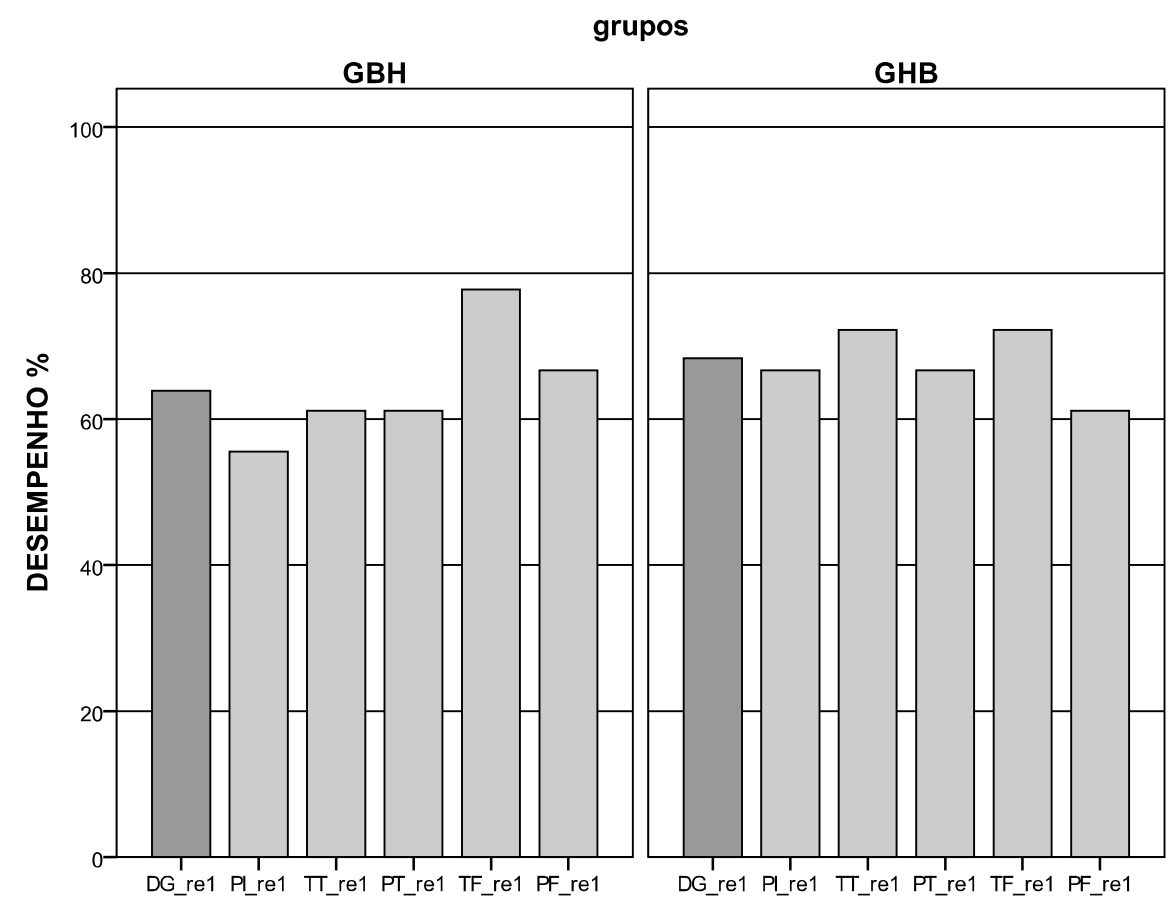

FIGURA 31 - Mediana do desempenho global e do desempenho por componente, dos componentes posição inicial (PI), transição para a tina (TT), posição de tina (PT), transição para a posição final (TF) e posição final (PT) no bloco 1 do teste de retenção (RE1), de GBH e GHB.

A FIGURA 32 apresenta o desempenho obtido pelos grupos GBH e GHB, no bloco 2 do teste de retenção (RE2) referentes ao desempenho global (DG) e desempenho nos componentes (DC). 


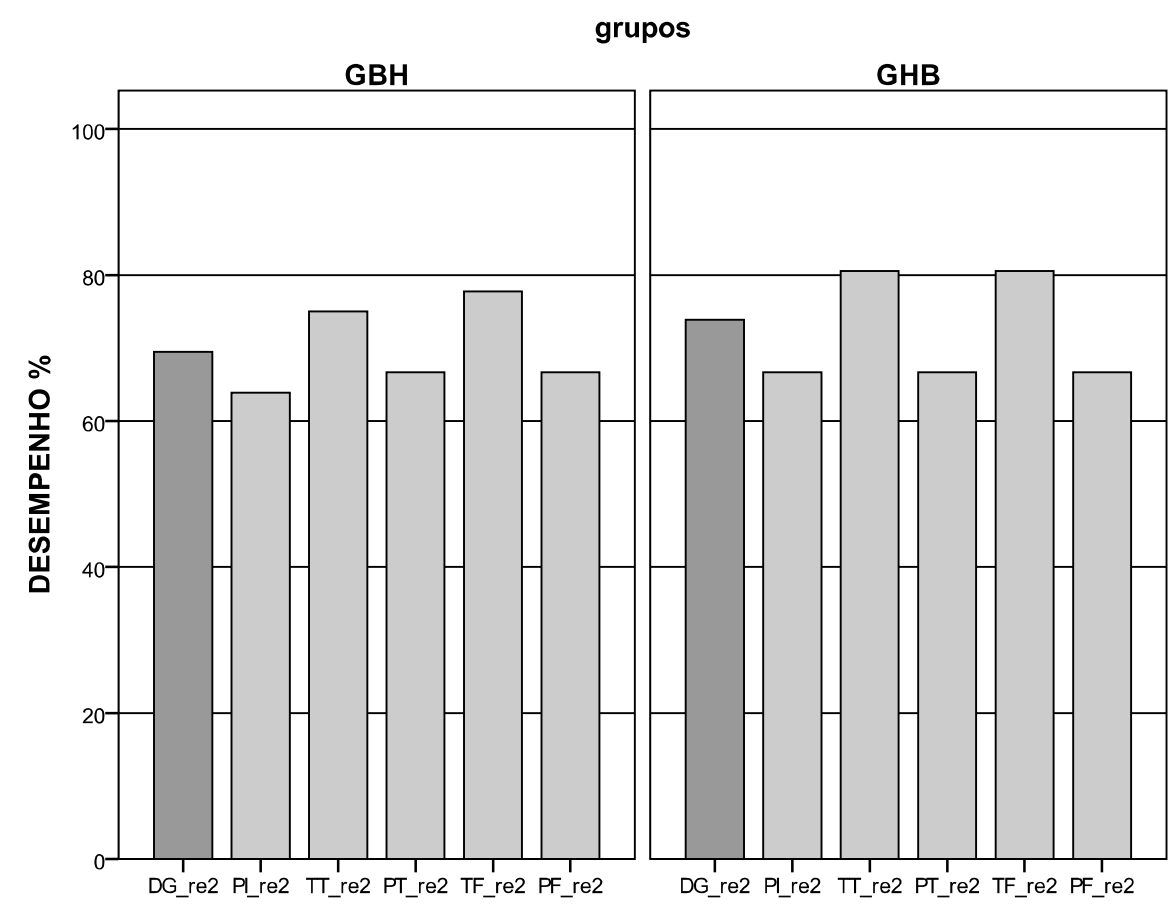

FIGURA 32 - Mediana do desempenho global e do desempenho por componente, dos componentes posição inicial (PI), transição para a tina (TT), posição de tina (PT), transição para a posição final (TF) e posição final (PT) no bloco 2 do teste de retenção (RE2), de GBH e GHB.

Na FIGURA 31, considerando a coluna correspondente ao DG, verifica-se que o desempenho na tina como um todo parece inferior para o $\mathrm{GBH}$ em relação ao GHB. No entanto, o teste $U$ de Mann-Whitney, não detectou foi diferença significativa entre GBH e GHB ( $z=-1,099 ; p=, 272)$.

Quanto ao DG, em RE1, não houve diferença entre GBH e GHB.

Verifica-se na FIGURA 32, considerando a coluna correspondente ao DG, que o desempenho na tina como um todo parece inferior para o $\mathrm{GBH}$ em relação ao GHB. No entanto, o teste $U$ de Mann-Whitney, não detectou foi diferença significativa entre GBH e GHB $(z=-1,215 ; p=, 225)$. 
Sendo assim, quanto ao DG, não houve diferença entre GBH e GHB em RE2.

\subsubsection{Desempenho por componente}

\section{Posição inicial}

$\mathrm{Na}$ FIGURA 31, na coluna correspondente à $\mathrm{PI}$, verifica-se que 0 desempenho neste componente parece ter sido inferior para o $\mathrm{GBH}$ em relação ao GHB. Não foram encontradas diferenças significativas entre GBH e GHB, em relação ao mesmo $(z=-1,305 ; p=, 192)$.

$\mathrm{Na}$ coluna PI (FIGURA 32), verifica-se que o desempenho neste componente parece ter sido inferior para o $\mathrm{GBH}$ em relação ao GHB. Não foram encontradas diferenças significativas entre $\mathrm{GBH}$ e $\mathrm{GHB}$, em relação ao mesmo ( $\mathrm{z}=-$ ,488; $p=, 626)$.

\section{Transição para a tina}

$\mathrm{Na}$ coluna correspondente à $\mathrm{TT}$, verifica-se que o desempenho neste componente parece inferior para o GBH em relação ao GHB (FIGURA 31). Não foi detectada diferença significativa entre GBH e GHB, no mesmo $(z=-1,298 ; p=, 194)$.

$\mathrm{Na}$ FIGURA 32, na coluna TT, verifica-se que o desempenho neste componente parece inferior para o $\mathrm{GBH}$ em relação ao GHB. Não foi detectada diferença significativa entre GBH e GHB, no mesmo $(z=-, 884 ; p=, 377)$. 


\section{Posição de tina}

$\mathrm{Na}$ coluna PT, verifica-se na FIGURA 31 que o desempenho neste componente parece inferior para o $\mathrm{GBH}$ em relação ao GHB. Não foi detectada diferença significativa entre GBH e GHB, no mesmo ( $z=-, 853 ; p=, 393)$.

No componente $\mathrm{PT}$, verifica-se que o desempenho parece semelhante para o GBH e GHB (FIGURA 32). Não foi detectada diferença significativa entre GBH e GHB, no mesmo $(z=-, 823 ; p=, 410)$.

\section{Transição para a posição final}

Neste componente na coluna correspondente à TF, verifica-se (FIGURA 31) que o desempenho do GBH parece superior ao do GHB. Como para os demais, o teste $U$ de Mann-Whitney não revelou diferenças significativas entre GBH e GHB, em relação a este componente ( $z=-, 000 ; p=1,000)$.

Na FIGURA 32 o desempenho em TF do GBH parece inferior ao do GHB. Como para os demais, o teste $U$ de Mann-Whitney não revelou diferenças significativas entre GBH e GHB, em relação a este componente ( $z=-, 844 ; p=, 399$ ).

\section{Posição final}

$\mathrm{Na}$ FIGURA 31, na coluna correspondente à $\mathrm{PF}$, verifica-se que 0 desempenho de GBH parece superior ao de GHB. $O$ teste $U$ de Mann-Whitney não revelou diferenças significativas entre GBH e GHB, em relação a este componente $(\mathrm{z}=-, 540 ; \mathrm{p}=, 589)$.

Na FIGURA 32, na coluna PF, verifica-se que o desempenho de GBH e de GHB parece semelhante. $O$ teste $U$ de Mann-Whitney não revelou diferenças significativas entre GBH e GHB, em relação a este componente ( $z=-, 334 ; p=, 738)$.

Em suma, em conjunto, os resultados referentes ao bloco 1 e bloco 2 do teste de retenção, mostram que não houve diferença entre $\mathrm{GBH}$ e GHB na aprendizagem dos componentes da tina. 


\subsection{Discussão}

O objetivo do experimento 2 foi Investigar os efeitos da ordem de apresentação do modelo, boneca e humano, na aprendizagem da tina do nado sincronizado. Neste experimento a tarefa foi a execução da tina, figura muito utilizada na iniciação do nado sincronizado e que compreende uma sequência composta por três posições e dois movimentos de transição: (1) posição inicial, (2) transição para a tina, (3) posição de tina; (4) transição para a posição final, e (5) posição final.

Considerando o objetivo deste experimento, a discussão dos dados seguirá a mesma ordem de apresentação dos resultados a fim de responder 0 objetivo específico do experimento 1. Para fins de análise foram considerados os blocos referentes ao pré-teste, ao pós-teste, primeiro bloco da retenção e segundo bloco da retenção. O desempenho global (DG) foi considerado como a medida que expressa o desempenho na figura como um todo é, portanto, a medida principal. Por sua vez o desempenho por componente (DC), foi considerado a medida que expressa o desempenho em cada componente da figura é portanto, uma medida complementar.

Quanto à caracterização da amostra, de acordo com os resultados do préteste, os grupos não se apresentaram diferentes, tanto em DG como em DC. Assim, as diferenças obtidas no desempenho e na aprendizagem da tina do nado sincronizado não podem ser atribuídas à heterogeneidade da amostra.

Em relação ao DG, a análise intragrupos possibilitou verificar que o grupo para o qual foi apresentado modelo boneca seguido de modelo humano (GBH) associado à instrução verbal, aprendeu a tarefa tina do nado sincronizado, pois melhorou o desempenho global do pré-teste para o pós-teste e manteve esta melhora no bloco dois do teste de retenção. Houve piora no bloco 1 da retenção, porém o desempenho foi recuperado no bloco 2. Em relação aos resultados obtidos para o grupo com modelo humano seguido de modelo boneca (GHB) associado à instrução verbal, houve melhora no desempenho global do pré-teste para o pós-teste e manutenção do desempenho alcançado no bloco pós-teste nos blocos 1 e 2 do teste de retenção. A partir destes resultados pode-se inferir que estes grupos, $\mathrm{GBH}$ e GHB aprenderam a tina do nado sincronizado. 
Em relação à medida de desempenho por componente (DC), seguindo a mesma lógica anterior em relação à interpretação dos resultados relativos ao DG, pode-se inferir que o grupo com modelo boneca $(\mathrm{GBH})$ aprendeu todos os cinco componentes da tina do nado sincronizado. Este grupo apresentou melhora do desempenho em todos os componentes, entre pré e pós-teste, e, do pós-teste para o bloco 2 do teste de retenção, manteve o desempenho em todos os componentes. Sendo assim, em relação ao $\mathrm{GBH}$, os resultados permitem afirmar que todos os componentes da tina do nado sincronizado foram adquiridos, ou seja, posição inicial $(\mathrm{PI})$, transição para a tina (TT), posição de tina (PT), transição para a posição final (TF), e posição final (PF). Embora tenha piorado o desempenho do componente (TT) no bloco 1 da retenção, houve melhora no bloco 2 (RE2) mostrando que o desempenho foi recuperado. Nesse sentido, a aprendizagem da tina inferida a partir do DG, foi resultante da melhora nos seus cinco componentes.

Os resultados mostraram que na medida de DC, o grupo com modelo humano-boneca (GHB) também apresentou melhora do desempenho em todos os componentes entre o pré e o pós-teste. Entretanto, embora tenha mantido o desempenho de PI, TT, PT, TF e PT no bloco 2 do teste de retenção (RE2), no bloco 1 do teste de retenção (RE1), no componente posição de tina (PT), houve piora no desempenho, porém recuperado em (RE2). Nesse sentido, os resultados permitem inferir que para GHB, a aprendizagem da tina (DG) ocorreu como resultante da melhora e manutenção desta, a longo prazo, em função de seus cinco componentes.

Em suma, referentes os resultados ao DC permitem inferir que o modelo boneca-humano, associado à instrução verbal, foi eficaz em promover a aprendizagem de todos os componentes da tina. Da mesma maneira, a apresentação do modelo humano-boneca, associado à instrução verbal também foi eficaz no que diz respeito à manutenção em longo prazo (1 dia) do desempenho dos componentes. Uma possível explicação para a piora do desempenho no bloco 1 do teste de retenção (RE1) seria a associação dos 2 modelos, visto que ocorreu tanto para GBH como para GHB. A diferença foi em relação aos componentes afetados, sendo o de GBH um componente mais dinâmico e de GHB, mais estável.

O movimento de transição é aquele que permite a mudança de uma posição relativamente estabilizada para outra, com características diferentes da 
anterior. No caso da TT, chega-se a ela a partir da posição estendida, que é bastante complexa, pela necessidade de manter o corpo o mais próximo da superfície, mantendo o foco na flexão do quadril. Como a executante está preocupada em manter-se na superfície, não consegue, de imediato, provocar o afundamento do quadril. São necessários novos ajustes para esta troca e para a imediata retomada do equilíbrio a assumir a posição de tina. Neste caso, parece que o primeiro modelo, a boneca, é mais eficiente em mostrar a flexão do quadril e a executante pode ter sofrido a interferência do modelo humano, último a ser visto, no qual é mais visível o palmateio de sustentação do que o afundamento do quadril, que deve ser provocado.

No caso do desempenho do GHB em relação à posição de tina, o último modelo visto, boneca, pode ter salientado as relações entre as articulações do tornozelo, joelho e quadril para formar um ângulo reto entre perna e coxa. Isso pode ter atrapalhado a solução fornecida pelo modelo humano, primeiro a ser visto. Sendo que não houve demonstração e nem instrução verbal no teste de retenção, o aprendiz pode não ter conseguido escolher a melhor alternativa, dentre tantas, nas primeiras tentativas. Ou seja, a troca de modelo pode não ser benéfica para iniciantes, devido ao excesso de informação desponibilizada..

Por sua vez, em relação à análise considerada central para o problema deste estudo, ou seja, a comparação inter-grupos na fase de retenção, blocos RE1 e RE2, nas medidas DG e DC, não foram detectadas diferenças entre GBH e GHB na aprendizagem da tina do nado sincronizado. Estes resultados permitem inferir que, na aquisição compreendendo 60 tentativas, usando modelo habilidoso associado à instrução verbal e fornecendo a demonstração com frequência relativa de $100 \%$, não houve efeito da ordem de apresentação dos modelos na aprendizagem da tina do nado sincronizado.

\section{$7 \quad$ CONCLUSÃO}

Concluiu-se neste estudo sobre efeitos do modelo na aprendizagem do nado sincronizado, que na aprendizagem da tina do nado sincronizado, com os 
seguintes cuidados metodológicos: (a) demonstração associada à instrução verbal; (b) modelo habilidoso; (c) frequência de 100\% de demonstração e (d) prática com 60 tentativas:

1- Não houve efeito do tipo de modelo na aprendizagem da tina do nado sincronizado;

2- $\quad$ Não houve efeito da ordem de apresentação do modelo (bonecahumano e humano-boneca);

3- $\quad$ Com modelo humano, aprendeu-se a tina, porém houve dificuldade em manter o desempenho em longo prazo, do componente "transição para a posição final";

4- $\quad$ Com modelo boneca seguido de modelo humano, aprendeu-se a tina, porém, para o componente "transição para a tina", houve dificuldade para manter o desempenho no bloco 1 do teste de retenção;

5- $\quad$ Com modelo humano seguido de boneca, aprendeu-se a tina, porém para o componente "posição de tina", houve dificuldade para manter o desempenho no bloco 1 do teste de retenção. 


\section{REFERÊNCIAS}

ADAMS, J.A. A closed-loop theory of motor learning. Journal of Motor Behavior, Washington, v.3, n.2, p.111-150, 1971.

ADAMS, J.A. Historical review and appraisal of research on the learning, retention, and transfer of human motor skills. Psychological Bulletin, Lancaster, v.101, n.1, p. 41-74, 1987.

AL-ABOOD, S.A.; DAVIDS, K.; BENNET, S.J. Specificity of task constraints and effects of visual demonstrations and verbal instructions in directing learners search during skill acquisition. Journal of Motor Behavior, Washington, v.33, n.3, p.295305, 2001.

AL-ABOOD, S.A.; DAVIDS, K.; BENNET, S.J.; ASHFORD, D.; MARIN, M.M. Effects of manipulating relative and absolute motion information during observational learning of an aiming task. Journal of Sports Science, Leeds, v.19, n.7, p.507-520, 2001.

ALENTEJANO, T; MARSHALL, D.; BELL, G. A time-motion analysis of elite solo synchronized Swimming. International Journal of Sports Physiology and Performance, Champaign, v.3, n.1, p.31-40, 2008.

BOSCHKER, M.S.J.; BAKKER, F.C. Inexperienced sport climbers might perceive and utilize new opportunities for action by merely observing a model. Perceptual And Motor Skills, Missoula, v.95, n.4, p.3-9, aug. 2002.

BRUZZI, A.T.; PALHARES, L.R.; FIALHO, J.V.A.P.; BENDA, R.N.; UGRINOWITSCH, $\mathrm{H}$. Efeito do número de demonstrações na aquisição de uma habilidade motora: um estudo exploratório. Revista Portuguesa de Ciências do Desporto, Porto, v.6, n.2, p.179-187, 2006. 
CALLEGARI-JACQUES, S. M. Bioestatística: princípios e aplicações. Porto Alegre: Artmed Editora, 2003.

CARROLL, W.; BANDURA, A. Representation guidance of action production in observational learning: a causal analysis. Journal of Motor Behavior, Washington, v.22, n.1, p.85-97, 1990.

CBDA. Regras de Natação Sincronizada: regras, figuras e rotinas técnicas 19982002 e demais regras 1998-2000, Rio de Janeiro: CBDA, s/d.

CHU, D.A. Athletic training issues in synchronized swimming. Clinics in Sports Medicine, Philadelphia, v.18, n.2, p.437-445, 1999.

CORREAA, U.; BENDA, R.N.; UGRINOWITSCH, H. Processo Ensino-Aprendizagem no Ensino do Desporto. In: TANI, G.; BENTO, J. O.; PETERSEN, R.D.S. (Eds). Pedagogia do Desporto. Rio de Janeiro: Guanabara Koogan, 2006. p.241-250.

DARIDO, S. C. Efeitos de dois procedimentos de apresentação da informação na aprendizagem motora: demonstração e instrução verbal. 1991. $114 \mathrm{f}$. Dissertação (Mestrado) - Escola de Educação Física e Esporte, Universidade de São Paulo, São Paulo, 1991.

FINA. Fédération Internationale de Natation. Manual for Synchronised Swimming Judges, Coaches \& Referees. FINA Office. 2005.

How synchro has changed. Disponível em:

$<$ http://www.fina.org/project/index.php?option=com content\&task=blogcategory\&id=0 \&ltemid=53>. Acesso em: 30 out. 2009.

FITTS, P. M; POSNER, M. I. Human Performance. Belmon: Brooks/Cole, 1967.

FREUDENHEIM, A. M.; IWAMIZU, J.S., SANTOS, S. Da pesquisa sobre instrução ao intervenção profissional. In: CORREA, U.C. (Org.), Comportamento motor: a 
intervenção profissional em perspectiva. São Paulo: EFP/EEFEUSP, 2008, p.231239.

FUGITA, M. Fundamentos do Nado Sincronizado: estabilizar e deslocar. In: COSTA, P.H.L. (Org.), Natação e Atividades aquáticas: subsídios para o ensino. Barueri: Manole, 2009, p.71-88.

FUGITA, M.; FREUDENHEIM, A.M. Efeito do tipo de instrução na aquisição de uma figura de nado sincronizado:um estudo exploraltório. In: X SIMPÓSIO PAULISTA DE EDUCAÇÃO FÍSICA, 2005, Rio Claro/SP. Motriz-Revista de Educação Física UNESP. Rio Claro: UNESP, 2005, v. 11, p.S77.

FUGITA, M.; FREUDENHEIM, A.M. Proposição e validação de lista de checagem para avaliação do nível de proficiência em uma tarefa de nado sincronizado. In: III CONGRESSO BRASILEIRO DE COMPORTAMENTO MOTOR, 2006, Rio Claro. Anais do III Congresso Brasileiro de Comportamento Motor, Rio Claro: UNESP, 2006.

GUADAGNOLI, M.A.; LEE, T.D. Journal of Motor behavior, v.36, n.2, p.212-224, 2004.

GALLAHUE, D. A classificação das habilidades de movimento: um caso para modelos multidimensionais. Revista da Educação Física/UEM, Maringá, v.13, n.2, p.105-111, 2002.

GENTILE, A. M. A Working Model of Skill Acquisition with Application to Teaching. Quest, Champaign, v.17, n.1, p.3-23, jan., 1972.

GLENCROSS, D.J. Human skill and motor learning: a critical review. Sport Science Review, Champaign, v.1, n.2, 65-78, 1992 
GODINHO, M.; MENDES, R.; MELO, F.; BARREIROS, J. Instrução e Demonstração. In: GODINHO, M. (Ed.), Controlo Motor e Aprendizagem: fundamentos e aplicações. 2ª edição, Lisboa: FMH edições, 2002, p.151-162.

GUADA

GUEDES, M.D.S. A aprendizagem motora: do laboratório às aulas de Educação Física. In: Guedes, M.G.S. (Ed.), Aprendizagem motora: problemas e contextos. Lisboa: Edições FMH, 2001.

HERCOWITZ, S.; LOBO, A.M.; XAVIER, M.; PÉRILLIER, R.; BUNN, S. IV Manual de ensino do Nado Sincronizado. Rio de Janeiro: CBDA, 2004.

HODGES, N.J.; FRANKS, I.M. Modeling coaching practice: the role of instruction and demonstration. Journal of Sports Sciences, London, v.20, n.10, p.793-811, 2002./

HOO, S.S.; TAKEMOTO, K.Y.; McCULLAGH, P. A comparison of modeling and imagery on the performance of a motor skill. Journal of Sport Behavior, Alabama, v.27, n.4, p. 349-366, dec. 2004.

KAMPIOTIS, S.; THEODORAKOU, K. The influence of five different types of observation based teaching on the cognitive level of learning. Kinesiology, Washington, v.38, n.2, p. 116-125, 2006.

LANDERS, D.; LANDERS, D. Teacher versus peer models: effects of model's presence and performance level on motor behavior. Journal of Motor Behavior, Washington, v.5, p.139-159, 1973.

LIMA, W. U. Ensinando Natação. São Paulo: Phorte, 1999.

LIRGG, C.D.; FELTZ, D.L. Teacher versus peer models revisited: effects on motor performance and self-efficacy. Research Quarterly for Exercise and Sport, Washington, v.62, n.2, p.217-224, 1991. 
MAGILL, R. A. Aprendizagem motora: conceitos e aplicações. São Paulo: Edgard Blücher, 2000.

MEIRA JUNIOR, C. M. Validação de uma lista de checagem para análise qualitativa do saque do voleibol. Motriz, Rio Claro, v.9, n.3, p.153-160, 2003.

MENDES, R. Modelo ou modelos? O que mostrar na demonstração. In: BARREIROS, J.; GODINHO, M., MELO, F.; NETO, C. (Eds.), Desenvolvimento e aprendizagem: perspectivas cruzadas., Lisboa: Edições FMH, 2004. p. 95-117.

MOUNTJOY, M. The basics of synchronized swimming and its injuries. Clinics in Sports Medicine, Philadelphia, v.18, n.2, p.321-336, apr. 1999.

PELLEGRINI, A.M. A Aprendizagem de Habilidades Motoras I: O Que Muda com a Prática? Revista Paulista de Educação Física, São Paulo, supl.3, p.29-34, 2000.

POLLOCK, B.J; LEE, T.D. Effects of the model's skill level on observational motor learning. Research Quarterly for Exercise and Sport, Washington, v.63, n.1, p.2529, 1992.

PUBLIO, N.S.; TANI, G.; MANOEL, E.J. Efeitos da demonstração e instrução verbal na aprendizagem de habilidades motoras da ginástica olímpica. Revista Paulista de Educação Física, São Paulo, v.9, n.2, 111-124, 1995.

SANCHEZ, B.F. Bases para uma didática de educación física. Madrid: Gymnos, 1986.

SCHMIDT, R. A.; WRISBERG, C. A. Aprendizagem e Performance Motora: uma abordagem da aprendizagem baseada no problema. Porto Alegre: Artmed, 2001.

SCHMIDT, R. A; LEE, T.D. Motor control and learning: a behavioral emphasis. 3.ed. Champaign: Human Kinetics, 1999. 
SCULLY, D.M.; NEWELL, K.M. Observational learning and the acquisition of motor skills: toward a visual perception perspective. Journal of Human Movement Studies, Edinburgh, v.11, p.169-186, 1985.

SIDAWAY, B.; HAND, M.J. Frequency of modeling effects on the acquisition and retention of a motor skill. Research Quarterly for Exercise and Sport, Washington, v.64, n.1, p.122-126, 1993.

SIEGEL, S.; CASTELLAN JR, N. J. Estatística não-paramétrica para ciências do comportamento. Porto Alegre: Artmed, 2006.

SYNCHRO CANADA RESOURCE CENTER. Instructor/coach resources miscellaneous. Disponível em: $<$ http://www.synchro.ca/e/resources/documents/SrcNEWcatJun08.pdf $>$, Acesso em: 30 nov. 2009.

TANI, G. Variabilidade de resposta e processo adaptativo em aprendizagem motora. 1989. 78f. Tese (Livre Docência) - Escola de Educação Física e Esporte, Universidade de São Paulo, São Paulo. 1989.

TANI, G.; FREUDENHEIM, A. M.; MEIRA-JUNIOR, C. M.; CORRÊA, U. C. Aprendizagem motora: tendências, perspectivas e aplicações. Revista Paulista de Educação Física, São Paulo, v.18, n. especial, p.55-72, 2004.

THOMAS, J.R.; NELSON, J.K. Métodos de Pesquisa em Atividade Física. Porto Alegre: Artmed, 2002.

WEISS, M. R. Modeling and motor performance: developmental perspective. Research quarterly for exercise and sport, Washington, v.54, n.2, p.190-197, 1983. 
WULF, G; SHEA, C.H. Principles derived from the study of simple skills do not generalize to complex skill learning. Psychonomic Bulletin \& Review, Austin, v.9, n.2, p.185-211, 2002.

ZETOU, E.; FRAGOULI, M.; TZETZIS, G. The influence of star and self modeling on volleyball skill acquisition. Journal of Human Movement Studies, Edinburgh, v.37, p.127-143, 1999. 
ANEXO I - Aprovação do projeto de pesquisa pelo Comitê de Ética em Pesquisa

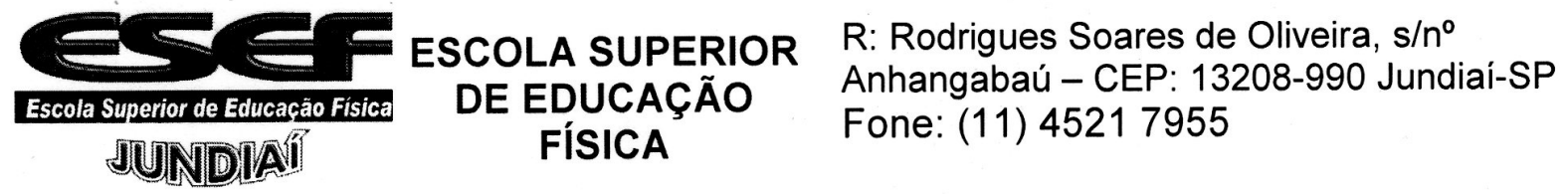

Jundiaí, 09 de novembro de 2007.

IImo Sra

Profa. Ms. Bettina Ried

Pesquisadora Responsável

\section{REF: APROVAÇÃO DO PROJETO DE PESQUISA}

O Comitê de Ética em Pesquisa da Escola Superior de Educação Física de Jundiaí informa que aprovou em reunião ordinária realizada em 09/11/2007.

O Projeto de Pesquisa Temático: "PROCESSO DE AQUISIÇÃO DA TINA NO NADO SINCRONIZADO: UM ESTUDO DESCRITIVO" (Processo $n^{\circ}$ 008/07 CAAE - 0006.0.335.000-07), Termo de Consentimento Livre e Esclarecido e o Parecer do relator.

O respectivo relatório parcial deve ser encaminhado a este CEP até 09/05/2008 e o final até 09/11/2008.

Atenciosamente.

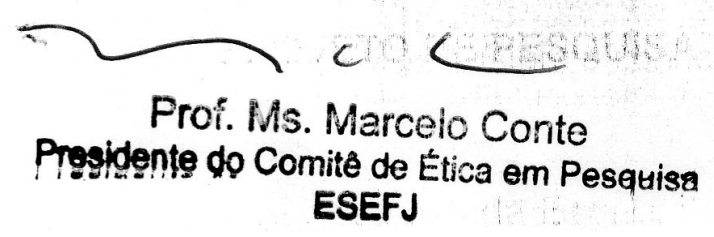


ANEXO II - Escala de notas explicadas

\begin{tabular}{|c|c|c|c|c|c|}
\hline $\begin{array}{l}10 \\
\text { Perfeito }\end{array}$ & $\begin{array}{l}9.5 \text { a } 9.9 \\
\text { Quase } \\
\text { Perfeito }\end{array}$ & $\begin{array}{l}9.0 \text { a } 9.4 \\
\text { Excelente }\end{array}$ & $\begin{array}{l}8.0 \text { a } 8.9 \\
\text { Muito Bom }\end{array}$ & $\begin{array}{l}7.0 \text { a } 7.9 \\
\text { Bom }\end{array}$ & $\begin{array}{l}6.0 \text { a } 6.9 \\
\text { Competente }\end{array}$ \\
\hline Impecável & $\begin{array}{l}\text { Mínimos } \\
\text { desvios para } \\
\text { a perfeição. }\end{array}$ & $\begin{array}{l}\text { Dificilmente } \\
\text { vemos erros }\end{array}$ & $\begin{array}{l}\text { Um pequeno } \\
\text { número de } \\
\text { mínimos erros }\end{array}$ & $\begin{array}{l}\text { Acima da } \\
\text { média }\end{array}$ & $\begin{array}{l}\text { Confortavelmente } \\
\text { na média }\end{array}$ \\
\hline \multicolumn{6}{|l|}{ Transições } \\
\hline $\begin{array}{l}\text { Muito } \\
\text { eficiente e } \\
\text { precisa no } \\
\text { curso da } \\
\text { ação. } \\
\text { Totalmente } \\
\text { fluída e } \\
\text { suave }\end{array}$ & $\begin{array}{l}\text { Curso direto } \\
\text { da ação. } \\
\text { Posições } \\
\text { fechadas no } \\
\text { lugar. Sem } \\
\text { marolas }\end{array}$ & 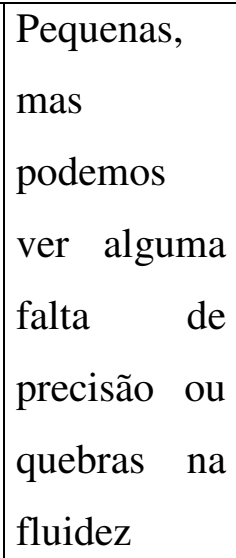 & $\begin{array}{l}\text { Pequenos } \\
\text { desvios de } \\
\text { precisão, } \\
\text { eficiência e/ou } \\
\text { fluidez. }\end{array}$ & $\begin{array}{l}\text { Desvios óbvios } \\
\text { mas nenhum } \\
\text { muito } \\
\text { expressivo. }\end{array}$ & \begin{tabular}{|l} 
Sem consistência. \\
Problemas com \\
grande \\
dificuldade nas \\
transições.
\end{tabular} \\
\hline \multicolumn{6}{|c|}{ Posições do corpo } \\
\hline Apuro total & $\begin{array}{l}\text { Muito } \\
\text { precisa, } \\
\text { sólida, } \\
\text { pequenos } \\
\text { desvios. }\end{array}$ & $\begin{array}{l}\text { Precisa, mas } \\
\text { algumas } \\
\text { falhas para } \\
\text { ser } \\
\text { totalmente } \\
\text { limpa }\end{array}$ & $\begin{array}{l}\text { Muito clara e } \\
\text { apurada. } \\
\text { Algumas } \\
\text { poucas } \\
\text { incorreções }\end{array}$ & \begin{tabular}{|lr} 
Óbvias, & mas \\
não & grandes \\
irregularidades.
\end{tabular} & $\begin{array}{l}\text { Muitas pequenas } \\
\text { incorreções. } \\
\text { Sem consistência }\end{array}$ \\
\hline \multicolumn{6}{|c|}{ Limpeza e definição } \\
\hline $\begin{array}{l}\text { A distinção } \\
\text { entre } \\
\text { posições e } \\
\text { transições é } \\
\text { clara }\end{array}$ & $\begin{array}{l}\text { Precisa, } \\
\text { mostra e vai. } \\
\text { Clara } \\
\text { distinção } \\
\text { entre as } \\
\text { partes. }\end{array}$ & \begin{tabular}{|l} 
Pouco e \\
pequenos \\
erros.
\end{tabular} & $\begin{array}{l}\text { Precisa e clara } \\
\text { com pequenos } \\
\text { problemas na } \\
\text { precisão }\end{array}$ & 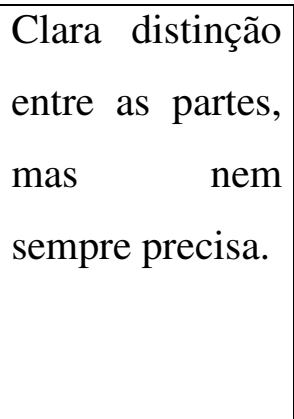 & $\begin{array}{l}\text { Falta limpeza } \\
\text { entre posições e } \\
\text { transições. }\end{array}$ \\
\hline
\end{tabular}


ANEXO III- Lista de checagem da tina

\begin{tabular}{|l|l|l|l|l|l|}
\hline Componentes & Critérios & $\mathbf{0}$ & $\mathbf{1}$ & $\mathbf{2}$ & $\mathbf{3}$ \\
\hline Posição inicial & AL1 & & & & \\
\hline & NV1 & & & & \\
\hline & MS1 & & & & \\
\hline \multirow{5}{*}{ Transição para tina } & PE2 & & & & \\
\hline & FL2 & & & & \\
\hline & MS2 & & & & \\
\hline Posição de tina & CX3 & & & & \\
\hline & NV3 & & & & \\
\hline & MS3 & & & & \\
\hline Transição para posição final & PE4 & & & & \\
\hline & EX4 & & & & \\
\hline & MS4 & & & & \\
\hline Posição final & AL5 & & & & \\
\hline & NV5 & & & & \\
\hline & MS5 & & & & \\
\hline
\end{tabular}




\section{ANEXO IV - Critérios da lista de checagem da tina}

(Escore 0: figura não executada)

I. Alinhamento do corpo, tanto na posição inicial como na final:

(1) não alinhado: os pontos - orelhas, quadril e tornozelos - não se alinharam em nenhum momento.

(2) instável ou diagonal à superfície: observa-se uma linha reta e inclinada, com os pés submersos e o rosto na superfície, ou o quadril não se manteve estendido todo o tempo, ou as pernas ficaram em diferentes níveis em relação à superfície.

(3) alinhado e paralelo à superfície o tempo todo.

II. Nível do corpo em relação à superfície nos três componentes - posições inicial, de tina e final:

(1) submerso: todas as partes (rosto, tronco e membros) afundadas todo o tempo.

(2) parcial/instável: alguma parte do corpo (rosto, por exemplo) rompe a linha da superfície em algum momento ou todo o tempo ou oscila acima e abaixo da superfície.

(3) emerso: rosto e parte anterior do tronco e dos membros inferiores aparentes na superfície todo o tempo.

III. Movimentos supérfluos, tanto nas posições inicial e final como nas transições e na posição de tina:

(1) muitos.

- $\quad$ pernas: movimentos exagerados de flexionar e estender, unir e afastar visando estabilização.

- mãos: batem na superfície (espirrando água) ou provocam turbulências (ondas) devido a movimentos exagerados e ineficientes.

(2) poucos: oscilações, marolas e círculos perceptíveis mas não evidentes ou exagerados; instabilidade.

(3) ausentes: a superfície permanece lisa; se houver oscilação, é imperceptível, e o corpo permanece estabilizado. (É esperada a formação de um pequeno redemoinho.)

IV. Pernas em relação à superfície, durante a transição para a tina (flexão joelhos-quadril) e para a posição final (extensão joelhos-quadril):

(1) muito inclinadas:

na transição para a tina, os calcanhares muito próximos ao quadril; muitas vezes, só os joelhos aparecem, e
os pés ficam afundados. os pés ficam afundados.

os pés se aproximam da superfície, devido à elevação do quadril. Para a avaliação, deve-se levar em conta principalmente o primeiro terço da extensão.

(2) instáveis ou pouco inclinadas:

- na transição para a tina, há mínima flexão dos joelhos, mas os pés permanecem afundados.

- $\quad$ na transição para a posição final, as pernas se estendem abaixo da superfície, mas perto dela; pés na superfície e joelhos afundados estão neste caso.

(3) paralelas: o segmento joelho-tornozelo está paralelo e na superfície em ambas as transições.

V. Coordenação entre joelhos e quadril, nas transições para a tina e para a posição final:

(1) não ocorre:

- na transição para a tina, ocorre flexão de uma das articulações (joelho ou quadril), enquanto a outra resiste, podendo ou não se flexionar em conseqüência; a participante tenta manter o quadril sem afundar ou o joelho estendido.

- $\quad$ na transição para a posição final, ocorre extensão de uma ou outra articulação (geralmente, os joelhos são estendidos e o quadril permanece flexionado, em V).

(2) não fluente:

- na transição para a tina, ocorre flexão de uma articulação e, voluntariamente, em seguida, da outra; geralmente começa-se flexionando exageradamente o joelho e, conseqüentemente, o quadril afunda; ocorre porque o foco da flexão não está no quadril.

- $\quad$ na transição para a flutuação final, os joelhos são estendidos e em seguida o quadril; muitas vezes, o quadril não é estendido totalmente porque o foco da extensão não está ali.

(3) fluente: articulações em sincronização, movimento fluente

- na transição para a tina, ocorre flexão coordenada dos joelhos; foco no quadril.

- $\quad$ na transição para a flutuação, ocorre extensão coordenada dos joelhos e do quadril, que completam a extensão; foco no quadril.

VI. Ângulo entre coxas-pernas e superfície na posição de tina:

(1) não perpendicular: em nenhum momento as coxas estão perpendiculares à superfície e nem às pernas, e estas não estão paralelas à superfície.

(2) muito próximo de $90^{\circ}$ : a relação parece quase correta, mas é pouco evidente ou duvidosa.

(3) perpendicular: a coxa está perpendicular à linha da superfície e as pernas, paralelas a ela o tempo todo; a relação é perfeitamente evidente. 
ANEXO V - Experiência dos avaliadores de conteúdo da lista

\begin{tabular}{|l|l|}
\hline Avaliador & Experiência \\
\hline 1 & $\begin{array}{l}\text { Licenciado e Mestre em Educação Física; } \\
\text { professor universitário da disciplina natação, } \\
\text { atividades aquáticas e dança; pesquisador da } \\
\text { área de aprendizagem motora. }\end{array}$ \\
\hline 2 & $\begin{array}{l}\text { Licenciado e Mestre em Educação Física; } \\
\text { professor universitário da disciplina educação } \\
\text { física adaptada; pesquisador da área de } \\
\text { aprendizagem motora. }\end{array}$ \\
\hline 3 & $\begin{array}{l}\text { Licenciado e Mestre em Educação Física, } \\
\text { árbitro de nado sincronizado de nível } \\
\text { internacional, professor universitário da } \\
\text { disciplina atividades aquáticas e natação, } \\
\text { pesquisador da área de treinamento esportivo. }\end{array}$ \\
\hline 4 & $\begin{array}{l}\text { Licenciado e em Educação Física; professor } \\
\text { de ensino fundamental e médio da disciplina } \\
\text { Educação Física; árbitro de nado sincronizado } \\
\text { de nível nacional. }\end{array}$ \\
\hline 5 & $\begin{array}{l}\text { Bacharel em Esporte e técnico da equipe de } \\
\text { um clube filiado à Federação Aquática } \\
\text { Paulista e técnico de seleção nacional. }\end{array}$ \\
\hline
\end{tabular}


ANEXO VI - Experiência dos avaliadores de consistência e reprodutibilidade

\begin{tabular}{|l|l|}
\hline Avaliador & Experiência \\
\hline 1 & $\begin{array}{l}\text { Licenciado e Mestre em Educação Física; } \\
\text { professor universitário da disciplina } \\
\text { atividades aquáticas; pesquisador da área de } \\
\text { aprendizagem motora. }\end{array}$ \\
\hline 2 & $\begin{array}{l}\text { Licenciado e Mestre em Educação Física; } \\
\text { professor de educação física no ensino } \\
\text { fundamental e médio; pesquisador da área de } \\
\text { aprendizagem motora. }\end{array}$ \\
\hline 3 & $\begin{array}{l}\text { Licenciado e em Educação Física; professor } \\
\text { de ensino fundamental e médio da disciplina } \\
\text { Educação Física; árbitro de nado sincronizado } \\
\text { de nível estadual. }\end{array}$ \\
\hline
\end{tabular}


ANEXO VII - Concordância intra e inter avaliadores no critério 1

\begin{tabular}{|c|c|c|c|c|c|c|c|c|c|c|c|}
\hline Critério 1 & \multicolumn{2}{|c|}{ AV_1 } & Conc. & \multicolumn{2}{|c|}{ AV_2 } & Conc. & \multicolumn{2}{|c|}{ AV_3 } & Conc. & \multirow{2}{*}{$\begin{array}{c}\text { Conc. } \\
1^{\mathrm{a}} \\
\end{array}$} & \multirow{2}{*}{$\begin{array}{c}\text { Conc } \\
2^{\mathrm{a}} \\
\end{array}$} \\
\hline & $1^{a}$ & $2^{a}$ & & $1^{a}$ & $2^{a}$ & & $\mathbf{1}^{\mathrm{a}}$ & $2^{a}$ & \multirow[b]{2}{*}{ Intra } & & \\
\hline Participante & & & Intra & & & Intra & & & & Inter & Inter \\
\hline 1 & 3 & 3 & $\mathbf{C}$ & 3 & 2 & D & 3 & 3 & $\mathrm{C}$ & C & D \\
\hline 2 & 1 & 1 & $\mathbf{C}$ & 1 & 1 & $\mathbf{C}$ & 1 & 1 & $\mathbf{C}$ & $\mathrm{C}$ & $\mathrm{C}$ \\
\hline 3 & 3 & 3 & $\mathbf{C}$ & 3 & 3 & $\mathbf{C}$ & 3 & 3 & $\mathbf{C}$ & $\mathrm{C}$ & $\mathrm{C}$ \\
\hline 4 & 1 & 1 & $\mathbf{C}$ & 1 & 1 & $\mathbf{C}$ & 1 & 1 & $\mathbf{C}$ & $\mathrm{C}$ & $\mathrm{C}$ \\
\hline 5 & 1 & 1 & $\mathbf{C}$ & 1 & 1 & $\mathbf{C}$ & 1 & 1 & $\mathbf{C}$ & $\mathbf{C}$ & $\mathbf{C}$ \\
\hline 6 & 1 & 1 & $\mathbf{C}$ & 1 & 1 & $\mathbf{C}$ & 1 & 1 & $\mathbf{C}$ & $\mathbf{C}$ & $\mathbf{C}$ \\
\hline 7 & 1 & 1 & $\mathbf{C}$ & 1 & 1 & $\mathbf{C}$ & 1 & 1 & $\mathbf{C}$ & $\mathbf{C}$ & $\mathbf{C}$ \\
\hline 8 & 2 & 2 & $\mathbf{C}$ & 2 & 2 & $\mathbf{C}$ & 1 & 2 & D & D & $\mathbf{C}$ \\
\hline 9 & 1 & 1 & $\mathbf{C}$ & 1 & 1 & $\mathbf{C}$ & 1 & 1 & $\mathbf{C}$ & $\mathrm{C}$ & $\mathbf{C}$ \\
\hline 10 & 1 & 1 & $\mathbf{C}$ & 2 & 2 & $\mathbf{C}$ & 1 & 1 & $\mathbf{C}$ & D & D \\
\hline Percentual & & & $100 \%$ & & & $90 \%$ & & & $90 \%$ & $80 \%$ & $80 \%$ \\
\hline
\end{tabular}


ANEXO VIII - Concordância intra e inter avaliadores no critério 2

\begin{tabular}{|c|c|c|c|c|c|c|c|c|c|c|c|}
\hline Critério 2 & $\mathbf{A V _ { - }}$ & & Conc. & $\mathbf{A V _ { - }}$ & & Conc. & $\mathbf{A V _ { - }}$ & & Conc. & Conc. & Conc. \\
\hline & $\mathbf{1}^{\mathrm{a}}$ & $2^{a}$ & & $1^{\mathrm{a}}$ & $2^{2^{a}}$ & & $1^{\mathrm{a}}$ & $2^{a}$ & & $\mathbf{1}^{\mathbf{a}}$ & $2^{\mathbf{a}}$ \\
\hline Participante & & & Intra & & & Intra & & & Intra & Inter & Inter \\
\hline 1 & 2 & 2 & C & 2 & 2 & C & 2 & 2 & $\mathrm{C}$ & $\mathbf{C}$ & $\mathbf{C}$ \\
\hline 2 & 2 & 2 & $\bar{C}$ & 2 & 2 & $\bar{C}$ & 2 & 2 & $\bar{C}$ & $\mathrm{C}$ & $\mathrm{C}$ \\
\hline 3 & 2 & 2 & $\mathrm{C}$ & 2 & 2 & $\mathrm{C}$ & 2 & 2 & $\bar{C}$ & $\mathrm{C}$ & $\mathrm{C}$ \\
\hline 4 & 2 & 2 & $\mathrm{C}$ & 2 & 2 & $\mathrm{C}$ & 2 & 2 & $\mathrm{C}$ & $\mathrm{C}$ & $\mathrm{C}$ \\
\hline 5 & 2 & 2 & $\bar{C}$ & 2 & 2 & $\bar{C}$ & 2 & 2 & $\bar{C}$ & $\mathrm{C}$ & $\mathrm{C}$ \\
\hline 6 & 2 & 2 & $\mathrm{C}$ & 2 & 2 & $\mathrm{C}$ & 2 & 2 & $\mathrm{C}$ & $\mathrm{C}$ & $\mathrm{C}$ \\
\hline 7 & 2 & 2 & $\mathrm{C}$ & 2 & 2 & $\mathrm{C}$ & 2 & 2 & $\mathrm{C}$ & $\mathrm{C}$ & $\mathrm{C}$ \\
\hline 8 & 2 & 2 & $\mathrm{C}$ & 2 & 2 & $\mathrm{C}$ & 2 & 2 & $\mathrm{C}$ & $\mathrm{C}$ & $\mathrm{C}$ \\
\hline 9 & 2 & 2 & $\mathrm{C}$ & 2 & 2 & $\mathrm{C}$ & 2 & 2 & $\mathrm{C}$ & $\mathrm{C}$ & C \\
\hline 10 & 2 & 2 & $\mathbf{C}$ & 2 & 2 & $\mathrm{C}$ & 2 & 2 & $\mathrm{C}$ & $\mathrm{C}$ & $\mathrm{C}$ \\
\hline Percentual & & & $100 \%$ & & & $100 \%$ & & & $100 \%$ & $100 \%$ & $100 \%$ \\
\hline
\end{tabular}


ANEXO IX - Concordância intra e inter avaliadores no critério 3

\begin{tabular}{|c|c|c|c|c|c|c|c|c|c|c|c|}
\hline Critério 3 & \multicolumn{2}{|c|}{$\mathbf{A V} \_1$} & \multirow{3}{*}{$\begin{array}{l}\text { Conc. } \\
\text { Intra } \\
\end{array}$} & \multicolumn{2}{|c|}{ AV_2 } & \multirow{3}{*}{\begin{tabular}{|l} 
Conc. \\
Intra \\
\end{tabular}} & \multicolumn{2}{|c|}{ AV_3 } & \multirow{3}{*}{\begin{tabular}{|l} 
Conc. \\
Intra
\end{tabular}} & \multirow{3}{*}{$\begin{array}{c}\text { Conc. } \\
1^{\mathrm{a}} \\
\text { Inter }\end{array}$} & \multirow{2}{*}{$\begin{array}{c}\text { Conc. } \\
2^{\mathbf{a}} \\
\end{array}$} \\
\hline & \multirow[t]{2}{*}{$1^{\mathrm{a}}$} & \multirow[t]{2}{*}{$2^{a}$} & & \multirow[t]{2}{*}{$\mathbf{1}^{\mathrm{a}}$} & \multirow[t]{2}{*}{$2^{a}$} & & \multirow[t]{2}{*}{$\mathbf{1}^{\mathrm{a}}$} & \multirow[t]{2}{*}{$2^{a}$} & & & \\
\hline Participante & & & & & & & & & & & Inter \\
\hline 1 & 3 & 3 & $\mathbf{C}$ & 3 & 3 & $\mathbf{C}$ & 3 & 3 & C & C & $\mathrm{C}$ \\
\hline 2 & 2 & 2 & $\mathbf{C}$ & 1 & 1 & $\mathrm{C}$ & 2 & 1 & $\bar{C}$ & D & D \\
\hline 3 & 3 & 3 & $\mathbf{C}$ & 3 & 3 & $\mathbf{C}$ & 3 & 3 & $\mathbf{C}$ & $\mathbf{C}$ & $\mathbf{C}$ \\
\hline 4 & 1 & $\overline{1}$ & $\mathbf{C}$ & 1 & 1 & $\mathbf{C}$ & 1 & 1 & $\mathbf{C}$ & $\mathrm{C}$ & $\mathrm{C}$ \\
\hline 5 & 1 & 1 & $\mathbf{C}$ & 1 & 1 & $\mathbf{C}$ & 1 & 1 & $\mathbf{C}$ & $\mathbf{C}$ & $\mathbf{C}$ \\
\hline 6 & 1 & 2 & $\overline{\mathbf{D}}$ & 1 & 1 & $\mathrm{C}$ & 1 & 1 & $\bar{C}$ & $\mathrm{C}$ & D \\
\hline 7 & 2 & 2 & $\mathbf{C}$ & 1 & 1 & $\mathbf{C}$ & 2 & 2 & $\mathbf{C}$ & D & D \\
\hline 8 & 2 & 2 & $\mathbf{C}$ & 2 & 2 & $\mathbf{C}$ & 2 & 2 & $\mathbf{C}$ & $\mathrm{C}$ & $\mathrm{C}$ \\
\hline 9 & 3 & 3 & $\mathrm{C}$ & 2 & 2 & $\mathrm{C}$ & 3 & 2 & $\mathbf{C}$ & D & D \\
\hline 10 & 3 & 2 & $\overline{\mathbf{D}}$ & 2 & 2 & $\bar{C}$ & 3 & 2 & $\bar{D}$ & D & $\mathrm{C}$ \\
\hline Percentual & & & $80 \%$ & & & $100 \%$ & & & $90 \%$ & $60 \%$ & $60 \%$ \\
\hline
\end{tabular}


ANEXO X - Concordância intra e inter avaliadores no critério 4

\begin{tabular}{|c|c|c|c|c|c|c|c|c|c|c|c|}
\hline Critério 4 & $\overline{\mathbf{A V} \mathbf{V}_{-}}$ & & Conc. & $\overline{\mathbf{A V} \mathbf{V}_{-}}$ & & Conc. & $\mathbf{A \mathbf { V } _ { - }}$ & & Conc. & Conc. & Conc. \\
\hline & $\mathbf{1}^{\mathrm{a}}$ & $2^{a}$ & & $\overline{1^{a}}$ & $2^{a}$ & & $1^{a}$ & $2^{\mathrm{a}}$ & & $\mathbf{1}^{\mathbf{a}}$ & $2^{\mathbf{a}}$ \\
\hline Participante & & & Intra & & & Intra & & & Intra & Inter & Inter \\
\hline 1 & 2 & 2 & $\mathrm{C}$ & 2 & 2 & $\mathbf{C}$ & 2 & 2 & $\mathbf{C}$ & $\mathbf{C}$ & C \\
\hline 2 & 2 & 2 & $\bar{C}$ & 2 & 2 & $\bar{C}$ & 2 & 2 & $\bar{C}$ & $\mathrm{C}$ & $\mathrm{C}$ \\
\hline 3 & 2 & 2 & $\mathrm{C}$ & 2 & 2 & $\mathrm{C}$ & 2 & 2 & $\mathrm{C}$ & $\mathrm{C}$ & $\mathrm{C}$ \\
\hline 4 & 1 & 1 & $\bar{C}$ & 1 & 1 & $\bar{C}$ & 1 & 1 & $\bar{C}$ & $\mathrm{C}$ & $\mathrm{C}$ \\
\hline 5 & 2 & 2 & $\bar{C}$ & 2 & 2 & $\bar{C}$ & 2 & 2 & $\bar{C}$ & $\mathrm{C}$ & $\mathrm{C}$ \\
\hline 6 & 1 & 1 & $\mathrm{C}$ & 1 & 1 & $\mathrm{C}$ & 1 & 1 & $\mathrm{C}$ & $\mathrm{C}$ & $\mathrm{C}$ \\
\hline 7 & 1 & 1 & $\mathrm{C}$ & 1 & 1 & $\mathbf{C}$ & 1 & 1 & $\mathrm{C}$ & $\mathrm{C}$ & $\mathrm{C}$ \\
\hline 8 & 2 & 2 & $\mathrm{C}$ & 2 & 2 & $\mathrm{C}$ & 1 & 2 & D & D & $\mathrm{C}$ \\
\hline 9 & 1 & 1 & $\mathrm{C}$ & 1 & 1 & $\bar{C}$ & 1 & 1 & $\mathrm{C}$ & $\mathrm{C}$ & $\mathrm{C}$ \\
\hline 10 & 1 & 1 & $\mathbf{C}$ & 2 & 2 & $\mathbf{C}$ & 1 & 1 & $\mathbf{C}$ & D & D \\
\hline Percentual & & & $100 \%$ & & & $100 \%$ & & & $90 \%$ & $80 \%$ & $90 \%$ \\
\hline
\end{tabular}


ANEXO XI - Concordância intra e inter avaliadores no critério 5

\begin{tabular}{|c|c|c|c|c|c|c|c|c|c|c|c|}
\hline Critério 5 & $\mathbf{A \mathbf { V } _ { - }}$ & & Conc. & $\mathbf{A V _ { - }}$ & & \begin{tabular}{|l|} 
Conc. \\
\end{tabular} & $\mathbf{A V _ { - }}$ & & Conc. & Conc. & Conc. \\
\hline & $\mathbf{1}^{\mathrm{a}}$ & $2^{a}$ & & $\mathbf{1}^{\mathrm{a}}$ & $2^{a}$ & & $1^{a}$ & $2^{\mathrm{a}}$ & & $\mathbf{1}^{\mathrm{a}}$ & $2^{\mathrm{a}}$ \\
\hline Participante & & & Intra & & & Intra & & & Intra & Inter & Inter \\
\hline 1 & 3 & 3 & $\mathrm{C}$ & 3 & 3 & $\mathrm{C}$ & 3 & 3 & $\mathbf{C}$ & C & $\mathbf{C}$ \\
\hline 2 & 3 & 3 & $\mathrm{C}$ & 2 & 2 & $\mathrm{C}$ & 3 & 3 & $\mathrm{C}$ & D & D \\
\hline 3 & 3 & 3 & $\bar{C}$ & 3 & 3 & $\bar{C}$ & 3 & 3 & $\bar{C}$ & $\mathrm{C}$ & $\mathrm{C}$ \\
\hline 4 & 2 & 2 & $\mathrm{C}$ & 1 & 1 & $\mathrm{C}$ & 2 & 2 & $\mathrm{C}$ & D & D \\
\hline 5 & 3 & 2 & D & 3 & 2 & $\mathbf{D}$ & 3 & 2 & $\bar{D}$ & $\mathrm{C}$ & $\mathrm{C}$ \\
\hline 6 & 3 & 3 & $\mathrm{C}$ & 3 & 3 & $\mathrm{C}$ & 3 & 3 & $\mathrm{C}$ & $\mathrm{C}$ & $\mathrm{C}$ \\
\hline 7 & 3 & 3 & $\mathrm{C}$ & 3 & 2 & D & 3 & 2 & D & $\mathrm{C}$ & D \\
\hline 8 & 2 & 2 & $\bar{C}$ & 2 & 2 & $\bar{C}$ & 2 & 2 & $\bar{C}$ & $\mathrm{C}$ & $\mathrm{C}$ \\
\hline 9 & 3 & 3 & $\mathrm{C}$ & 3 & 3 & $\mathrm{C}$ & 3 & 3 & $\mathrm{C}$ & $\mathrm{C}$ & $\mathrm{C}$ \\
\hline 10 & 2 & 2 & $\mathrm{C}$ & 2 & 2 & $\mathbf{C}$ & 2 & 2 & $\mathbf{C}$ & $\mathrm{C}$ & $\mathrm{C}$ \\
\hline Percentual & & & $90 \%$ & & & $80 \%$ & & & $80 \%$ & $80 \%$ & $70 \%$ \\
\hline
\end{tabular}


ANEXO XII - $\underline{\text { Concordância intra e inter avaliadores no critério } 6}$

\begin{tabular}{|c|c|c|c|c|c|c|c|c|c|c|c|}
\hline Critério 6 & $\mathbf{A} \mathbf{V}_{-}$ & & Conc. & $\mathbf{A V _ { - }}$ & & Conc. & $\mathbf{A \mathbf { V } _ { - }}$ & & Conc. & Conc. & Conc. \\
\hline & $\mathbf{1}^{\mathrm{a}}$ & $2^{a}$ & & $\mathbf{1}^{\mathrm{a}}$ & $2^{\mathrm{a}}$ & & $1^{a}$ & $2^{\mathrm{a}}$ & & $\mathbf{1}^{\mathrm{a}}$ & $2^{\mathbf{a}}$ \\
\hline Participante & & & Intra & & & Intra & & & Intra & Inter & Inter \\
\hline 1 & 3 & 3 & C & 3 & 3 & $\mathrm{C}$ & 3 & 3 & $\mathbf{C}$ & $\mathbf{C}$ & C \\
\hline 2 & 2 & 2 & $\bar{C}$ & 2 & 2 & $\bar{C}$ & 2 & 2 & $\bar{C}$ & $\mathrm{C}$ & $\mathrm{C}$ \\
\hline 3 & 3 & 3 & $\mathrm{C}$ & 3 & 3 & $\mathrm{C}$ & 3 & 3 & $\mathrm{C}$ & $\mathrm{C}$ & $\mathrm{C}$ \\
\hline 4 & 1 & 1 & $\bar{C}$ & 1 & 1 & $\bar{C}$ & 1 & 1 & $\bar{C}$ & $\mathrm{C}$ & $\mathrm{C}$ \\
\hline 5 & 2 & 1 & $\bar{D}$ & 2 & 1 & $\bar{D}$ & 2 & 1 & $\bar{D}$ & $\mathrm{C}$ & $\mathrm{C}$ \\
\hline 6 & 2 & 2 & $\mathrm{C}$ & 1 & 1 & $\mathrm{C}$ & 2 & 2 & $\mathrm{C}$ & D & D \\
\hline 7 & 1 & 2 & D & 1 & 2 & D & 1 & 2 & D & $\mathrm{C}$ & $\mathrm{C}$ \\
\hline 8 & 1 & 1 & $\mathrm{C}$ & 1 & 1 & $\mathrm{C}$ & 1 & 1 & $\mathrm{C}$ & $\mathrm{C}$ & $\mathrm{C}$ \\
\hline 9 & 2 & 2 & $\mathrm{C}$ & 2 & 2 & $\mathrm{C}$ & 2 & 2 & $\mathrm{C}$ & $\mathrm{C}$ & $\mathrm{C}$ \\
\hline 10 & 1 & 1 & $\mathbf{C}$ & 1 & 1 & $\mathbf{C}$ & 1 & 1 & $\mathbf{C}$ & C & $\mathrm{C}$ \\
\hline Percentual & & & $80 \%$ & & & $80 \%$ & & & $80 \%$ & $90 \%$ & $90 \%$ \\
\hline
\end{tabular}


ANEXO XIII - Concordância intra e inter avaliadores no critério 7

\begin{tabular}{|c|c|c|c|c|c|c|c|c|c|c|c|}
\hline Critério 7 & $\mathbf{A V _ { - }}$ & & Conc. & $\mathbf{A V _ { - }}$ & & Conc. & $\mathbf{A V _ { - }}$ & & Conc. & Conc. & Conc. \\
\hline & $1^{a}$ & $2^{\mathrm{a}}$ & & $1^{a}$ & $2^{a}$ & & $\overline{1^{\mathrm{a}}}$ & $2^{\mathrm{a}}$ & & $\mathbf{1}^{\mathbf{a}}$ & $2^{a}$ \\
\hline Participante & & & Intra & & & Intra & & & Intra & Inter & Inter \\
\hline 1 & 3 & 3 & $\mathbf{C}$ & 3 & 3 & $\mathrm{C}$ & 3 & 3 & $\mathbf{C}$ & C & $\mathbf{C}$ \\
\hline 2 & 1 & 1 & $\mathrm{C}$ & 1 & 1 & $\mathrm{C}$ & 1 & 1 & $\mathrm{C}$ & $\mathrm{C}$ & $\mathrm{C}$ \\
\hline 3 & 3 & 3 & $\mathrm{C}$ & 3 & 3 & $\bar{C}$ & 3 & 3 & $\mathrm{C}$ & $\mathrm{C}$ & $\mathrm{C}$ \\
\hline 4 & 2 & 2 & $\mathrm{C}$ & 2 & 2 & $\mathrm{C}$ & 2 & 2 & $\mathrm{C}$ & $\mathrm{C}$ & $\mathrm{C}$ \\
\hline 5 & 1 & 1 & $\mathrm{C}$ & 1 & 1 & $\mathrm{C}$ & 1 & 1 & $\mathrm{C}$ & $\mathrm{C}$ & $\mathrm{C}$ \\
\hline 6 & 1 & 1 & $\bar{C}$ & 1 & 1 & $\mathrm{C}$ & 1 & $\overline{1}$ & $\bar{C}$ & $\mathrm{C}$ & $\mathrm{C}$ \\
\hline 7 & 1 & 1 & $\mathrm{C}$ & 2 & 1 & $\mathrm{C}$ & 1 & 1 & $\mathrm{C}$ & D & $\mathrm{C}$ \\
\hline 8 & 1 & 1 & $\mathrm{C}$ & 1 & 1 & $\mathrm{C}$ & 1 & 1 & $\mathrm{C}$ & $\mathrm{C}$ & C \\
\hline 9 & 2 & 2 & $\mathbf{C}$ & 2 & 2 & $\mathrm{C}$ & 2 & 2 & $\mathrm{C}$ & $\mathrm{C}$ & $\mathrm{C}$ \\
\hline 10 & 1 & 1 & $\mathbf{C}$ & 1 & 1 & $\mathbf{C}$ & 1 & 1 & $\mathbf{C}$ & $\mathrm{C}$ & C \\
\hline Percentual & & & $100 \%$ & & & $100 \%$ & & & $100 \%$ & $90 \%$ & $100 \%$ \\
\hline
\end{tabular}


ANEXO XIV - Concordância intra e inter avaliadores no critério 8

\begin{tabular}{|c|c|c|c|c|c|c|c|c|c|c|c|}
\hline Critério 8 & $\mathbf{A \mathbf { V } _ { - }}$ & & Conc. & $\mathbf{A \mathbf { V } _ { - }}$ & & Conc. & $\mathbf{A \mathbf { V } _ { - }}$ & & Conc. & Conc. & Conc. \\
\hline & $\mathbf{1}^{\mathrm{a}}$ & $2^{a}$ & & $1^{a}$ & $2^{\mathrm{a}}$ & & $1^{\mathrm{a}}$ & $2^{\mathrm{a}}$ & & $1^{a}$ & $2^{\mathrm{a}}$ \\
\hline Participante & & & Intra & & & Intra & & & Intra & Inter & Inter \\
\hline 1 & 2 & 2 & $\mathrm{C}$ & 3 & 3 & $\mathrm{C}$ & 3 & 3 & $\mathbf{C}$ & D & D \\
\hline 2 & 2 & 2 & $\bar{C}$ & 2 & 2 & $\bar{C}$ & 2 & 2 & $\bar{C}$ & $\mathrm{C}$ & $\mathrm{C}$ \\
\hline 3 & 2 & 2 & $\mathrm{C}$ & 2 & 2 & $\mathrm{C}$ & 2 & 2 & $\bar{C}$ & $\mathrm{C}$ & $\mathrm{C}$ \\
\hline 4 & 2 & 2 & $\mathbf{C}$ & 2 & 2 & $\mathrm{C}$ & 2 & 2 & $\mathrm{C}$ & $\mathrm{C}$ & $\mathrm{C}$ \\
\hline 5 & 2 & 2 & $\bar{C}$ & 2 & 2 & $\mathrm{C}$ & 2 & 2 & $\mathrm{C}$ & $\mathrm{C}$ & C \\
\hline 6 & 2 & 2 & $\mathrm{C}$ & 2 & 2 & $\mathrm{C}$ & 2 & 2 & $\mathrm{C}$ & $\mathrm{C}$ & $\mathrm{C}$ \\
\hline 7 & 2 & 2 & $\mathrm{C}$ & 2 & 2 & $\mathrm{C}$ & 2 & 2 & $\mathrm{C}$ & $\mathrm{C}$ & $\mathrm{C}$ \\
\hline 8 & 2 & 2 & $\mathrm{C}$ & 2 & 2 & $\mathrm{C}$ & 2 & 2 & $\mathrm{C}$ & $\mathrm{C}$ & $\mathrm{C}$ \\
\hline 9 & 2 & 2 & $\mathrm{C}$ & 2 & 2 & $\mathrm{C}$ & 2 & 2 & C & $\mathrm{C}$ & $\mathrm{C}$ \\
\hline 10 & 2 & 2 & $\mathrm{C}$ & 2 & 2 & $\mathbf{C}$ & 2 & 2 & $\mathbf{C}$ & $\mathrm{C}$ & $\mathrm{C}$ \\
\hline Percentual & & & $100 \%$ & & & $100 \%$ & & & $100 \%$ & $90 \%$ & $90 \%$ \\
\hline
\end{tabular}


ANEXO XV - Concordância intra e inter avaliadores no critério 9

\begin{tabular}{|c|c|c|c|c|c|c|c|c|c|c|c|}
\hline Critério 9 & $\mathbf{A V _ { - } 1}$ & & Conc. & $\mathbf{A V _ { - }}$ & & \begin{tabular}{|l|} 
Conc. \\
\end{tabular} & $\mathbf{A \mathbf { V } _ { - }}$ & & Conc. & Conc. & Conc. \\
\hline & $\mathbf{1}^{\mathrm{a}}$ & $2^{a}$ & & $\mathbf{1}^{\mathrm{a}}$ & $2^{a}$ & & $1^{\mathrm{a}}$ & $2^{\mathrm{a}}$ & & $\mathbf{1}^{\mathbf{a}}$ & $2^{\mathrm{a}}$ \\
\hline Participante & & & Intra & & & Intra & & & Intra & Inter & Inter \\
\hline 1 & 3 & 3 & $\mathrm{C}$ & 3 & 3 & $\mathrm{C}$ & 3 & 3 & $\mathbf{C}$ & C & $\mathrm{C}$ \\
\hline 2 & 3 & 3 & $\mathrm{C}$ & 3 & 3 & $\bar{C}$ & 3 & 3 & $\mathrm{C}$ & $\mathrm{C}$ & $\mathrm{C}$ \\
\hline 3 & 3 & 3 & $\bar{C}$ & 3 & 3 & $\mathrm{C}$ & 3 & 3 & $\bar{C}$ & $\mathrm{C}$ & $\mathrm{C}$ \\
\hline 4 & 2 & 2 & $\mathrm{C}$ & 1 & 1 & $\mathrm{C}$ & 2 & 2 & $\mathrm{C}$ & D & D \\
\hline 5 & 3 & 3 & $\bar{C}$ & 2 & 2 & $\bar{C}$ & 2 & 2 & $\bar{C}$ & D & D \\
\hline 6 & 1 & 2 & D & 1 & 2 & D & 1 & 2 & D & $\mathrm{C}$ & $\mathrm{C}$ \\
\hline 7 & 3 & 2 & D & 3 & 2 & $\mathbf{D}$ & 3 & 2 & $\mathbf{D}$ & $\mathrm{C}$ & $\mathrm{C}$ \\
\hline 8 & 3 & 3 & $\bar{C}$ & 3 & 3 & $\bar{C}$ & 3 & 3 & $\mathrm{C}$ & $\mathrm{C}$ & $\mathrm{C}$ \\
\hline 9 & 1 & 1 & $\mathrm{C}$ & 1 & 1 & $\mathrm{C}$ & 1 & 1 & $\mathrm{C}$ & $\mathrm{C}$ & C \\
\hline 10 & 1 & 1 & $\mathrm{C}$ & 1 & 1 & $\mathbf{C}$ & 1 & 1 & $\mathbf{C}$ & $\mathrm{C}$ & $\mathrm{C}$ \\
\hline Percentual & & & $80 \%$ & & & $80 \%$ & & & $80 \%$ & $80 \%$ & $80 \%$ \\
\hline
\end{tabular}


ANEXO XVI - Concordância intra e inter avaliadores no critério 10

\begin{tabular}{|c|c|c|c|c|c|c|c|c|c|c|c|}
\hline Critério 10 & $\mathbf{A \mathbf { V } _ { - }}$ & & Conc. & $\mathbf{A V _ { - }}$ & & Conc. & $\mathbf{A \mathbf { V } _ { - }}$ & & Conc. & Conc. & Conc. \\
\hline & $\mathbf{1}^{\mathrm{a}}$ & $2^{a}$ & & $\mathbf{1}^{\mathrm{a}}$ & $2^{a}$ & & $1^{\mathrm{a}}$ & $\mathbf{2}^{\mathrm{a}}$ & & $1^{a}$ & $2^{\mathrm{a}}$ \\
\hline Participante & & & Intra & & & Intra & & & Intra & Inter & Inter \\
\hline 1 & 2 & 2 & $\mathrm{C}$ & 2 & 2 & $\mathrm{C}$ & 2 & 2 & $\mathbf{C}$ & $\mathrm{C}$ & $\mathrm{C}$ \\
\hline 2 & 2 & 2 & $\mathrm{C}$ & 2 & 2 & $\bar{C}$ & 2 & 2 & $\mathrm{C}$ & $\mathrm{C}$ & $\mathrm{C}$ \\
\hline 3 & 2 & 2 & $\mathrm{C}$ & 2 & 2 & $\mathrm{C}$ & 2 & 2 & $\bar{C}$ & $\mathrm{C}$ & $\mathrm{C}$ \\
\hline 4 & 2 & 2 & $\mathrm{C}$ & 2 & 1 & D & 2 & 1 & D & $\mathrm{C}$ & D \\
\hline 5 & 1 & 1 & $\mathrm{C}$ & 1 & 1 & $\bar{C}$ & 2 & 1 & D & D & $\mathrm{C}$ \\
\hline 6 & 1 & 1 & C & 1 & 1 & C & 1 & 1 & C & $\mathrm{C}$ & $\mathrm{C}$ \\
\hline 7 & 2 & 2 & $\mathrm{C}$ & 2 & 1 & D & 2 & 2 & $\mathrm{C}$ & $\mathrm{C}$ & D \\
\hline 8 & 1 & 1 & $\bar{C}$ & 1 & 1 & $\mathrm{C}$ & 2 & 2 & $\mathrm{C}$ & D & D \\
\hline 9 & 2 & 2 & $\bar{C}$ & 2 & 2 & $\mathrm{C}$ & 2 & 2 & $\mathrm{C}$ & $\mathrm{C}$ & C \\
\hline 10 & 1 & 1 & $\mathbf{C}$ & 1 & 1 & $\mathrm{C}$ & 1 & 1 & $\mathbf{C}$ & $\mathrm{C}$ & $\mathrm{C}$ \\
\hline Percentual & & & $100 \%$ & & & $80 \%$ & & & $80 \%$ & $80 \%$ & $70 \%$ \\
\hline
\end{tabular}


ANEXO XVII - Concordância intra e inter avaliadores no critério 11

\begin{tabular}{|c|c|c|c|c|c|c|c|c|c|c|c|}
\hline \multirow{2}{*}{ Critério 11} & \multicolumn{2}{|c|}{ AV_1 } & \multirow{3}{*}{$\begin{array}{l}\text { Conc. } \\
\text { Intra }\end{array}$} & \multicolumn{2}{|c|}{$\mathbf{A V \_ 2}$} & \multirow{3}{*}{\begin{tabular}{|l|} 
Conc. \\
Intra
\end{tabular}} & \multicolumn{2}{|c|}{$A V \_3$} & \multirow{3}{*}{\begin{tabular}{|l} 
Conc. \\
Intra \\
\end{tabular}} & \multirow{3}{*}{$\begin{array}{c}\text { Conc. } \\
1^{\mathbf{a}} \\
\text { Inter }\end{array}$} & \multirow{3}{*}{$\frac{\text { Conc. }}{\frac{2^{\mathrm{a}}}{\text { Inter }}}$} \\
\hline & \multirow{2}{*}{$1^{a}$} & \multirow[t]{2}{*}{$2^{a}$} & & \multirow[t]{2}{*}{$\mathbf{1}^{\mathrm{a}}$} & \multirow[t]{2}{*}{$2^{a}$} & & \multirow{2}{*}{$1^{\mathrm{a}}$} & \multirow[t]{2}{*}{$2^{\mathrm{a}}$} & & & \\
\hline Participante & & & & & & & & & & & \\
\hline 1 & 3 & 3 & $\mathbf{C}$ & 3 & 3 & $\mathrm{C}$ & 3 & 3 & $\mathbf{C}$ & $\mathrm{C}$ & C \\
\hline 2 & 3 & 3 & $\bar{C}$ & 3 & 3 & $\bar{C}$ & 3 & 3 & $\bar{C}$ & $\mathrm{C}$ & $\mathrm{C}$ \\
\hline 3 & 3 & 3 & $\mathrm{C}$ & 2 & 3 & $\bar{D}$ & 3 & 3 & $\mathbf{C}$ & D & $\mathrm{C}$ \\
\hline 4 & 2 & 2 & $\mathrm{C}$ & 2 & 2 & $\mathbf{C}$ & 2 & 2 & $\mathrm{C}$ & $\mathrm{C}$ & $\mathrm{C}$ \\
\hline 5 & 3 & 3 & $\bar{C}$ & 2 & 2 & $\bar{C}$ & 2 & 2 & $\bar{C}$ & D & D \\
\hline 6 & 2 & 2 & $\mathrm{C}$ & 2 & 2 & $\mathbf{C}$ & 2 & 2 & $\mathbf{C}$ & $\mathrm{C}$ & $\mathrm{C}$ \\
\hline 7 & 3 & 2 & $\mathbf{D}$ & 3 & 2 & $\mathbf{D}$ & 2 & 2 & $\mathbf{C}$ & D & $\mathrm{C}$ \\
\hline 8 & 2 & 2 & $\mathrm{C}$ & 2 & 2 & $\mathbf{C}$ & 3 & 2 & D & D & $\mathrm{C}$ \\
\hline 9 & 2 & 2 & $\mathrm{C}$ & 2 & 2 & $\bar{C}$ & 2 & 2 & $\mathrm{C}$ & $\mathrm{C}$ & $\mathrm{C}$ \\
\hline 10 & 2 & 2 & $\mathbf{C}$ & 2 & 2 & $\mathbf{C}$ & 2 & 2 & $\mathbf{C}$ & $\mathrm{C}$ & $\mathrm{C}$ \\
\hline Percentual & & & $90 \%$ & & & $80 \%$ & & & $90 \%$ & $60 \%$ & $90 \%$ \\
\hline
\end{tabular}


ANEXO XVIII - Concordância intra e inter avaliadores no critério 12

\begin{tabular}{|c|c|c|c|c|c|c|c|c|c|c|c|}
\hline \multirow{2}{*}{ Critério 12} & \multicolumn{2}{|c|}{$\overline{A V} \_1$} & \multirow{3}{*}{$\begin{array}{l}\text { Conc. } \\
\text { Intra }\end{array}$} & \multicolumn{2}{|c|}{$\mathbf{A V} \_2$} & \multirow{3}{*}{\begin{tabular}{|l|} 
Conc. \\
Intra
\end{tabular}} & \multicolumn{2}{|c|}{ AV_3 } & \multirow{3}{*}{\begin{tabular}{|l|} 
Conc. \\
Intra \\
\end{tabular}} & \multirow{3}{*}{$\begin{array}{c}\text { Conc. } \\
\frac{1^{\mathrm{a}}}{\text { Inter }}\end{array}$} & \multirow{3}{*}{$\frac{\text { Conc. }}{\mathbf{2}^{\mathrm{a}}}$} \\
\hline & \multirow{2}{*}{$\mathbf{1}^{\mathrm{a}}$} & \multirow[t]{2}{*}{$2^{\mathrm{a}}$} & & \multirow[t]{2}{*}{$\mathbf{1}^{\mathrm{a}}$} & \multirow[t]{2}{*}{$2^{\mathrm{a}}$} & & \multirow{2}{*}{$1^{\mathrm{a}}$} & \multirow[t]{2}{*}{$2^{a}$} & & & \\
\hline Participante & & & & & & & & & & & \\
\hline 1 & 3 & 3 & $\mathbf{C}$ & 3 & 3 & C & 3 & 3 & $\mathbf{C}$ & $\mathrm{C}$ & C \\
\hline 2 & 1 & 1 & $\bar{C}$ & 1 & 1 & $\bar{C}$ & 1 & 1 & $\bar{C}$ & $\mathrm{C}$ & $\mathrm{C}$ \\
\hline 3 & 3 & 3 & $\mathrm{C}$ & 3 & 3 & $\mathbf{C}$ & 3 & 3 & $\mathbf{C}$ & $\mathrm{C}$ & $\mathrm{C}$ \\
\hline 4 & 1 & 1 & $\mathrm{C}$ & 1 & 1 & $\mathbf{C}$ & 1 & 1 & $\bar{C}$ & $\mathrm{C}$ & $\mathrm{C}$ \\
\hline 5 & 3 & 3 & $\bar{C}$ & 3 & 3 & $\bar{C}$ & 3 & 3 & $\bar{C}$ & $\mathrm{C}$ & $\mathrm{C}$ \\
\hline 6 & 2 & 2 & $\mathrm{C}$ & 1 & 2 & $\mathbf{D}$ & 2 & 2 & $\mathbf{C}$ & D & $\mathrm{C}$ \\
\hline 7 & 3 & 2 & D & 3 & 2 & D & 3 & 2 & D & $\mathrm{C}$ & $\mathrm{C}$ \\
\hline 8 & 2 & 2 & $\mathrm{C}$ & 2 & 3 & $\mathbf{D}$ & 2 & 3 & $\mathbf{D}$ & C & D \\
\hline 9 & 1 & 1 & $\mathrm{C}$ & 1 & 1 & $\mathbf{C}$ & 1 & 1 & $\mathrm{C}$ & $\mathrm{C}$ & $\mathrm{C}$ \\
\hline 10 & 2 & 1 & D & 1 & 1 & $\mathbf{C}$ & 1 & 1 & $\mathbf{C}$ & D & $\mathrm{C}$ \\
\hline Percentual & & & $80 \%$ & & & 70\% & & & $80 \%$ & $80 \%$ & $90 \%$ \\
\hline
\end{tabular}


ANEXO XIX - Concordância intra e inter avaliadores no critério 13

\begin{tabular}{|c|c|c|c|c|c|c|c|c|c|c|c|}
\hline Critério 13 & $\mathbf{A \mathbf { V } _ { - }}$ & & Conc. & $\mathbf{A \mathbf { V } _ { - }}$ & & Conc. & $\mathbf{A V _ { - }}$ & & Conc. & Conc. & Conc \\
\hline & $1^{a}$ & $2^{a}$ & & $1^{\mathrm{a}}$ & $2^{\mathrm{a}}$ & & $\mathbf{1}^{\mathrm{a}}$ & $2^{a}$ & & $\mathbf{1}^{\mathrm{a}}$ & $2^{\mathrm{a}}$ \\
\hline Participante & & & Intra & & & Intra & & & Intra & Inter & Inter \\
\hline 1 & 3 & 3 & $\mathrm{C}$ & 3 & $\overline{2}$ & D & 3 & 3 & $\mathrm{C}$ & $\mathrm{C}$ & D \\
\hline 2 & 1 & 1 & $\mathrm{C}$ & 1 & 1 & $\mathrm{C}$ & 1 & 1 & $\mathrm{C}$ & $\mathrm{C}$ & $\mathrm{C}$ \\
\hline 3 & 3 & 3 & $\mathrm{C}$ & 2 & 2 & $\bar{C}$ & 3 & 3 & $\bar{C}$ & D & D \\
\hline 4 & 1 & 1 & $\mathrm{C}$ & 1 & 1 & $\mathrm{C}$ & 1 & 1 & $\mathrm{C}$ & $\mathrm{C}$ & $\mathrm{C}$ \\
\hline 5 & 1 & 2 & $\overline{\mathbf{D}}$ & 1 & 1 & $\bar{C}$ & 1 & 1 & $\bar{C}$ & $\mathrm{C}$ & D \\
\hline 6 & 1 & 1 & $\mathrm{C}$ & 1 & 1 & $\mathrm{C}$ & 1 & 1 & $\mathrm{C}$ & $\mathrm{C}$ & $\mathrm{C}$ \\
\hline 7 & 1 & 1 & $\mathbf{C}$ & 2 & 1 & D & 1 & 1 & $\mathbf{C}$ & D & $\mathrm{C}$ \\
\hline 8 & 2 & 2 & $\mathrm{C}$ & 1 & 1 & $\bar{C}$ & 1 & 1 & $\mathrm{C}$ & D & D \\
\hline 9 & 1 & 1 & $\mathrm{C}$ & 1 & 1 & $\mathrm{C}$ & 1 & 1 & $\mathrm{C}$ & $\mathrm{C}$ & $\mathrm{C}$ \\
\hline 10 & 1 & 1 & $\mathbf{C}$ & 1 & 1 & $\mathbf{C}$ & 1 & 1 & $\mathbf{C}$ & $\mathrm{C}$ & $\mathrm{C}$ \\
\hline Percentual & & & $90 \%$ & & & $80 \%$ & & & $100 \%$ & $70 \%$ & $60 \%$ \\
\hline
\end{tabular}


ANEXO XX - Concordância intra e inter avaliadores no critério 14

\begin{tabular}{|c|c|c|c|c|c|c|c|c|c|c|c|}
\hline Critério 14 & $\overline{\mathbf{A V} \mathbf{V}_{-}}$ & & Conc. & $\overline{\mathbf{A V}}$ & & Conc. & AV_3 & & Conc. & Conc. & Conc. \\
\hline & $\mathbf{1}^{\mathrm{a}}$ & $2^{a}$ & & $\mathbf{1}^{\mathrm{a}}$ & $2^{\mathrm{a}}$ & & $1^{\mathrm{a}}$ & $2^{\mathrm{a}}$ & & $1^{\mathrm{a}}$ & $\mathbf{2}^{\mathbf{a}}$ \\
\hline Participante & & & Intra & & & Intra & & & Intra & Inter & Inter \\
\hline 1 & 2 & 2 & $\mathrm{C}$ & 2 & 2 & $\mathbf{C}$ & 2 & 2 & $\mathbf{C}$ & C & C \\
\hline 2 & 2 & 2 & $\bar{C}$ & 2 & 2 & $\bar{C}$ & 2 & 2 & $\bar{C}$ & $\mathrm{C}$ & $\mathrm{C}$ \\
\hline 3 & 2 & 2 & $\mathrm{C}$ & 2 & 2 & $\mathrm{C}$ & 2 & 2 & $\mathrm{C}$ & $\mathrm{C}$ & $\mathrm{C}$ \\
\hline 4 & 2 & 2 & $\mathrm{C}$ & 2 & 2 & $\mathrm{C}$ & 2 & 2 & $\mathrm{C}$ & $\mathrm{C}$ & $\mathrm{C}$ \\
\hline 5 & 2 & 2 & $\bar{C}$ & 2 & 2 & $\bar{C}$ & 2 & 2 & $\bar{C}$ & $\mathrm{C}$ & $\mathrm{C}$ \\
\hline 6 & 2 & 2 & $\mathrm{C}$ & 2 & 2 & $\mathrm{C}$ & 2 & 2 & $\mathrm{C}$ & $\mathrm{C}$ & $\mathrm{C}$ \\
\hline 7 & 2 & 2 & $\mathrm{C}$ & 2 & 2 & $\mathrm{C}$ & 2 & 2 & $\mathrm{C}$ & $\mathrm{C}$ & $\mathrm{C}$ \\
\hline 8 & 2 & 2 & $\mathrm{C}$ & 2 & 2 & $\mathrm{C}$ & 2 & 2 & $\mathrm{C}$ & $\mathrm{C}$ & C \\
\hline 9 & 2 & 2 & $\mathrm{C}$ & 2 & 2 & $\mathrm{C}$ & 2 & 2 & $\mathrm{C}$ & $\mathrm{C}$ & $\mathrm{C}$ \\
\hline 10 & 2 & 2 & $\mathbf{C}$ & 2 & 2 & $\mathbf{C}$ & 2 & 2 & $\mathbf{C}$ & C & $\mathrm{C}$ \\
\hline Percentual & & & $100 \%$ & & & $100 \%$ & & & $100 \%$ & $100 \%$ & $100 \%$ \\
\hline
\end{tabular}


ANEXO XXI - Concordância intra e inter avaliadores no critério 15

\begin{tabular}{|c|c|c|c|c|c|c|c|c|c|c|c|}
\hline Critério 15 & $\mathbf{A} \mathbf{V}_{-}$ & & Conc. & $\mathbf{A \mathbf { V } _ { - }}$ & & Conc. & $\mathbf{A \mathbf { V } _ { - }}$ & & Conc. & Conc. & Conc. \\
\hline & $\mathbf{1}^{\mathrm{a}}$ & $2^{a}$ & & $1^{a}$ & $2^{a}$ & & $1^{a}$ & $2^{\mathrm{a}}$ & & $\mathbf{1}^{\mathrm{a}}$ & $2^{\mathrm{a}}$ \\
\hline Participante & & & Intra & & & Intra & & & Intra & Inter & Inter \\
\hline 1 & 2 & 3 & D & 2 & 2 & $\mathbf{C}$ & 2 & 2 & $\mathbf{C}$ & $\mathbf{C}$ & D \\
\hline 2 & 2 & 2 & $\mathrm{C}$ & 2 & 1 & D & 2 & 1 & D & $\mathrm{C}$ & D \\
\hline 3 & 3 & 3 & $\bar{C}$ & 3 & 3 & $\bar{C}$ & 3 & 3 & $\bar{C}$ & $\mathrm{C}$ & $\mathrm{C}$ \\
\hline 4 & 1 & 1 & $\mathrm{C}$ & 1 & 1 & $\mathrm{C}$ & 1 & 1 & $\mathrm{C}$ & $\mathrm{C}$ & $\mathrm{C}$ \\
\hline 5 & 3 & 3 & $\mathrm{C}$ & 2 & 3 & D & 3 & 3 & $\mathrm{C}$ & $\mathrm{C}$ & $\mathrm{C}$ \\
\hline 6 & 1 & 2 & D & 1 & 2 & D & 1 & 2 & D & $\mathrm{C}$ & $\mathrm{C}$ \\
\hline 7 & 3 & 2 & D & 3 & 2 & D & 3 & 2 & D & $\mathrm{C}$ & $\mathrm{C}$ \\
\hline 8 & 3 & 3 & $\bar{C}$ & 3 & 2 & D & 3 & 2 & $\bar{D}$ & $\mathrm{C}$ & D \\
\hline 9 & 1 & 1 & $\mathrm{C}$ & 1 & 1 & $\mathrm{C}$ & 1 & 1 & $\mathrm{C}$ & $\mathrm{C}$ & C \\
\hline 10 & 2 & 2 & $\bar{C}$ & 2 & 2 & $\bar{C}$ & 2 & 2 & $\bar{C}$ & $\mathrm{C}$ & $\mathrm{C}$ \\
\hline Percentual & & & $70 \%$ & & & $50 \%$ & & & $40 \%$ & $100 \%$ & $70 \%$ \\
\hline
\end{tabular}


ANEXO XXII - Boneca articulada para demonstração de figuras do nado sincronizado

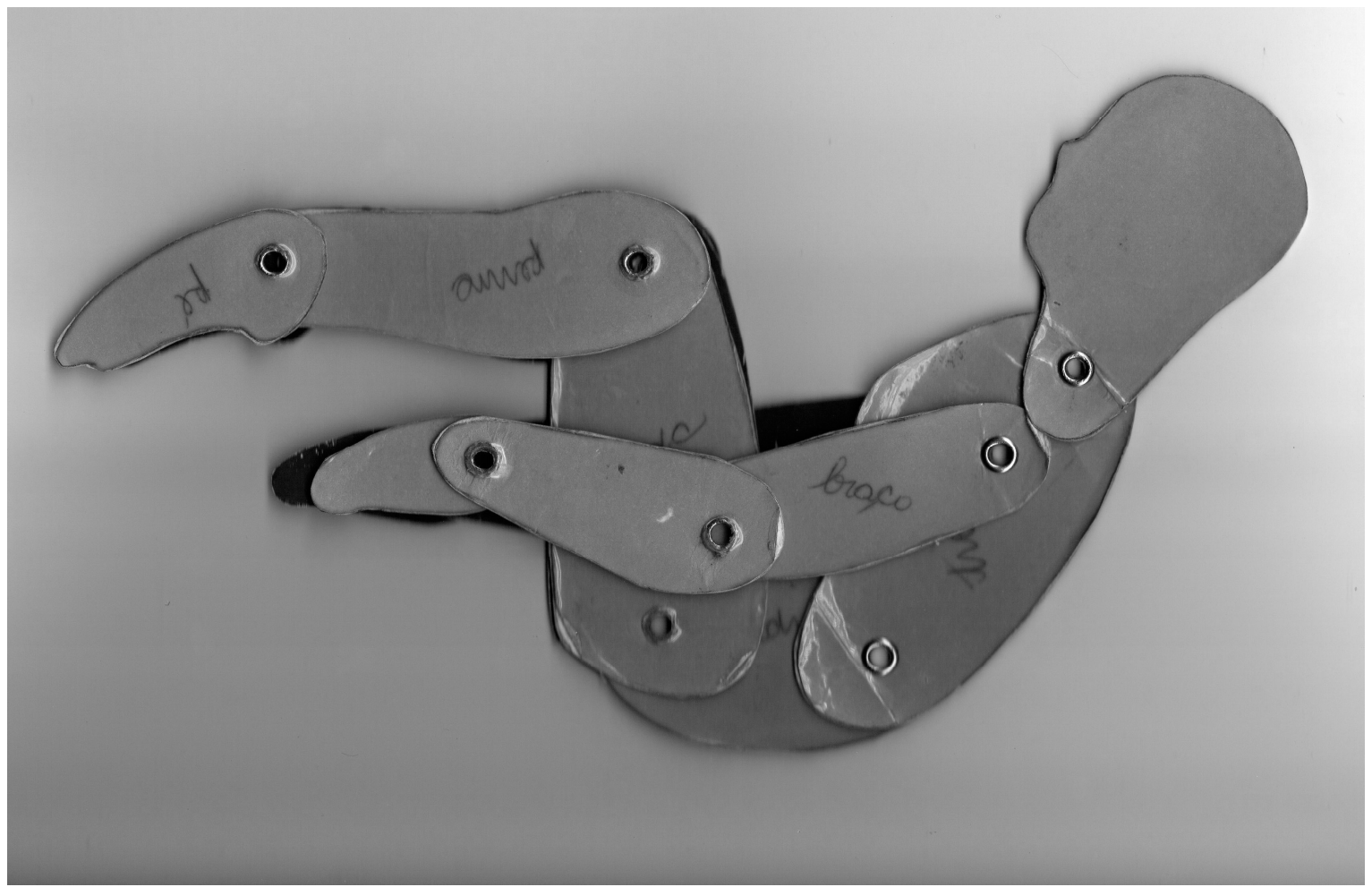




\section{ANEXO XXIII - Dados das participantes do GB e GH}

\begin{tabular}{|l|c|c|c|c|c|c|c|c|c|c|c|c|}
\hline grupos & PI_pre & TI_pre & PT_pre & TF_pre & PF_pre & DG_pre & PI_pos & TT_pos & PT_pos & TF_pos & PF_pos & DG_pos \\
\hline GB & 55,56 & 44,44 & 55,56 & 66,67 & 44,44 & 53,33 & 44,44 & 66,67 & 61,11 & 66,67 & 55,56 & 60,00 \\
\hline GB & 0,00 & 0,00 & 55,56 & 55,56 & 44,44 & 31,11 & 66,67 & 61,11 & 55,56 & 72,22 & 66,67 & 64,44 \\
\hline GB & 0,00 & 0,00 & 0,00 & 0,00 & 0,00 & 0,00 & 83,33 & 77,78 & 77,78 & 88,89 & 77,78 & 80,00 \\
\hline GB & 44,44 & 44,44 & 66,67 & 55,56 & 44,44 & 51,11 & 72,22 & 50,00 & 66,67 & 77,78 & 66,67 & 67,78 \\
\hline GB & 0,00 & 44,44 & 44,44 & 33,33 & 22,22 & 30,00 & 55,56 & 77,78 & 61,11 & 66,67 & 50,00 & 62,22 \\
\hline GB & 44,44 & 44,44 & 33,33 & 33,33 & 0,00 & 31,11 & 55,56 & 44,44 & 44,44 & 38,89 & 44,44 & 46,67 \\
\hline GB & 44,44 & 44,44 & 44,44 & 44,44 & 0,00 & 35,56 & 72,22 & 88,89 & 88,89 & 77,78 & 66,67 & 78,89 \\
\hline GB & 44,44 & 55,56 & 44,44 & 55,56 & 44,44 & 48,89 & 66,67 & 77,78 & 77,78 & 88,89 & 83,33 & 76,67 \\
\hline GB & 50,00 & 55,56 & 55,56 & 44,44 & 44,44 & 51,11 & 44,44 & 77,78 & 61,11 & 66,67 & 50,00 & 60,00 \\
\hline GB & 44,44 & 44,44 & 44,44 & 50,00 & 55,56 & 51,11 & 66,67 & 61,11 & 55,56 & 77,78 & 61,11 & 65,56 \\
\hline GH & 0,00 & 0,00 & 0,00 & 0,00 & 0,00 & 0,00 & 88,89 & 88,89 & 100,00 & 88,89 & 88,89 & 91,11 \\
\hline GH & 66,67 & 77,78 & 66,67 & 77,78 & 66,67 & 72,22 & 61,11 & 88,89 & 66,67 & 88,89 & 66,67 & 75,56 \\
\hline GH & 61,11 & 33,33 & 55,56 & 44,44 & 44,44 & 51,11 & 61,11 & 88,89 & 66,67 & 88,89 & 66,67 & 75,56 \\
\hline GH & 44,44 & 44,44 & 44,44 & 44,44 & 50,00 & 48,89 & 50,00 & 72,22 & 83,33 & 66,67 & 61,11 & 67,78 \\
\hline GH & 44,44 & 44,44 & 33,33 & 0,00 & 0,00 & 24,44 & 55,56 & 66,67 & 66,67 & 66,67 & 55,56 & 63,33 \\
\hline GH & 0,00 & 55,56 & 44,44 & 33,33 & 0,00 & 26,67 & 44,44 & 55,56 & 55,56 & 66,67 & 50,00 & 57,78 \\
\hline GH & 44,44 & 33,33 & 44,44 & 0,00 & 0,00 & 24,44 & 55,56 & 61,11 & 66,67 & 77,78 & 55,56 & 62,22 \\
\hline GH & 44,44 & 44,44 & 44,44 & 44,44 & 44,44 & 45,56 & 55,56 & 72,22 & 66,67 & 77,78 & 66,67 & 66,67 \\
\hline GH & 50,00 & 44,44 & 44,44 & 16,67 & 0,00 & 31,11 & 55,56 & 44,44 & 50,00 & 66,67 & 55,56 & 55,56 \\
\hline GH & 44,44 & 44,44 & 33,33 & 0,00 & 0,00 & 24,44 & 44,44 & 44,44 & 55,56 & 50,00 & 44,44 & 46,67 \\
\hline
\end{tabular}

\begin{tabular}{|c|c|c|c|c|c|c|c|c|c|c|c|}
\hline PI_re1 & TI_re1 & PT_re1 & TF_re1 & PF_re1 & DG_re1 & PI_re2 & TT_re2 & PT_re2 & TF_re2 & PF_re2 & DG_re2 \\
\hline 66,67 & 66,67 & 66,67 & 66,67 & 61,11 & 65,56 & 66,67 & 66,67 & 66,67 & 77,78 & 66,67 & 68,89 \\
\hline 44,44 & 61,11 & 66,67 & 55,56 & 44,44 & 55,56 & 44,44 & 66,67 & 66,67 & 66,67 & 44,44 & 55,56 \\
\hline 66,67 & 88,89 & 77,78 & 88,89 & 66,67 & 74,44 & 66,67 & 88,89 & 66,67 & 88,89 & 66,67 & 75,56 \\
\hline 55,56 & 66,67 & 61,11 & 66,67 & 55,56 & 62,22 & 77,78 & 72,22 & 88,89 & 88,89 & 77,78 & 83,33 \\
\hline 44,44 & 55,56 & 50,00 & 44,44 & 44,44 & 46,67 & 55,56 & 55,56 & 77,78 & 66,67 & 55,56 & 61,11 \\
\hline 83,33 & 66,67 & 94,44 & 100,00 & 77,78 & 84,44 & 55,56 & 55,56 & 55,56 & 44,44 & 44,44 & 50,00 \\
\hline 55,56 & 50,00 & 55,56 & 44,44 & 44,44 & 50,00 & 61,11 & 77,78 & 88,89 & 72,22 & 83,33 & 75,56 \\
\hline 55,56 & 72,22 & 55,56 & 72,22 & 55,56 & 61,11 & 83,33 & 88,89 & 100,00 & 83,33 & 88,89 & 86,67 \\
\hline 55,56 & 44,44 & 61,11 & 66,67 & 44,44 & 55,56 & 55,56 & 77,78 & 66,67 & 77,78 & 55,56 & 66,67 \\
\hline 66,67 & 61,11 & 72,22 & 77,78 & 72,22 & 70,00 & 66,67 & 66,67 & 66,67 & 77,78 & 66,67 & 68,89 \\
\hline 88,89 & 88,89 & 88,89 & 88,89 & 88,89 & 88,89 & 88,89 & 88,89 & 100,00 & 88,89 & 88,89 & 91,11 \\
\hline 44,44 & 44,44 & 44,44 & 44,44 & 44,44 & 44,44 & 66,67 & 88,89 & 66,67 & 72,22 & 66,67 & 71,11 \\
\hline 61,11 & 77,78 & 66,67 & 77,78 & 66,67 & 68,89 & 66,67 & 88,89 & 66,67 & 72,22 & 66,67 & 71,11 \\
\hline 61,11 & 66,67 & 72,22 & 77,78 & 66,67 & 65,56 & 50,00 & 55,56 & 61,11 & 61,11 & 66,67 & 56,67 \\
\hline 55,56 & 61,11 & 61,11 & 83,33 & 66,67 & 64,44 & 50,00 & 83,33 & 66,67 & 72,22 & 55,56 & 64,44 \\
\hline 44,44 & 55,56 & 55,56 & 61,11 & 55,56 & 54,44 & 44,44 & 61,11 & 55,56 & 55,56 & 55,56 & 53,33 \\
\hline 44,44 & 66,67 & 66,67 & 66,67 & 55,56 & 61,11 & 44,44 & 55,56 & 61,11 & 55,56 & 44,44 & 55,56 \\
\hline 55,56 & 77,78 & 66,67 & 88,89 & 72,22 & 72,22 & 55,56 & 77,78 & 72,22 & 77,78 & 61,11 & 72,22 \\
\hline 66,67 & 44,44 & 55,56 & 55,56 & 55,56 & 55,56 & 88,89 & 44,44 & 44,44 & 55,56 & 50,00 & 56,67 \\
\hline 55,56 & 66,67 & 66,67 & 55,56 & 55,56 & 58,89 & 55,56 & 44,44 & 55,56 & 55,56 & 55,56 & 51,11 \\
\hline
\end{tabular}




\section{ANEXO XXIV - Dados das participantes do GBH e GHB}

\begin{tabular}{|l|c|c|c|c|c|c|c|c|c|c|c|c|}
\hline grupos & PI_pre & TT_pre & PT_pre & TF_pre & PF_pre & DG_pre & PI_pos & TT_pos & PT_pos & TF_pos & PF_pos & DG_pos \\
\hline GBH & 55,56 & 33,33 & 44,44 & 33,33 & 22,22 & 36,67 & 66,67 & 66,67 & 66,67 & 66,67 & 66,67 & 66,67 \\
\hline GBH & 44,44 & 44,44 & 44,44 & 44,44 & 0,00 & 35,56 & 61,11 & 83,33 & 66,67 & 72,22 & 66,67 & 67,78 \\
\hline GBH & 44,44 & 44,44 & 33,33 & 33,33 & 0,00 & 31,11 & 66,67 & 77,78 & 66,67 & 83,33 & 66,67 & 72,22 \\
\hline GBH & 44,44 & 44,44 & 44,44 & 0,00 & 0,00 & 26,67 & 55,56 & 83,33 & 72,22 & 77,78 & 66,67 & 71,11 \\
\hline GBH & 0,00 & 0,00 & 0,00 & 0,00 & 0,00 & 0,00 & 66,67 & 88,89 & 66,67 & 77,78 & 66,67 & 73,33 \\
\hline GBH & 44,44 & 44,44 & 44,44 & 33,33 & 0,00 & 33,33 & 44,44 & 44,44 & 55,56 & 44,44 & 61,11 & 51,11 \\
\hline GBH & 44,44 & 55,56 & 55,56 & 33,33 & 0,00 & 35,56 & 55,56 & 55,56 & 55,56 & 55,56 & 55,56 & 55,56 \\
\hline GBH & 44,44 & 61,11 & 66,67 & 77,78 & 44,44 & 56,67 & 55,56 & 77,78 & 83,33 & 66,67 & 50,00 & 66,67 \\
\hline GBH & 44,44 & 44,44 & 44,44 & 77,78 & 55,56 & 56,67 & 77,78 & 77,78 & 66,67 & 88,89 & 72,22 & 75,56 \\
\hline GBH & 44,44 & 44,44 & 44,44 & 44,44 & 44,44 & 44,44 & 55,56 & 88,89 & 72,22 & 77,78 & 72,22 & 73,33 \\
\hline GHB & 0,00 & 0,00 & 0,00 & 0,00 & 0,00 & 0,00 & 66,67 & 55,56 & 66,67 & 77,78 & 72,22 & 67,78 \\
\hline GHB & 0,00 & 0,00 & 66,67 & 77,78 & 61,11 & 40,00 & 66,67 & 88,89 & 100,00 & 83,33 & 77,78 & 80,00 \\
\hline GHB & 44,44 & 33,33 & 33,33 & 33,33 & 44,44 & 37,78 & 66,67 & 88,89 & 66,67 & 88,89 & 66,67 & 75,56 \\
\hline GHB & 55,56 & 66,67 & 66,67 & 33,33 & 44,44 & 53,33 & 66,67 & 83,33 & 83,33 & 77,78 & 66,67 & 73,33 \\
\hline GHB & 66,67 & 44,44 & 44,44 & 66,67 & 55,56 & 55,56 & 77,78 & 77,78 & 83,33 & 88,89 & 72,22 & 78,89 \\
\hline GHB & 66,67 & 77,78 & 55,56 & 33,33 & 44,44 & 55,56 & 61,11 & 72,22 & 66,67 & 66,67 & 61,11 & 64,44 \\
\hline GHB & 44,44 & 44,44 & 50,00 & 44,44 & 44,44 & 44,44 & 55,56 & 83,33 & 72,22 & 72,22 & 66,67 & 68,89 \\
\hline GHB & 44,44 & 55,56 & 44,44 & 44,44 & 44,44 & 46,67 & 61,11 & 77,78 & 66,67 & 66,67 & 44,44 & 64,44 \\
\hline GHB & 44,44 & 44,44 & 33,33 & 33,33 & 33,33 & 37,78 & 44,44 & 55,56 & 66,67 & 66,67 & 55,56 & 57,78 \\
\hline GHB & 0,00 & 0,00 & 33,33 & 0,00 & 0,00 & 6,67 & 44,44 & 44,44 & 50,00 & 50,00 & 44,44 & 47,78 \\
\hline
\end{tabular}

\begin{tabular}{|c|c|c|c|c|c|c|c|c|c|c|c|}
\hline PI_re1 & TT_re1 & PT_re1 & TF_re1 & PF_re1 & DG_re1 & PI_re2 & TT_re2 & PT_re2 & TF_re2 & PF_re2 & DG_re2 \\
\hline 55,56 & 50,00 & 55,56 & 77,78 & 66,67 & 61,11 & 66,67 & 55,56 & 55,56 & 66,67 & 66,67 & 62,22 \\
\hline 44,44 & 38,89 & 50,00 & 55,56 & 50,00 & 47,78 & 44,44 & 55,56 & 50,00 & 50,00 & 44,44 & 47,78 \\
\hline 66,67 & 66,67 & 77,78 & 83,33 & 66,67 & 71,11 & 66,67 & 77,78 & 83,33 & 77,78 & 66,67 & 74,44 \\
\hline 55,56 & 77,78 & 61,11 & 83,33 & 55,56 & 64,44 & 66,67 & 77,78 & 66,67 & 77,78 & 66,67 & 72,22 \\
\hline 55,56 & 72,22 & 61,11 & 77,78 & 72,22 & 65,56 & 61,11 & 72,22 & 66,67 & 88,89 & 77,78 & 72,22 \\
\hline 44,44 & 55,56 & 66,67 & 61,11 & 55,56 & 55,56 & 55,56 & 66,67 & 66,67 & 50,00 & 55,56 & 56,67 \\
\hline 44,44 & 44,44 & 44,44 & 44,44 & 44,44 & 46,67 & 44,44 & 50,00 & 44,44 & 50,00 & 44,44 & 47,78 \\
\hline 66,67 & 44,44 & 77,78 & 77,78 & 66,67 & 63,33 & 66,67 & 77,78 & 94,44 & 77,78 & 66,67 & 75,56 \\
\hline 66,67 & 72,22 & 66,67 & 66,67 & 77,78 & 68,89 & 66,67 & 77,78 & 66,67 & 77,78 & 66,67 & 70,00 \\
\hline 61,11 & 83,33 & 55,56 & 83,33 & 66,67 & 68,89 & 61,11 & 83,33 & 55,56 & 83,33 & 66,67 & 68,89 \\
\hline 66,67 & 55,56 & 66,67 & 66,67 & 72,22 & 63,33 & 61,11 & 61,11 & 66,67 & 61,11 & 66,67 & 64,44 \\
\hline 66,67 & 83,33 & 77,78 & 77,78 & 66,67 & 76,67 & 66,67 & 83,33 & 88,89 & 77,78 & 61,11 & 76,67 \\
\hline 66,67 & 72,22 & 72,22 & 88,89 & 66,67 & 73,33 & 66,67 & 66,67 & 66,67 & 83,33 & 66,67 & 72,22 \\
\hline 88,89 & 88,89 & 66,67 & 83,33 & 88,89 & 81,11 & 77,78 & 77,78 & 66,67 & 83,33 & 83,33 & 75,56 \\
\hline 66,67 & 83,33 & 72,22 & 88,89 & 61,11 & 74,44 & 66,67 & 83,33 & 77,78 & 88,89 & 66,67 & 77,78 \\
\hline 61,11 & 66,67 & 66,67 & 66,67 & 61,11 & 64,44 & 66,67 & 83,33 & 77,78 & 88,89 & 66,67 & 77,78 \\
\hline 66,67 & 88,89 & 66,67 & 77,78 & 55,56 & 72,22 & 66,67 & 88,89 & 77,78 & 88,89 & 66,67 & 75,56 \\
\hline 55,56 & 72,22 & 66,67 & 61,11 & 44,44 & 63,33 & 55,56 & 83,33 & 66,67 & 66,67 & 44,44 & 64,44 \\
\hline 44,44 & 44,44 & 44,44 & 44,44 & 44,44 & 44,44 & 44,44 & 44,44 & 55,56 & 55,56 & 44,44 & 48,89 \\
\hline 44,44 & 44,44 & 44,44 & 44,44 & 44,44 & 44,44 & 44,44 & 44,44 & 44,44 & 44,44 & 44,44 & 44,44 \\
\hline
\end{tabular}


